\title{
Sustainability-Based Expert System for Additive Manufacturing and CNC Machining
}

Josage Chathura Pamuditha Perera

West Virginia University, jp0076@mix.wvu.edu

Follow this and additional works at: https://researchrepository.wvu.edu/etd

Part of the Industrial Engineering Commons

\section{Recommended Citation}

Perera, Josage Chathura Pamuditha, "Sustainability-Based Expert System for Additive Manufacturing and CNC Machining" (2020). Graduate Theses, Dissertations, and Problem Reports. 7719.

https://researchrepository.wvu.edu/etd/7719

This Thesis is protected by copyright and/or related rights. It has been brought to you by the The Research Repository @ WVU with permission from the rights-holder(s). You are free to use this Thesis in any way that is permitted by the copyright and related rights legislation that applies to your use. For other uses you must obtain permission from the rights-holder(s) directly, unless additional rights are indicated by a Creative Commons license in the record and/ or on the work itself. This Thesis has been accepted for inclusion in WVU Graduate Theses, Dissertations, and Problem Reports collection by an authorized administrator of The Research Repository @ WVU. For more information, please contact researchrepository@mail.wvu.edu. 


\title{
Sustainability-Based Expert System for Additive Manufacturing and CNC Machining
}

\author{
Josage Chathura Perera
}

Thesis submitted to the Benjamin M. Statler College of Engineering and Mineral Resources at West Virginia University

in partial fulfillment of the requirements for the degree of

Master of Science in

Industrial Engineering

Bhaskaran Gopalakrishnan, Ph.D., P.E., Chair

Ashish Nimbarte, Ph.D.

Thorsten Wuest, Ph.D.

Department of Industrial and Management Systems Engineering

Morgantown, West Virginia

2020

Keywords: Sustainability, Additive Manufacturing, CNC Machining, Binder Jetting, Direct Metal Laser Sintering, Expert System

Copyright 2020 Josage Chathura Perera 


\section{ABSTRACT \\ Sustainability-Based Expert System for Additive Manufacturing and CNC \\ Machining}

Josage Chathura Perera

The development of technologies which enable resource efficient production is of paramount importance for the continued advancement of the manufacturing industry. In order to ensure a sustainable and clean energy future, manufacturers should be able to contrast and validate existing manufacturing technologies on a sustainability basis. In the post COVID-19 era of enterprise management, the use of artificial intelligence to simulate human expert decision making abilities will open new doors to achieving heightened levels of productivity and efficiency.

The introduction of innovative technologies such as $\mathrm{CNC}$ machining and 3D printing to production systems has redefined the manufacturing landscape in a way that has compelled users to investigate into their sustainability. For the purposes of this study, cost effectiveness, energy and auxiliary material usage efficiency have been considered to be key indicators of manufacturing process sustainability. The objective of this research study is to develop a set of expert systems which can aid metal manufacturing facilities in selecting Binder Jetting, Direct Metal Laser Sintering or CNC Machining based on viable product, process, system parameters and inherent sustainability aspects.

The expert systems have been developed using the knowledge automation software, Exsys Corvid ${ }^{\circledR}$. Comprehensive knowledge bases pertaining to the objectives of each expert system have been created using literature reviews and communications with manufacturing experts. An interactive environment which mimics the expertise of a human expert has been developed by the application of suitable logical rules and backward chaining. The programs have been verified by analyzing and comparing the sustainability impacts of Binder Jetting and CNC Machining during fabrication of a stainless steel 316L component. According to the results of the study, Binder Jetting is deemed to be characterized by more favorable indicators of sustainability in comparison to CNC Machining, for fabrication of components feasible for each technology. 


\section{Table of Contents}

ABSTRACT

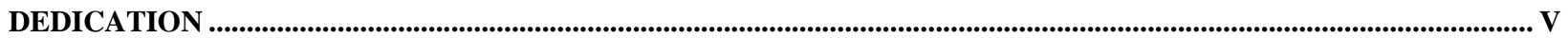

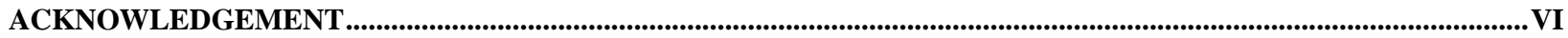

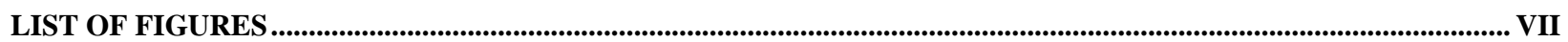

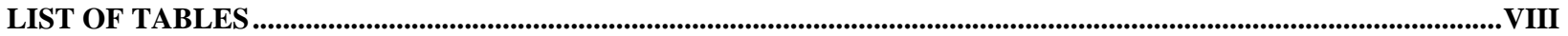

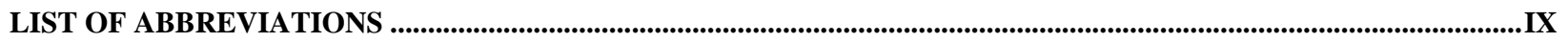

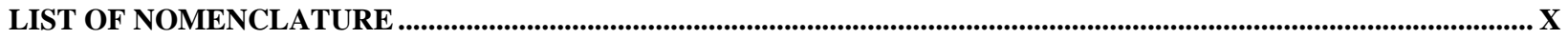

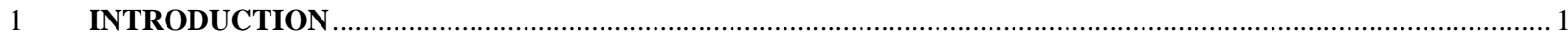

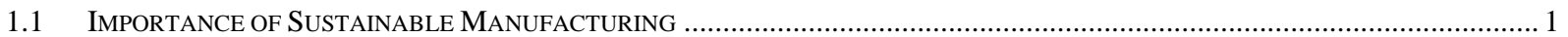

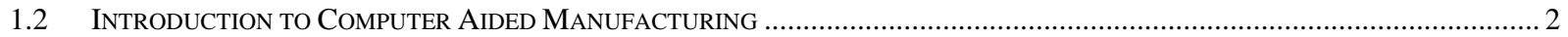

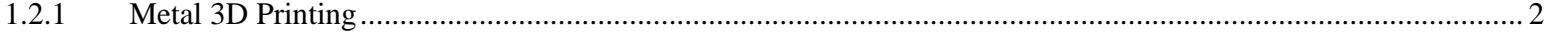

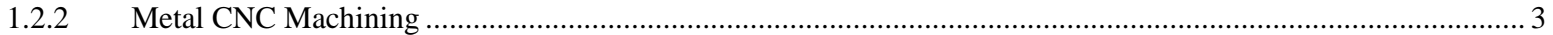

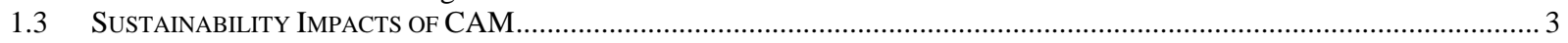

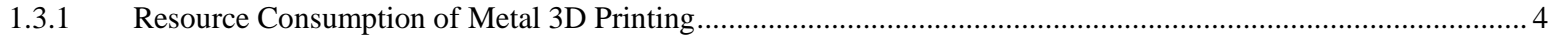

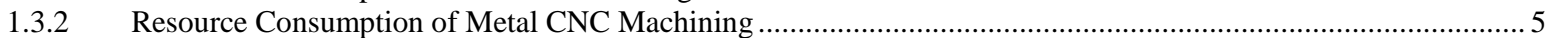

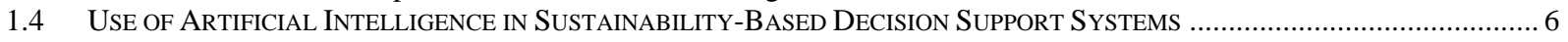

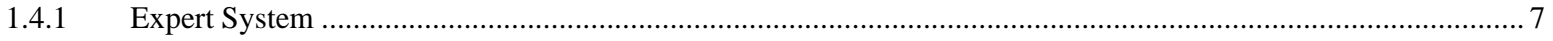

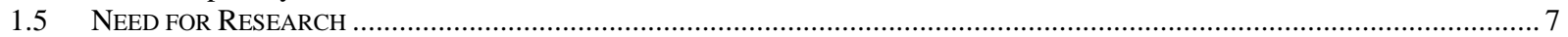

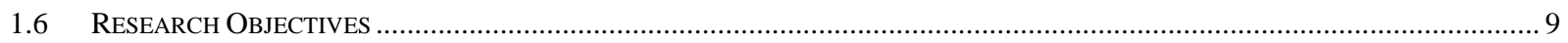

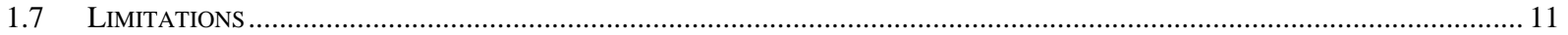

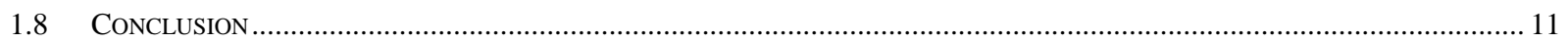

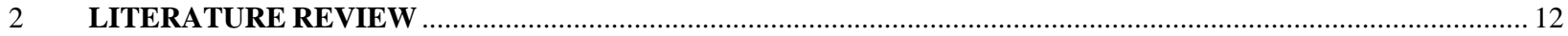

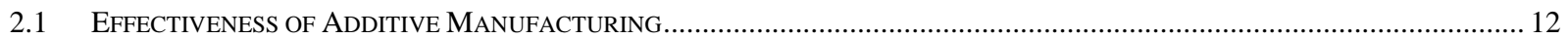

2.2 DECISION SUPPORT FOR SELECTION OF AdDITIVE MANUFACTURING AND CNC MACHINING....................................... 13

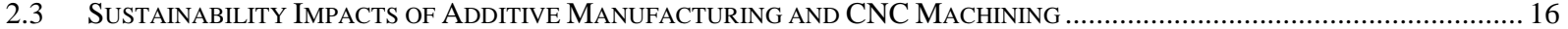

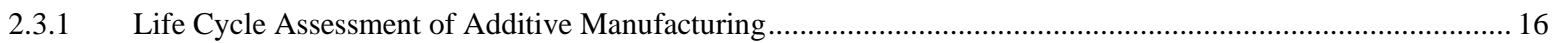

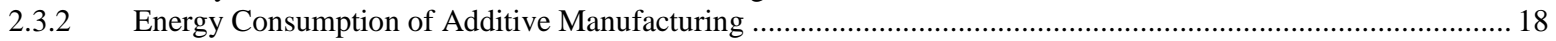

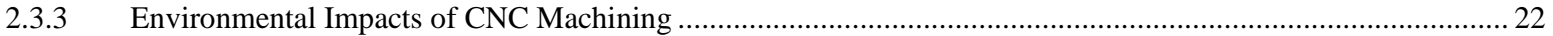

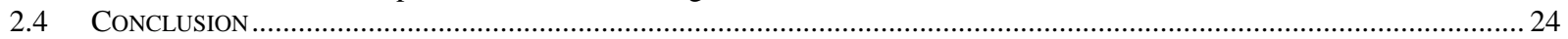

$3 \quad$ RESEARCH APPROACH

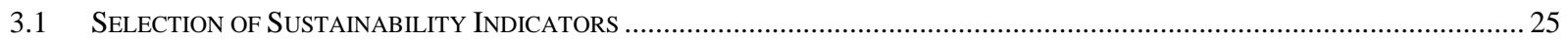

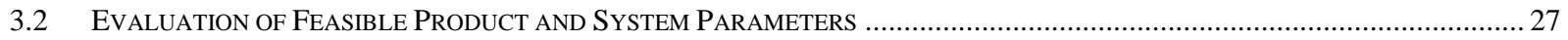

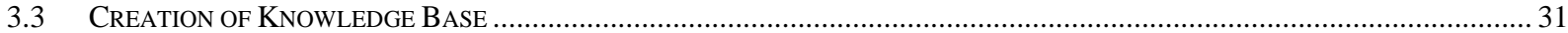

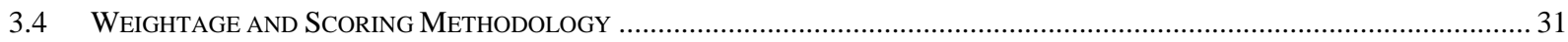

3.5 EXPERT SYSTEM SHELL

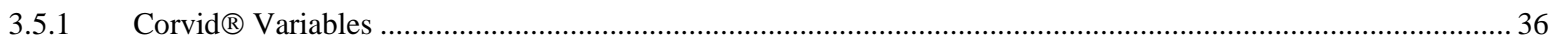

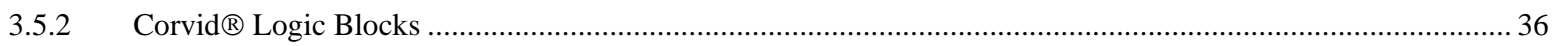

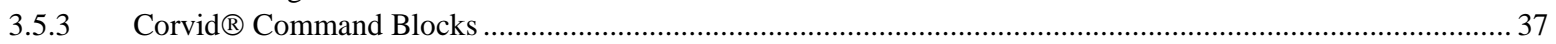

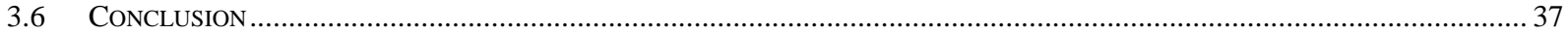




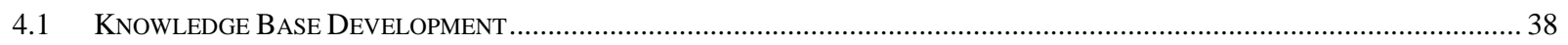

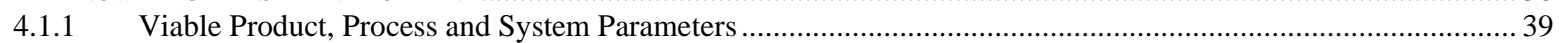

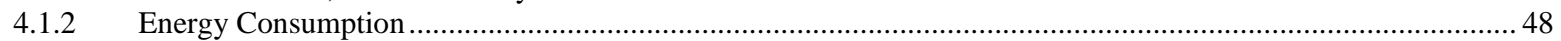

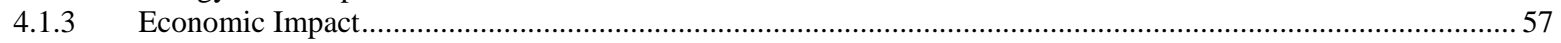

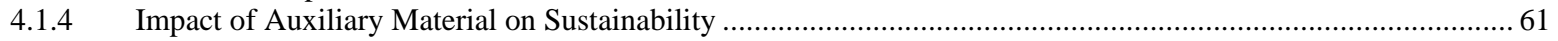

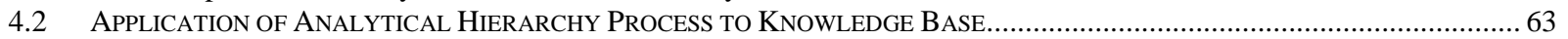

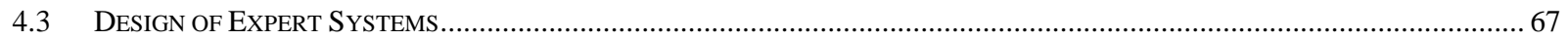

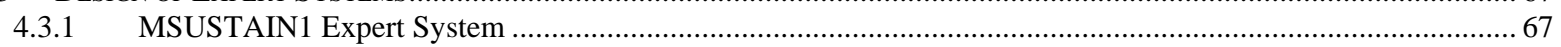

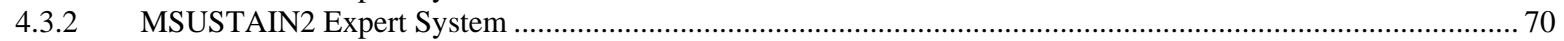

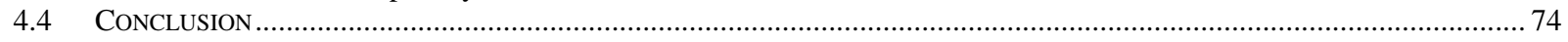

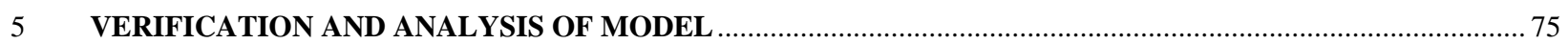

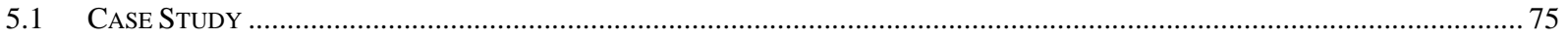

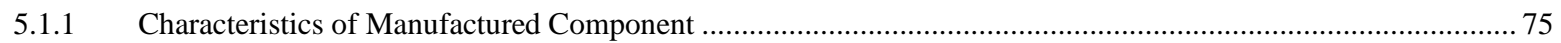

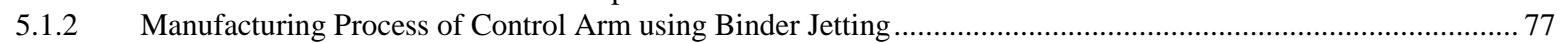

5.1.3 Energy and Material Consumption of the BJP Process .......................................................................... 78

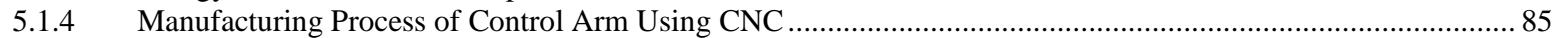

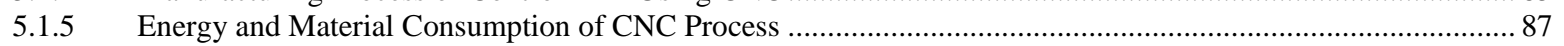

5.1.6 Comparison of Energy, Waste Material and Carbon Emissions ...................................................................90

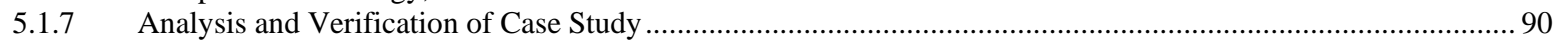

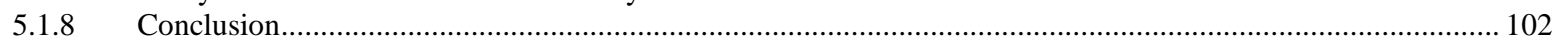

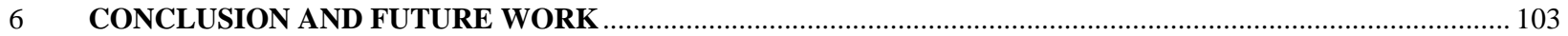

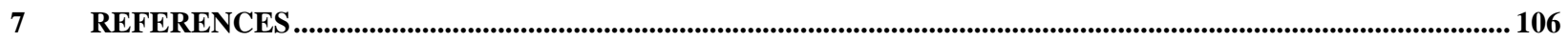

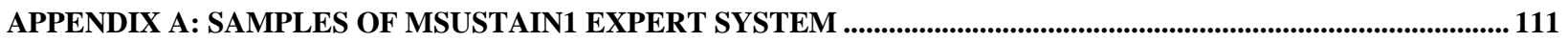

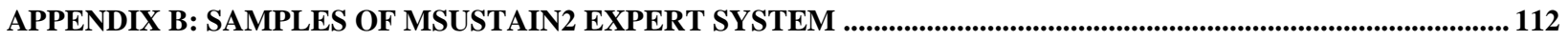

APPENDIX C: EXSYS CORVID CODE FOR MSUSTAIN1 EXPERT SYSTEM ...........................................................114

APPENDIX D: EXSYS CORVID CODE FOR MSUSTAIN2 EXPERT SYSTEM..ERROR! BOOKMARK NOT DEFINED. 


\section{Dedication}

To my beloved family, Quintus, Sriyani and Dinithi for their unending love, support, and guidance. 


\section{Acknowledgement}

First and foremost, I would like to take this opportunity to thank my committee chairperson and research advisor, Dr. Gopalakrishnan for his continued support and guidance provided towards the betterment of my professional career. I consider my time at the West Virginia University IAC a major turning point in my career due to the direction of Dr. Gopalakrishnan and Dr. Nimbarte. I sincerely appreciate the effort put forth by Dr. Gopalakrishnan and Dr. Nimbarte in cultivating my skills to lead a career in energy efficiency research. I would like to thank Dr. Wuest for serving in my research committee and providing the guidance necessary for successful thesis completion. I would also like to acknowledge Dr. Borkar, Taban Lariman, Shanti Hamburg and Exsys Inc. for

providing me the resources and necessary support required to successfully accomplish the deliverables of my thesis research. 


\section{List of Figures}

Figure 1.1: Sustainability Portrayed as an Intersection of the Environment, Economy and Society _____ 1

Figure 1.2: Carbon Emissions Generated from AM System ___ 5

Figure 1.3: Carbon Emissions Generated from CNC Machining System ___ 6

Figure 1.4: Structure of a Rule Based Expert System [15] ____ 7

Figure 1.5: System Design for First Expert System ___ 10

Figure 1.6: System Design for Second Expert System___ 10

Figure 3.1: Decision Hierarchy of the AHP Process _____________ 35

Figure 4.1: Average Breakeven Point for Geometric Complexity Factor [23] ___ 41

Figure 4.2: Material and Manufacturing Aspects Considered for Evaluation of Energy Consumption ___ 49

Figure 4.3: Design of Main Logic Block Rules for SS316L, BJP vs CNC __ 68

Figure 4.4: Example of Invalid Product Parameter Input by User ___ 69

Figure 4.5: Assignment of Backward Chaining to Derive Confidence Variables ___ 69

Figure 4.6: Algorithm for the MSUSTAIN1 ___ 70

Figure 4.7: Logic Block Sample for Energy Consumption of BJP Finishing Processes ___ 71

Figure 4.8: Logic Block Sample for Energy Consumption of CNC process ___ 72

Figure 4.9: Logic Block Sample for Overall Weight Calculation ___ 72

Figure 4.10: Logic Block Sample of Weights Calculation for Cost Indicator ___ 72

Figure 4.11: Command Block Structure for MSUSTAIN2 ___ 73

Figure 4.12: Sample of Final Results Screen___ Error! Bookmark not defined.

Figure 4.13: Algorithm for MSUSTAIN2 ___ 74

Figure 5.1: Autodesk Fusion 360® Model of Component_____ 76

Figure 5.2: BJP Process ___ 77

Figure 5.3: "Green Structure” Yielded from BJP Process ___ 78

Figure 5.4: Current Data Collection Procedure __ 79

Figure 5.5: Current Draw of the Printer During Build of 1 part___________ 80

Figure 5.6: Current Draw of the Curing Oven during Build of 1 Part ___ 81

Figure 5.7: Current Draw of the Printer during Build of 6 Parts ___ 84

Figure 5.8: Data logged during fabrication ___ 87

Figure 5.9: CNC machining, data logging ____ 88

Figure 5.10: Determination of Number of Facets in CAD Model ___ 91

Figure 5.11: Results Screen of MSUSTAIN1 for Case Study Component ___ 94

Figure 5.12: Results Screen of MSUSTAIN2 for Case Study Component ___ 95

Figure 5.13: Variation in BJP Energy Savings (vs CNC) due to Build Volume Utilization ___ 98

Figure 5.14: Variation in Overall Sustainability Rating for BJP due to Build Volume Utilization ____ 98

Figure 5.15: Variation in BJP Energy Performance due to the Sintering Profile Utilized ______ 99

Figure 5.16: Variation in Auxiliary Material Rating for CNC due to Types Utilized __ 100

Figure 5.17: Variation in Overall Sustainability Rating for CNC due to Auxiliary Material Types Utilized ___ 100

Figure 5.18: Variation in Overall Energy Performance due to CNC Waste Material Recovered ___ 101

Figure 5.19: Variation in Energy Performance due to the Milling Removal Rate Utilized _________________ 101 


\section{List of Tables}

Table 3.1: Viable System and Product Parameters for CNC Machining and AM [5], [8], [37], [38], [39].............................. 29

Table 3.2: Achievable Material Mechanical Properties for CNC Machining and AM [5], [8], [37], [38], [39]......................... 30

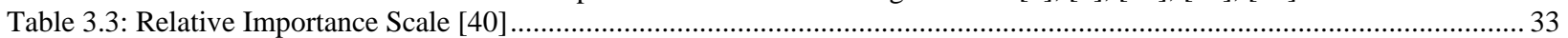

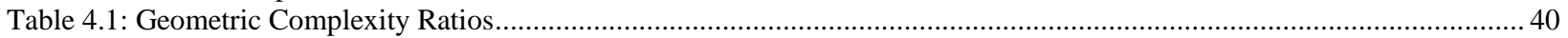

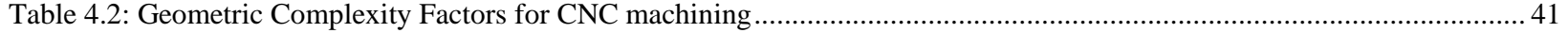

Table 4.3: Product Parameters Equally Feasible for BJP and CNC Machining ....................................................................42

Table 4.4: Product Parameters Equally Feasible for DMLS and CNC Machining ............................................................43

Table 4.5: Optimal Production Quantities for BJP, DMLS, CNC Machining Based on Geometric Complexity and Unit Cost..... 44

Table 4.6: Material Embodied Energy for Stainless Steel Billet [45] ............................................................................ 50

Table 4.7: Material Embodied Energy for Stainless Steel Powder [45], [10] …............................................................ 50

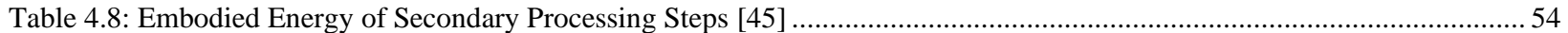

Table 4.9: Heat Treatment Processes Viable for CNC, BJP and DMLS Based on Material Type [47], [38], [39], [37].............. 55

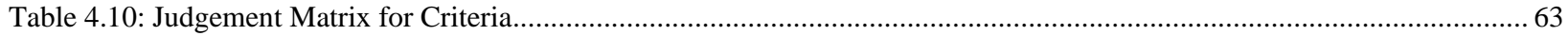

Table 4.11: Comparison Matrix for Alternatives in terms of Cost (Scenario 1) ............................. Error! Bookmark not defined.

Table 4.12: Comparison Matrix for Alternatives in terms of Cost (Scenario 2) ............................ Error! Bookmark not defined.

Table 4.13: Comparison Matrix for Alternatives in terms of Cost (Scenario 3) ............................ Error! Bookmark not defined.

Table 4.14: Comparison Matrix for Alternatives in terms of Cost (Scenario 4) ............................. Error! Bookmark not defined.

Table 4.15: Comparison Matrix for Alternatives in terms of Cost (Scenario 5) ............................. Error! Bookmark not defined.

Table 4.16: Comparison Matrix for Alternatives in terms of Energy (Scenario 1) ......................... Error! Bookmark not defined.

Table 4.17: Comparison Matrix for Alternatives in terms of Energy (Scenario 2) ......................... Error! Bookmark not defined.

Table 4.18: Comparison Matrix for Alternatives in terms of Energy (Scenario 3) ......................... Error! Bookmark not defined.

Table 4.19: Comparison Matrix for Alternatives in terms of Energy (Scenario 4) ......................... Error! Bookmark not defined.

Table 4.20: Comparison Matrix for Alternatives in terms of Energy (Scenario 5) .......................... Error! Bookmark not defined.

Table 4.21: Comparison Matrix for BJP, CNC in terms of Auxiliary Material (Scenario 1) .................................................6 65

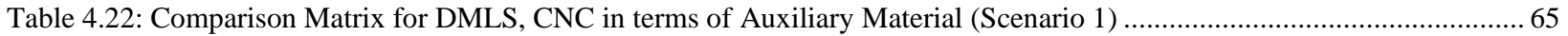

Table 4.23: Comparison Matrix for BJP, CNC in terms of Auxiliary Material (Scenario 2,3) ................................................65

Table 4.24: Comparison Matrix for DMLS, CNC in terms of Auxiliary Material (Scenario 2,3) ......................................65

Table 4.25: Comparison Matrix for BJP, CNC in terms of Auxiliary Material (Scenario 4,5) ................................................6 66

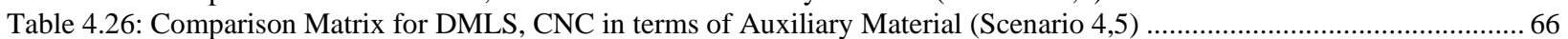

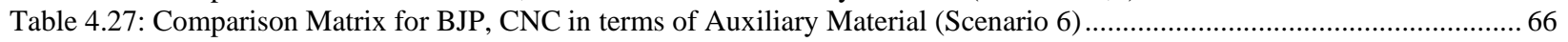

Table 4.28: Comparison Matrix for DMLS, CNC in terms of Auxiliary Material (Scenario 6) ...............................................6 66

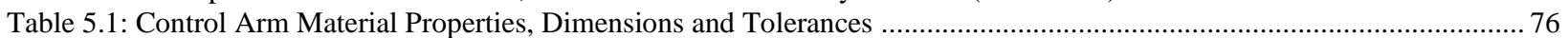

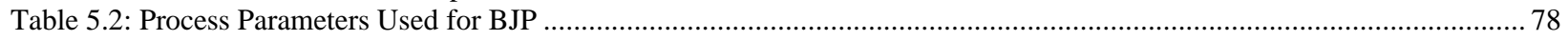

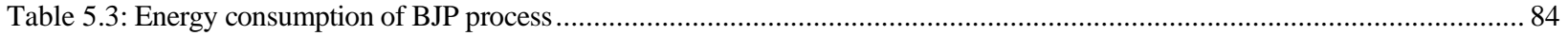

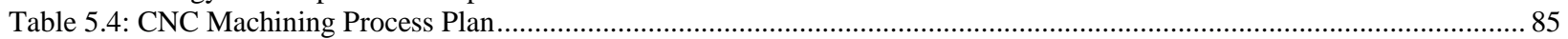

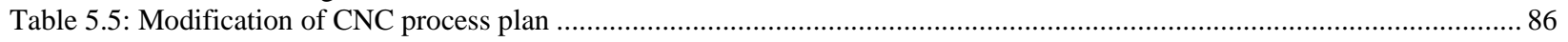

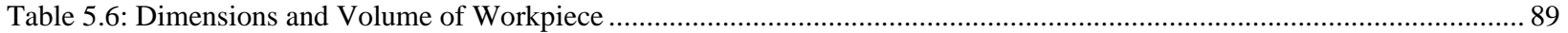

Table 5.7: Summary of Energy, Material Consumption and Carbon Emissions .................................................................... 90

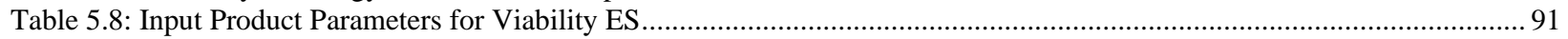

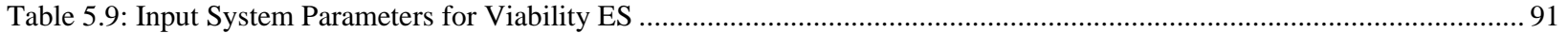

Table 5.10: BJP Parameters - Viability ES $\quad$ Table 5.11: CNC Parameters - Viability ES...............................................92

Table 5.12: BJP Inputs - Sustainability ES $\quad$ Table 5.13: CNC Inputs - Sustainability ES....................................93

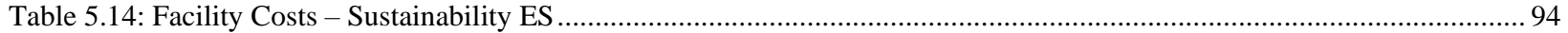

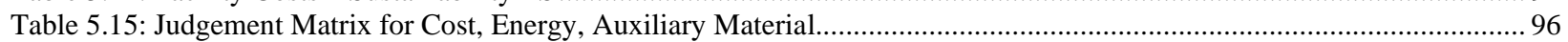

Table 5.16: Priority Weights Allocated to BJP and CNC Based on Cost of Manufacture ............... Error! Bookmark not defined.

Table 5.17: Priority Weights Allocated to BJP, CNC Based on Energy Consumption.................... Error! Bookmark not defined.

Table 5.18: Priority Weights Allocated to BJP, CNC Machining Based on Auxiliary Material ...............................................97

Table 5.19: Ratings Allocated to BJP, CNC Machining Based on Sustainability Indicators ...................................................97

Table 5.20: Model Accuracy Determination of Energy Consumption ................................................................................ 97 


\section{List of Abbreviations}

$\begin{array}{ll}\text { CAM } & \text { Computer Aided Manufacturing } \\ \text { AM } & \text { Additive Manufacturing } \\ \text { CNC } & \text { Computer Numerical Control } \\ \text { G-code } & \text { Geometry Code } \\ \text { PBF } & \text { Powder Bed Fusion } \\ \text { DED } & \text { Direct Energy Deposition } \\ \text { BJP } & \text { Binder Jet Printing } \\ \text { ES } & \text { Expert System } \\ \text { SM } & \text { Subtractive Manufacturing } \\ \text { CAD } & \text { Computer Aided Design } \\ \text { SLM } & \text { Selective Laser Melting } \\ \text { DMLS } & \text { Direct Metal Laser Sintering } \\ \text { SLA } & \text { Stereolithography } \\ \text { SLS } & \text { Selective Laser Sintering } \\ \text { FDM } & \text { Fused Deposition Modeling } \\ \text { EBM } & \text { Electron Beam Melting } \\ \text { CJP } & \text { ColorJet Printing } \\ \text { MJP } & \text { MultiJet Printing } \\ \text { CLIPS } & \text { C Language Integrated Production System } \\ \text { LCI } & \text { Life Cycle Inventory } \\ \text { AHP } & \text { Analytic Hierarchy Process } \\ & \end{array}$




\title{
List of Nomenclature
}

\author{
$\mathrm{T}_{\mathrm{c}} \quad$ repeating cycle time \\ a \\ b \\ $\mathrm{t}$ \\ n' \\ $\mathrm{m}$ \\ $t_{\text {required }}$ \\ $\mathrm{P}$ \\ $\mathrm{t}_{\mathrm{CNC}(\text { milling) }}$ \\ $\mathrm{V}_{\text {milling }}$ \\ Qmilling \\ $\alpha$ \\ $\mathrm{t}_{\mathrm{CNC} \text { (drilling) }}$ \\ $\mathrm{V}_{\text {drilling }}$ \\ $\mathrm{Q}_{\text {drilling }}$ \\ $\mathrm{t}_{\mathrm{CNC}(\text { turning) }}$ \\ $\mathrm{V}_{\text {turning }}$ \\ Qturning \\ $t_{\text {BJP }}$ \\ $t_{\text {curing }}$ \\ $t_{\text {sintering }}$ \\ $\mathrm{h}_{\text {component }}$ \\ $\mathrm{h}_{\text {layer }}$ \\ $t_{\text {layer }}$ \\ $\mathrm{N}$ \\ $t_{\text {DMLS }}$ \\ concurrent activity time (loading/unloading a machine) \\ independent operator activity time (inspecting/packing) \\ machine activity/process time (machining time/printing time) \\ ideal number of identical machines to assign an operator \\ number of identical machines assigned to an operator \\ process time to meet the required lead time (as per customer demand) \\ production quantity demanded by customer \\ time taken for the milling operation (hours) \\ volume removed by the milling process $\left(\mathrm{mm}^{3}\right)$ \\ material removal rate of the milling process $\left(\mathrm{mm}^{3} / \mathrm{min}\right)$ \\ geometric complexity \\ time taken for the drilling operation (hours) \\ volume removed by the drilling process $\left(\mathrm{mm}^{3}\right)$ \\ material removal rate of the drilling process $\left(\mathrm{mm}^{3} / \mathrm{min}\right)$ \\ time taken for the turning operation (hours) \\ volume removed by the turning process $\left(\mathrm{mm}^{3}\right)$ \\ material removal rate of the turning process $\left(\mathrm{mm}^{3} / \mathrm{min}\right)$ \\ time for the binder jetting process (hours) \\ curing time (hours) \\ sintering time (hours) \\ height of component as per the build orientation ( $\mathrm{mm}$ ) \\ height of print layer (mm) \\ time taken to print one layer (secs) \\ Number of simultaneous builds \\ process time for direct metal laser sintering (hours)
}




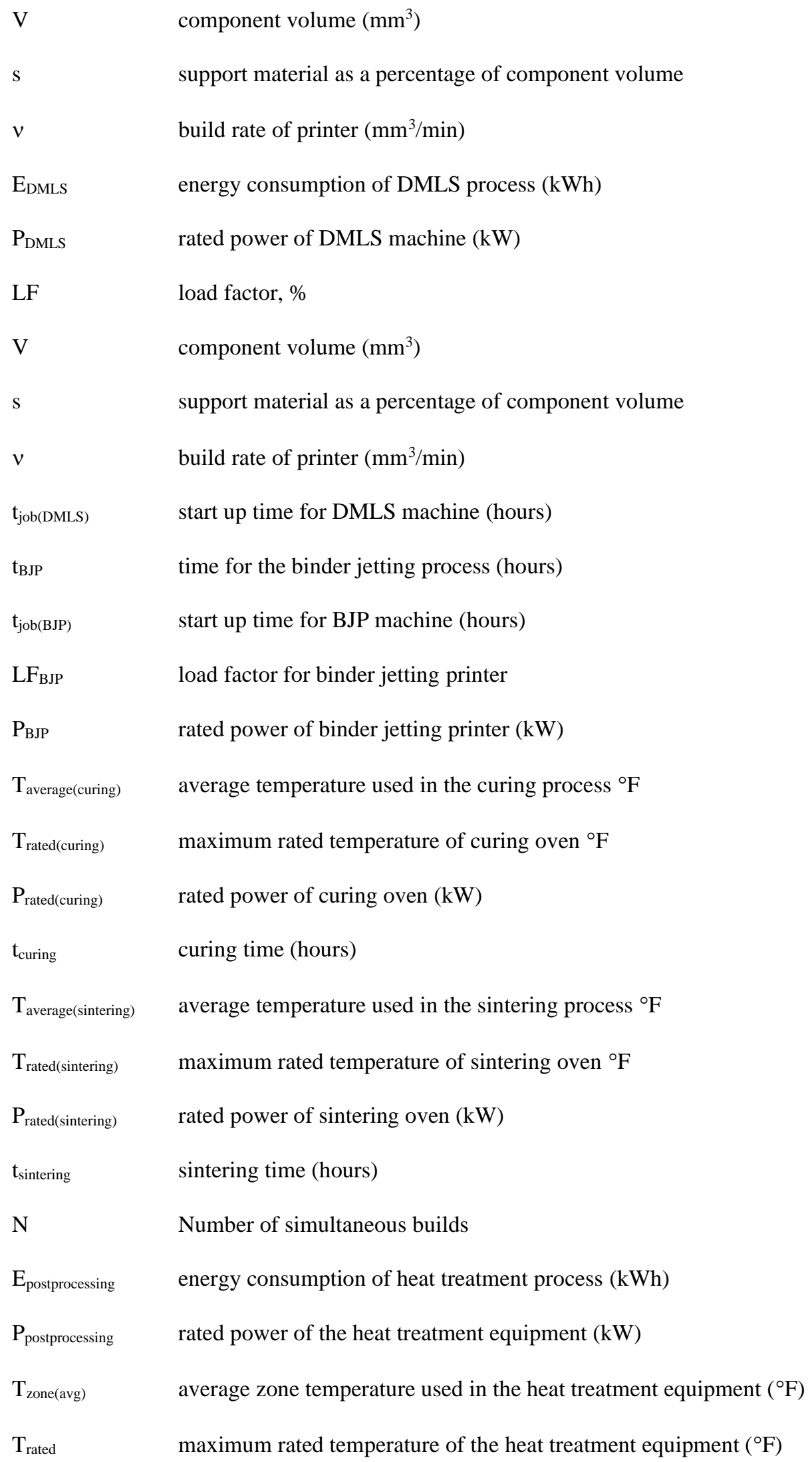

component volume $\left(\mathrm{mm}^{3}\right)$

support material as a percentage of component volume build rate of printer $\left(\mathrm{mm}^{3} / \mathrm{min}\right)$ energy consumption of DMLS process $(\mathrm{kWh})$ rated power of DMLS machine $(\mathrm{kW})$

load factor, $\%$

component volume $\left(\mathrm{mm}^{3}\right)$

support material as a percentage of component volume build rate of printer $\left(\mathrm{mm}^{3} / \mathrm{min}\right)$ start up time for DMLS machine (hours) time for the binder jetting process (hours) start up time for BJP machine (hours) load factor for binder jetting printer rated power of binder jetting printer $(\mathrm{kW})$ average temperature used in the curing process ${ }^{\circ} \mathrm{F}$ maximum rated temperature of curing oven ${ }^{\circ} \mathrm{F}$ rated power of curing oven $(\mathrm{kW})$ curing time (hours) average temperature used in the sintering process ${ }^{\circ} \mathrm{F}$ maximum rated temperature of sintering oven ${ }^{\circ} \mathrm{F}$ rated power of sintering oven $(\mathrm{kW})$ sintering time (hours) Number of simultaneous builds energy consumption of heat treatment process $(\mathrm{kWh})$ rated power of the heat treatment equipment $(\mathrm{kW})$ average zone temperature used in the heat treatment equipment $\left({ }^{\circ} \mathrm{F}\right)$ maximum rated temperature of the heat treatment equipment $\left({ }^{\circ} \mathrm{F}\right)$ 


\begin{tabular}{|c|c|}
\hline $\mathrm{t}_{\text {postprocessing }}$ & time taken for the heat treatment process (hours) \\
\hline $\mathrm{L}_{\text {cost }}$ & hourly labor cost at facility (\$/hour) \\
\hline $\mathrm{L}_{\mathrm{CNC}}$ & total labor cost for $\mathrm{CNC}$ machining $(\$)$ \\
\hline $\mathrm{L}_{\mathrm{BJP}}$ & total labor cost for BJP $(\$)$ \\
\hline $\mathrm{L}_{\text {DMLS }}$ & total labor cost for DMLS $(\$)$ \\
\hline $\mathrm{M}_{\mathrm{BJP}}$ & total material cost incurred during the BJP build $(\$)$ \\
\hline $\mathrm{M}_{\mathrm{DMLS}}$ & total material cost incurred during the DMLS build (\$) \\
\hline $\mathrm{M}_{\mathrm{CNC}}$ & total material cost incurred during the $\mathrm{CNC}$ machining build $(\$)$ \\
\hline $\mathbf{M}_{\text {component }}$ & mass of BJP/DMLS component (lb) \\
\hline $\mathbf{M}_{\text {billet }}$ & mass of billet used in CNC machining process (lb) \\
\hline $\mathbf{M}_{\text {cost(powder) }}$ & cost of metal powder $(\$ / \mathrm{lb})$ \\
\hline $\mathbf{M}_{\text {cost(billet) }}$ & cost of metal billet $(\$ / \mathrm{lb})$ \\
\hline $\mathrm{E}_{\mathrm{cost}(\mathrm{BJP})}$ & electricity cost incurred for the BJP process $(\$)$ \\
\hline $\mathrm{E}_{\mathrm{cost}(\mathrm{DMLS})}$ & electricity cost incurred for the DMLS process $(\$)$ \\
\hline $\mathrm{E}_{\mathrm{cost}(\mathrm{CNC})}$ & electricity cost incurred for the CNC machining process $(\$)$ \\
\hline $\mathrm{E}_{\text {total(BJP) }}$ & total energy consumption of BJP (kWh) \\
\hline $\mathrm{E}_{\text {total(DMLS) }}$ & total energy consumption of DMLS (kWh) \\
\hline $\mathrm{E}_{\mathrm{total}(\mathrm{CNC})}$ & total energy consumption of CNC machining $(\mathrm{kWh})$ \\
\hline $\mathrm{E}_{\text {cost }}$ & blended electricity cost at the facility $(\$ / \mathrm{kWh})$ \\
\hline $\mathrm{C}_{\text {cost }}$ & hourly cost of machine ( $\$ /$ hour $)$ \\
\hline $\mathrm{C}_{\text {capital }}$ & capital cost of equipment $(\$)$ \\
\hline $\mathrm{C}_{\text {installation }}$ & installation cost as a percentage of capital cost \\
\hline $\mathrm{C}_{\text {maintenance }}$ & maintenance cost as a percentage of capital cost \\
\hline $\mathrm{C}_{\text {increase }}$ & percentage annual increase in maintenance cost \\
\hline $\mathrm{R}$ & tax rate for manufacturing equipment \\
\hline UF & utilization factor of equipment on an annual basis \\
\hline $\mathrm{C}_{\mathrm{CNC}}$ & total CNC machine cost for the build $(\$)$ \\
\hline $\mathrm{C}_{\mathrm{BJP}}$ & total DMLS machine cost for the build (\$) \\
\hline
\end{tabular}




$\begin{array}{ll}\mathrm{C}_{\mathrm{DMLS}} & \text { total BJP machine cost for the build }(\$) \\ \mathrm{C}_{\operatorname{cost}(\mathrm{CNC})} & \text { cost per hour for the CNC machine (\$/hour) } \\ \mathrm{C}_{\text {cost(BJP) }} & \text { cost per hour for the BJP machine }(\$ / \text { hour }) \\ \mathrm{C}_{\text {cost(DMLS) }} & \text { cost per hour for the DMLS machine }(\$ / \text { hour) } \\ \mathrm{t}_{\mathrm{CNC}} & \text { process time for CNC machining (hour) } \\ \mathrm{t}_{\mathrm{BJP}} & \text { process time for BJP (hour) } \\ \mathrm{t}_{\mathrm{DMLS}} & \end{array}$




\section{Introduction}

The concept of sustainability can be interpreted in many ways. The most widely used description portrays sustainability as an intersection of the economy, society, and the environment [1]. Adopting sustainable practices, has the potential of benefitting each of these aspects and ensuring the continued advancement of mankind. This research study encompasses the sustainability benefits gained by manufacturing products through cost effective processes which conserve energy and natural resources.

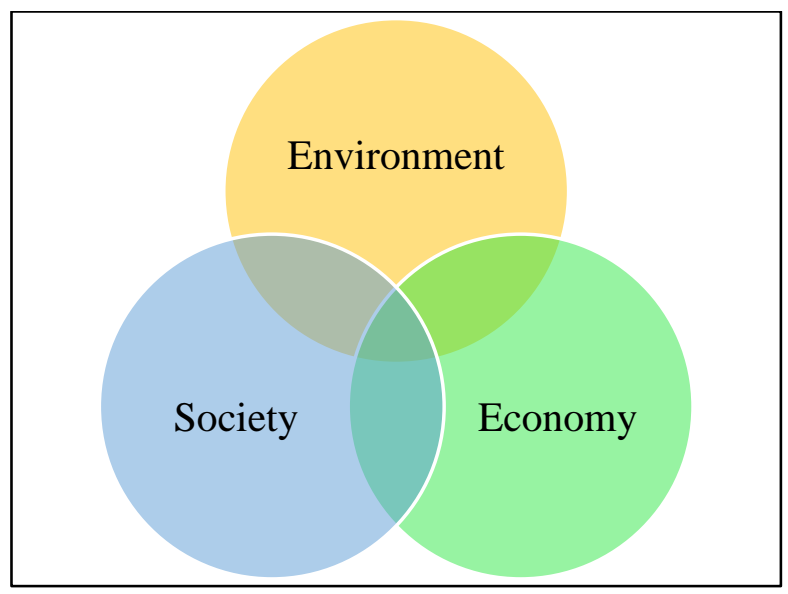

Figure 1.1: Sustainability Portrayed as an Intersection of the Environment, Economy and Society

\subsection{Importance of Sustainable Manufacturing}

Industrial manufacturing accounts for roughly $28 \%$ of energy usage and $18 \%$ of greenhouse gas emissions in the United States [2]. With the advancement in technology, machining progressively replaced primitive manufacturing methods which involved high intensity manual labor. Majority of modern manufacturing technologies operate with the aid of electrical power. In the United States, $60 \%$ of the electricity is generated from burning fossil fuels [2], which is widely known to negatively impact the environment. With the current trends in global warming and climate change, it is evident that immediate action is required in order to reduce the environmental impact caused by manufacturing. A comprehensive understanding of the emissions and energy flows associated with manufacturing processes is essential for the assessment of sustainability.

Manufacturing plays a significant role in a nation's economic prowess. The efficiency of energy use, as well as the cost and availability of energy, have a substantial impact on the competitiveness and economic health of U.S. manufacturers. Especially due to the increased implementation of 
ISO 50001 in manufacturing facilities, the transition to technologies which utilize less energy is of paramount importance. More efficient use of energy lowers production costs, conserves limited energy resources, increases productivity and profitability. Efficient energy use also minimizes adverse impact on the environment by reducing emissions of greenhouse gases and air pollutants [3]. However, manufacturing technologies which provide the perfect balance between aforementioned aspects is still to be determined and remains a challenge in the realm of research.

\subsection{Introduction to Computer Aided Manufacturing}

The concept of Computer Aided Manufacturing (CAM) was introduced in the late 1970s. This technology is capable of integrating software and hardware in order to facilitate computer aided modeling and design needed throughout the manufacturing lifecycle. In addition to utilizing reduced amounts of material, machinery and manpower, CAM enables responsiveness to rapid changes in product design and varying market demands [4]. The integration of CAM with machine tools has paved way to the birth of efficient technologies such as CNC (computer numerical control) machining and 3D printing, which are predominantly used in today's industrial sector.

\subsubsection{Metal 3D Printing}

3D printing, also known as additive manufacturing (AM) enables the fabrication of complex components layer by layer without the need for tools or assemblies. As opposed to subtractive processes, AM utilizes only the amount of material required for the component being manufactured, allowing minimized material wastage. Metal AM utilizes either metal powder or wire as the starting material for the manufacturing process. Powder Bed Fusion, Direct Energy Deposition and Binder Jetting are the three major types of metal AM processes [5]. The basis of all AM processes is Computer-Aided Design (CAD) software, according to which a set of instructions (G-code) is compiled pertaining to the fabrication of the part.

Most often, parts produced using AM techniques require an additional finishing step to achieve the desired surface finish. In the manufacturing industry, AM has been used to produce complex parts in small batch sizes [6]. Typically, use of metal AM is more suitable for applications requiring components with high mechanical properties. If used appropriately, AM technology presents the opportunity to substantially reduce energy consumption and environmental emissions. 


\subsubsection{Metal CNC Machining}

Computer Numerical Control (CNC) machining is a method of digitally controlling the movement and operation of spindle, axes, and other components to remove material from a workpiece by means of milling, turning, drilling, and boring. Milling is the use of rotary cutters to remove material by advancing the cutting tool into a workpiece [7]. Whereas, turning processes are characterized by a non-rotary cutting tool which moves linearly to remove material from a rotating workpiece [7]. Turning is predominantly employed for manufacturing rotational parts. Drilling, as suggested by its name, uses a drill bit to cut circular holes in workpieces. Similar to additive manufacturing, CNC machining uses CAD software to generate a G-code (Geometry code) which allows the cutting tools to follow a path specific to the component being created.

CNC machines can be categorized with respect to the number of axis in which the cutting tool can move simultaneously. 3-axis CNC machines allow the movement of the cutting tool in three linear axes relative to the workpiece. 5-axis CNC machining centers allow the rotation of the machine bed and/or the tool in addition to movement along the three linear axes, giving access to two supplementary rotational degrees of freedom [8]. This technology is a viable option for manufacturing parts with reasonable geometric complexity in small to medium volumes. CNC machining has the capability of producing parts with tight tolerances and high surface finish. The cost of CNC machining exponentially increases with the geometric complexity of the component due to the requirement of customized tools, fixtures, and additional machining steps. In addition, $\mathrm{CNC}$ machining consumes more resources in contrast to $3 \mathrm{D}$ printing during the manufacturing stage because of waste material generation.

\subsection{Sustainability Impacts of CAM}

The concept of green design and manufacturing is now extensively used in many industrial activities with a major emphasis on design for the environment. Green design considers all possible adverse environmental impacts of materials, processes, operations and products so that they can be all taken into consideration at the earliest stages of design and production [4]. The environmental impacts of manufacturing industries are well documented. These environmental impacts are seen in various forms as waste, carbon emissions, released energy and toxic chemicals [9]. The harmful effects of these activities on the ecosystem and eventually the human species, are 
now well recognized. The environmental impacts of $3 \mathrm{D}$ printing and $\mathrm{CNC}$ machining are elaborated in sections 1.3.1 and 1.3.2.

\subsubsection{Resource Consumption of Metal 3D Printing}

$\mathrm{AM}$ is widely used in industries such as automotive and aerospace due to its capability of producing components with reduced weights and minimal material wastage. Drawbacks of AM such as excessive costs and limited availability of feedstock material confines the adoption of this technology in small and medium sized industries. Incorporation of AM technology in manufacturing process will enable shorter value chains and result in reduced carbon emissions, energy and production related costs. In general, electricity consumption during the atomization process for the fabrication of metal powders, and machine operation during the printing process can be considered as dominant factors of environmental impact [10]. The warmup stage of 3D printing units consumes a significant portion of its energy usage. The effect of powder wastage on environmental impact can be considered to be negligible as waste material is most often reused in subsequent printing processes. It is important to note that the energy consumption and emissions resulting from each type of metal AM can be highly variant and process specific.

Metal AM techniques which utilize high power density beams can often be energy demanding. Powder Bed Fusion (PBF) uses a high intensity laser/electron beam to selectively melt metal powders layer by layer in a sealed chamber out of powder bed material stock to form a 3D component. As opposed to PBF, Direct Energy Deposition (DED) fabricates metal components through powder spreading or wire feeding using laser or electron beam as the heat source [10]. PBF and DED machines both consist of a laser unit, feedstock delivery system, control system and an inert gas circulation unit. Binder Jetting (BJP) is another metal AM technique, in which a liquid binding agent is selectively deposited on each powder layer to fabricate a "green structure." The printing process is followed by curing and sintering in order to obtain the final manufactured component. The printing system consists of a build platform, a feed powder bed, a print head, a roller, and a drying unit. BJP is distinctive from the prior two methods as it does not utilize a heat source during the print stage and requires the use of separate curing and sintering ovens in order to attain the final component. In order to determine emissions and the environmental impact 
associated with each of these metal AM methods, it is essential to consider the resource consumption by each of the subsystems in PBF, DED and BJP during the fabrication process.

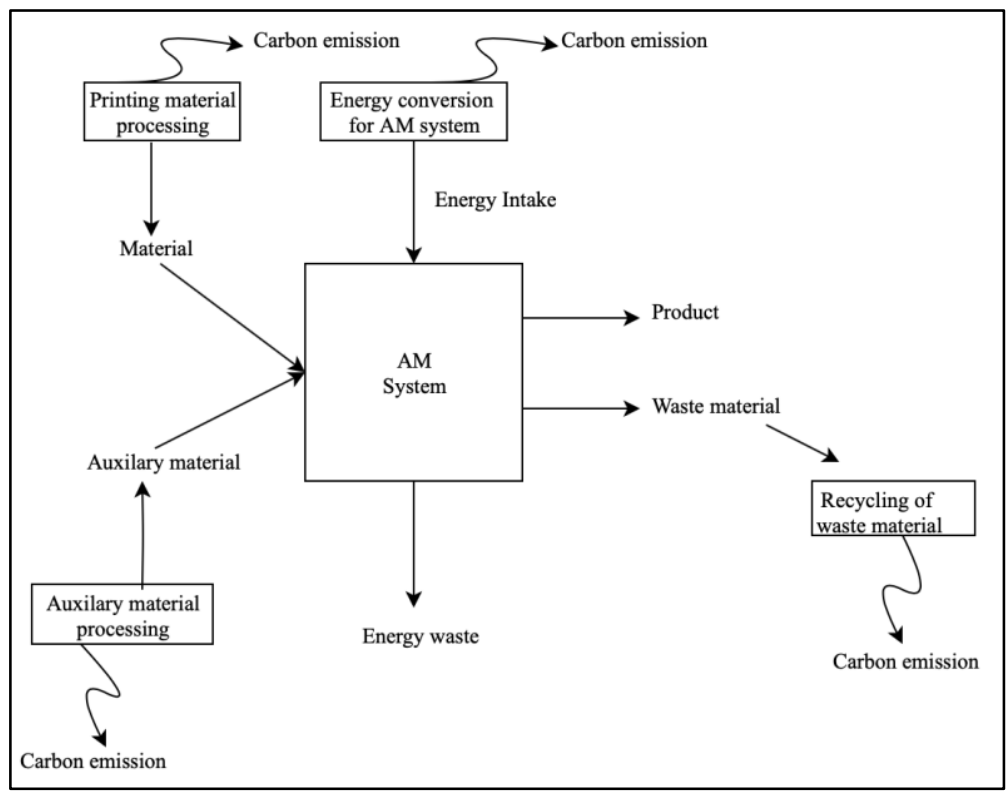

Figure 1.2: Carbon Emissions Generated from AM System

\subsubsection{Resource Consumption of Metal CNC Machining}

In general, machining operations result in the generation of waste material such as chips, lubricant and cutting fluids. Roughly 60-90\% of carbon emissions are generated during the machine working stage. Furthermore, energy consumption of CNC machining accounts for $20 \%$ of overall machine operating cost [11]. Although the stock material production process is outside the CNC machining system, it accounts for a major portion of electricity as well as other resources consumed. Likewise, the disposal and recycling of metal chips resulting from machining requires energy. While the environmental concerns associated with material removal and material production impact energy use, the environmental concerns associated with cutting fluid preparation and cleaning contribute to liquid and hazardous waste [12].

CNC machines function on electricity and the power drawn depends on the operational subsystems. The major subsystems of a CNC machine include the spindle system, hydraulic system, pneumatic unit, lubrication system, feed system and numerical control system. The warmup and non-productive stages of the machine consume additional energy, which is usually quite substantial. Once the G-code is executed, electric power is drawn as required to rotate the 
spindle, move the axes, apply cutting pressure, circulate cutting fluid [13]. The power demand during processing may vary depending on the production rate of the machine, the material being processed, and specific processing parameters such as spindle rates, feed rates and cutting tool configuration [12]. In order to determine the environmental impact of CNC machining, a broader understanding of the resources expended due to each subsystem is imperative. In addition, the energy requirement of raw and auxiliary materials should be included as part of energy required by machining operations [14].

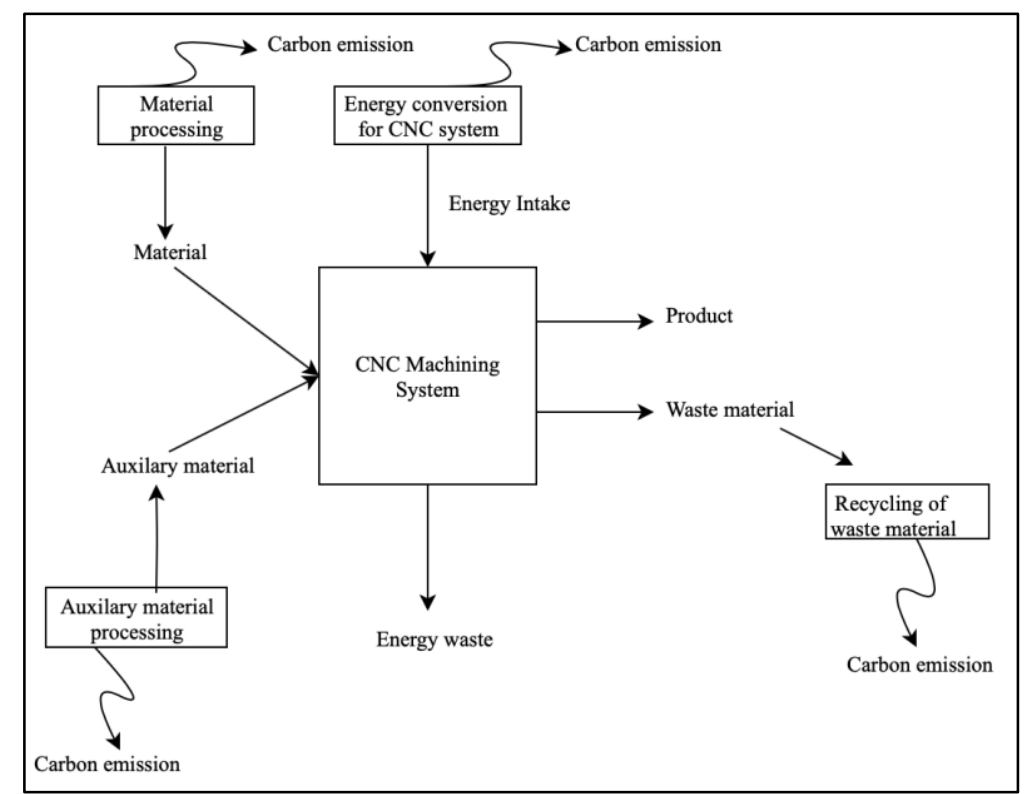

Figure 1.3: Carbon Emissions Generated from CNC Machining System

\subsection{Use of Artificial Intelligence in Sustainability-Based Decision Support Systems}

In the post COVID-19 era of enterprise management, the need for automation is undeniably transparent. Application of Artificial Intelligence (AI) in the domain of sustainability is still in its early phases. Due to the increased levels of automation being utilized in smart manufacturing systems, AI has the potential to yield significant benefits in terms of productivity enhancements and optimal human resource allocation. Expert systems were first introduced in the 1960's and were popular towards the latter stages of the $20^{\text {th }}$ Century. Due to the inability to learn from/adapt to unconventional user input, expert systems were soon replaced by other Enterprise Resource Planning (ERP) software. However, with the current sophistication of internet, the use of expert systems has significantly increased. As human expertise is a valuable, yet costly asset, knowledge 
automation would pave way to the utilization of human capital in a manner which benefits the sustainability of manufacturing facilities. Expert systems would additionally facilitate the use of human expertise only for activities which are infeasible to be automated.

\subsubsection{Expert System}

An expert system (ES) is a computerized artificial intelligence system which replicates the decision-making ability of a human expert [15]. Expert systems are comprised of a knowledge base and an inference engine. The knowledge base can be created with the use of existing literature, experimental data and human expertise. The inference engine iteratively applies defined logical rules to the knowledge base so that conclusions pertaining to the user defined problem are generated. General methods of inferencing are forward chaining, backward chaining, hierarchical planning, constraint handling and the least commitment principle. The resulting conclusions are the output of the expert system to information and criteria supplied by the user. A simplified depiction of an expert system is shown in figure 1.4.

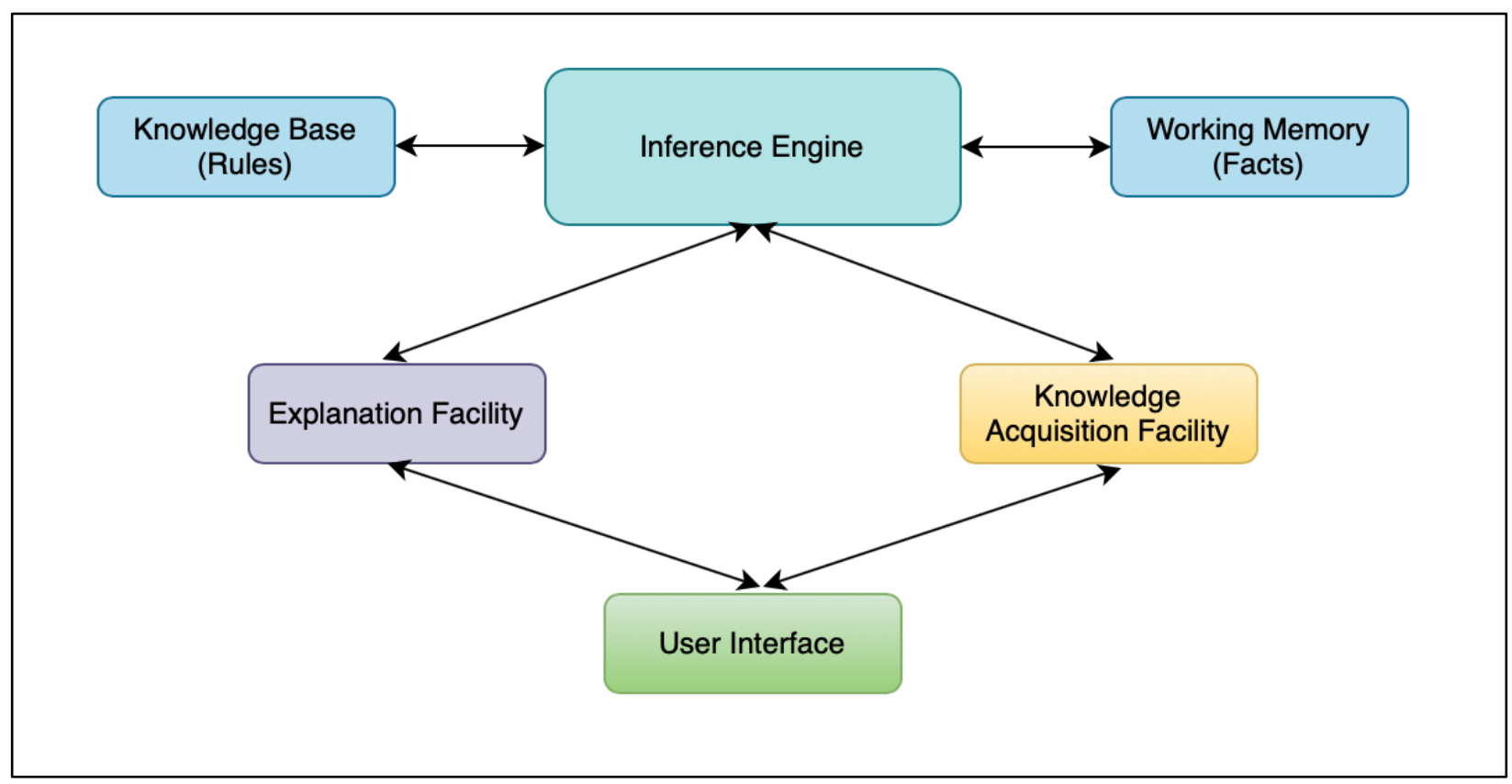

Figure 1.4: Structure of a Rule Based Expert System [15]

\subsection{Need for Research}

With increasing demand for energy and concern for environmental impact caused by manufacturing, the need for resource efficient manufacturing is paramount. In order to ensure a 
sustainable and clean energy future, manufacturers should be able to contrast and validate existing manufacturing technologies on a sustainability basis. It is important to understand that neither subtractive manufacturing (SM) nor additive manufacturing (AM) will be resource efficient on every occasion. In order to conduct a rational analysis, direct/indirect sustainability impacts of CNC machining and 3D printing should be identified and enumerated. Many research studies have been conducted to compare AM and SM in the domain of resource efficiency, but appear to have the following shortcomings:

1. Numerous studies have attempted to analyze and compare the sustainability aspects of AM and CNC machining through product life cycles, but lack the consideration of equally feasible product, process, and system parameters for each technology.

2. The existing research findings pertaining to sustainability are only applicable to specific manufacturing process, machines, and materials.

3. Although PBF and DED have been analyzed from a sustainability perspective, BJP has only limited findings. The unavailability of consistent energy intensity values for BJP is a major limitation.

4. The existing decision support systems do not provide a simple framework which could be used to analyze and compare energy, cost and auxiliary material usage of AM and CNC machining.

In most CAM based systems, concurrent engineering-based design processes are vastly used to integrate stages of manufacturing and design. In addition, concurrent engineering requires in-depth analysis of the product life cycle during early design phases. Therefore, designers and product development teams now bear more responsibility for manufacturing sustainability. The cost and effort involved in rectifying oversights of the product development phase tend to be quite substantial. Providing useful insight and information to product development teams will ensure that products are optimally designed for manufacturing technologies with least sustainability impact. Additionally, providing information related to the change in sustainability impact surrounding the manufacturing process due to alterations in product design would be critical. Sustainability of Additive Manufacturing and CNC machining is driven by the utilization of efficient tools. It is important to identify the next generation of tools which can allow designers to improve sustainability of these technologies. The development of an expert system which enables 
product developers to distinguish between tradeoffs of AM and CNC machining would be highly beneficial.

\subsection{Research Objectives}

The primary objective of this research is to develop a set of expert systems which enhance decision making capability during the product development phases of metal components fabricated using $\mathrm{AM}$ and CNC machining. The expert systems would be capable of providing advice in terms feasibility and sustainability impact factors. For the purposes of this research, sustainability of metal AM and $\mathrm{CNC}$ machining has been defined in terms of manufacturing cost, energy consumption and auxiliary material usage. The research study has been restricted to two types of AM (DMLS, BJP) and CNC machining, as each technology is capable of fabricating parts with comparable product parameters. The application of Direct Metal Laser Sintering (DMLS) and BJP in automotive and aerospace industries as a substitute for machining is widely being researched at present. It is important to conduct an impartial comparison to effectively facilitate decision making. The sustainability impact associated with manufacturing metal components which are only within the product and system parameters equally viable for $\mathrm{CNC}$ machining and $\mathrm{AM}$ will be analyzed. The research objectives are as follows:

1. Identify the range of product (material and its mechanical properties, geometric complexity, dimensional accuracy, and surface finish) and system parameters (cycle time, production quantity justifiable by unit cost) in which metal $\mathrm{AM}$ and $\mathrm{CNC}$ machining would be considered viable.

2. Create a knowledge base of AM and CNC machining in terms of sustainability with the use of existing literature and expert knowledge. This knowledge base would serve as logical rules within the expert system to generate advice pertaining to the manufacturing processes.

3. Utilize the Exsys Corvid $®$ knowledge automation software to develop an expert system that would enable a user to compare the efficiency of AM versus CNC machining processes for the fabrication of a product in terms of cost, energy consumption and auxiliary material usage.

4. Conduct a sensitivity analysis of major parameters affecting the sustainability of CNC machining and BJP. 


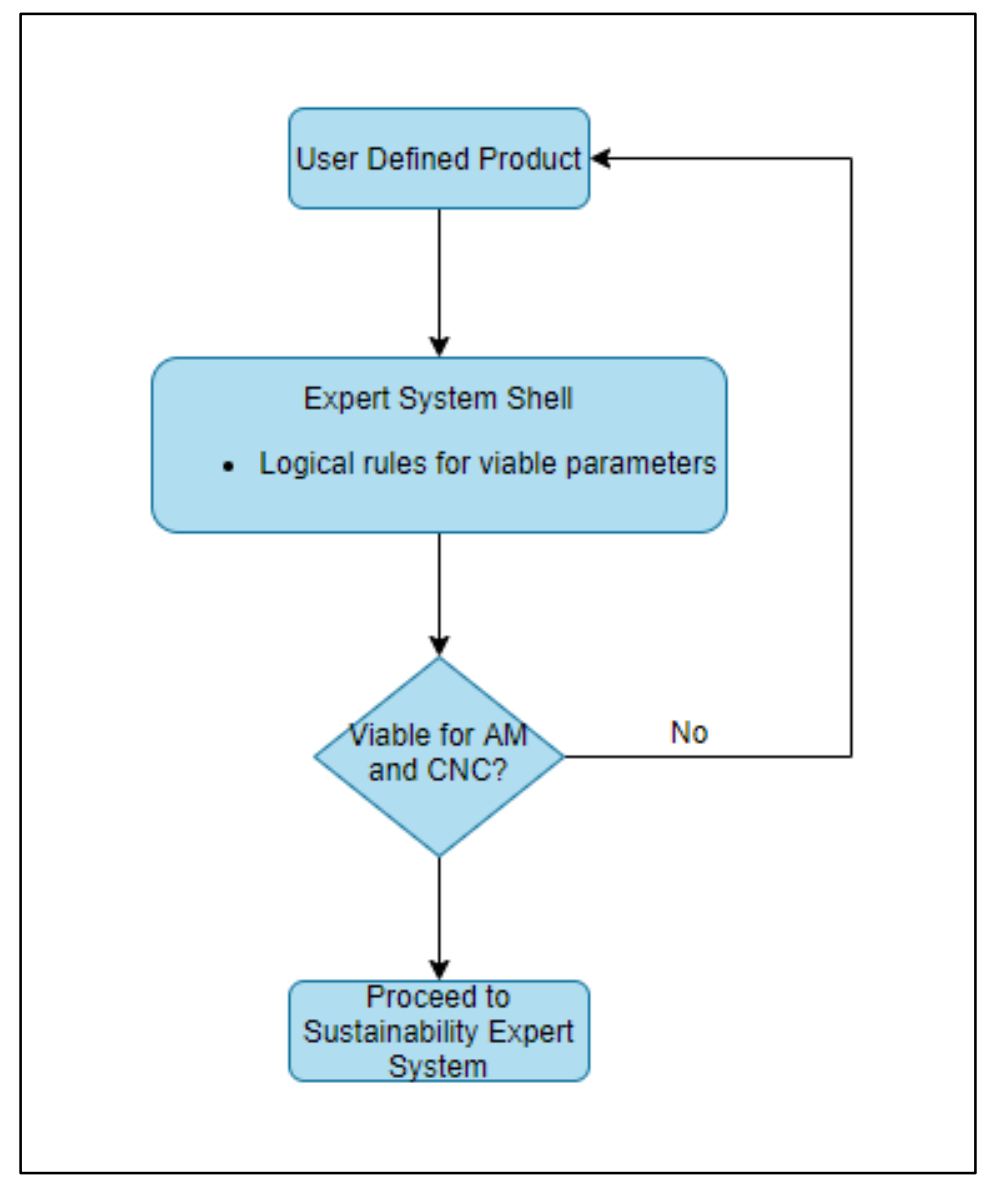

Figure 1.5: System Design for First Expert System

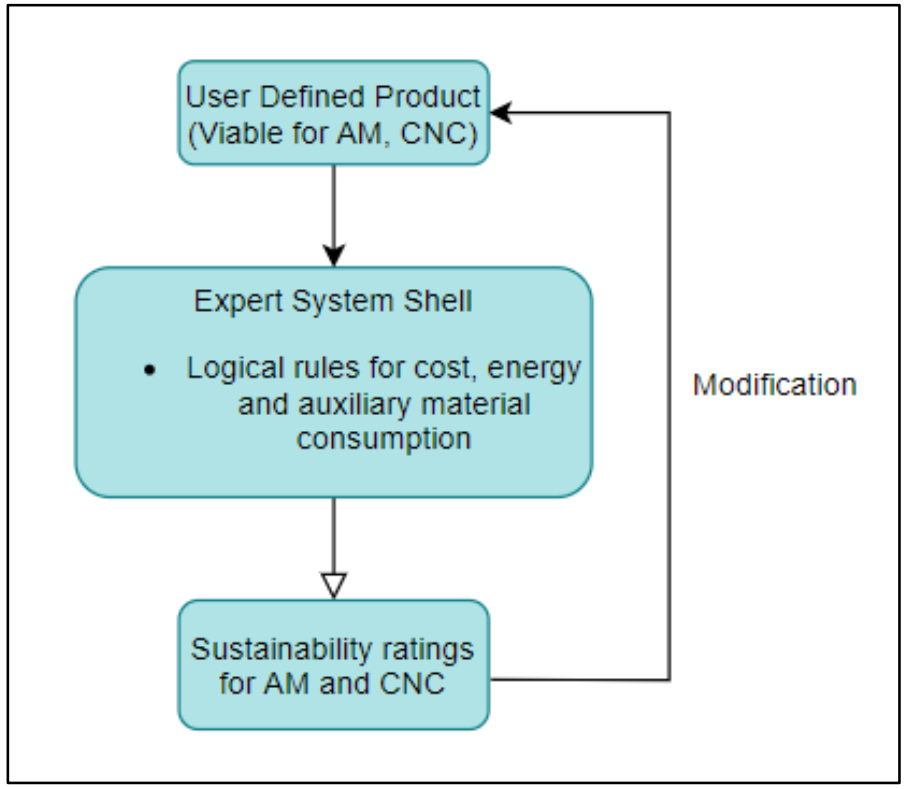

Figure 1.6: System Design for Second Expert System 


\subsection{Limitations}

This research study does not consider sustainability impacts due to the entire life cycle of the product. Impacts of AM and CNC machining on supply chains, product use/end of life energy consumption, would be additional criteria to be considered in further research studies. The conducted study only compares two types of metal additive manufacturing (DMLS, BJP) to CNC machining. Furthermore, the CNC machining operations are restricted to milling, turning, and drilling.

\subsection{Conclusion}

The domain of manufacturing is ever-growing. The development of manufacturing technologies which enable resource efficient production is a dominant factor which contributes towards this continued advancement. The introduction of innovative technologies such as CNC machining and 3D printing to production systems has redefined the manufacturing landscape in a way that has compelled users to investigate into their sustainability. This research study aims to develop a set of expert systems which can be used in the product development phase to gain insight into the feasibility/sustainability impact of metal AM and CNC machining. 


\section{Literature Review}

\subsection{Effectiveness of Additive Manufacturing}

Mpofu, Maware and Mukosera [16] conducted a study titled "The Impact and Application of 3D Printing Technology." Their paper discusses the current applications of 3D printing and the ways in which it has transformed manufacturing processes in various industries. The authors explore the application of additive manufacturing in various industries such as dentistry, prosthetics, bionics, manufacturing, clothing, etc and illustrate the benefits gained by each of these industries by adopting this technology. Based on this paper, 3D printing has provided a way to decrease costs and lead time in most manufacturing setups while delivering products with higher quality and durability. The authors forecast that the $3 \mathrm{D}$ printed part market will grow to an 8.4-billion-dollar industry by 2025 with a year on year 18 percent growth.

Systematic analysis of the impacts of additive manufacturing on production and logistics systems performed by Pour et al. [17] demonstrated the need for reconfigurations in these processes. The authors also discussed operations management and sustainability impacts as a result of implementing additive manufacturing. In this study, the authors investigated the additive manufacturing system in isolation so that the activities which are present within manufacturing processes of companies could be spotted for optimization. In this paper, the authors state that the production flexibility offered by $3 \mathrm{D}$ printing allows manufacturers to customize products based on customer demand, thus, eliminating production bottlenecks and the need for line balancing. This paper emphasizes on the need for promotion and advancement of automation within the design phase of products to facilitate additive manufacturing. Pour et al. recommends that all types of industries which struggle with complex supply chains should investigate into adopting additive manufacturing technology. The authors explain that by doing so, industries would be able to decide on opting for either a centralized or decentralized manufacturing strategy. According to this paper, Additive manufacturing is most beneficial for industries which possess supply chains with shorter lead times and produce small to medium volumes.

Kianian et al. [18] conducted statistical analysis on survey data from additive manufacturing users (companies, universities, research institutes) across Sweden to investigate the current 
applications and factors affecting the variation in adoption of this technology. The authors performed regression analysis on data obtained from 70 surveys in order to understand the relationship between the type of 3D printing and its application. Additionally, the authors use a multinomial logit model to estimate the effect of each type of 3D printing on the choice of additive manufacturing application. The findings of this study suggest that there is variation among users' choice of additive manufacturing, and majority of these users are expanding their utilization of this technology beyond rapid prototyping. The authors further concluded that being a small sized company and using multiple types of additive manufacturing have a positive correlation on the decision to expand the use of this technology beyond prototyping.

\subsection{Decision Support for Selection of Additive Manufacturing and CNC Machining}

Mancanares et al. [6] developed a decision support model which could be used to evaluate which AM technology would be most effective for manufacturing a particular part. The model utilizes the Analytic Hierarchy Process (AHP) to rank the most suited machines and technologies for a given part. The AHP first uses a set of predefined constraints to rule out machines not suitable for production. Afterwards, machines are ranked in descending order of suitability with the use of multiple criteria selections. The parts selection criteria included material, surface quality, post finishing, precision, resistance to impact, flexural strength, prototype cost and post cure. The 3D printing types considered were Stereolithography (SLA), Selective Laser Sintering (SLS), Fused Deposition Modeling (FDM), DMLS, Color Jet Printing (CJP) and Multi Jet Printing (MJP). In this research study, the curing and sintering steps for color jetting were not considered.

Fousova et al. [19] compared the effectiveness of metal 3D printing to conventional manufacturing technologies such as casting, forging and machining. In this article, the authors emphasized on numerous advantages of 3D printing from a manufacturing standpoint, such as ease in fabrication of complex shapes, and minimal wastage of raw material. The authors describe cost effectiveness in mass production setups to be a major disadvantage of additive manufacturing. Fousova et al. explores the effectiveness of 3D printing by comparing the mechanical properties of austenitic stainless steel AISI 316L when prepared by selective laser melting (SLM) and hot forging. Fousova et al. concluded that SLM leads to equivalent mechanical properties. 
A comparison between additive manufacturing and casting technology, in terms of mechanical properties, production times and production costs were conducted by Vevers et al. [20]. The purpose of this research was to determine if additive manufacturing is competitive with casting technology. The authors compared tensile strength, hardness, surface roughness, microstructure and chemical composition for samples produced using direct metal printing and iron casting. All $3 \mathrm{~d}$ printed samples were made using iron powder which corresponds to GJS-400-15 metal grade. Upon conducting tests for mechanical properties, the authors concluded that parts produced using metal additive manufacturing have better or identical parameters when compared to cast parts. As per this study, the price and production time of $3 \mathrm{~d}$ printed parts were comparable to casted parts when manufacturing was constrained to small parts and batch sizes of 1-5.

Faludi et al. [21] compared environmental impacts of additive manufacturing vs traditional machining via life cycle assessment. The types of 3D printing considered for this research were FDM and Inkjet Printing (IJP.) The main objective of this research was to conduct a thorough comparison across all major sources of ecological impacts as well as major types of impacts such as climate change and toxicity so that prototypers or job shop owners can make decisions regarding which type of manufacturing to use. According to this paper, $85 \%$ of the energy used by machining equipment is constant regardless of whether or not a part is produced. As stated in this paper, the primary difference between additive manufacturing and CNC is that machining typically uses cutting oil for lubrication, which is an additional source of waste. The authors emphasize on the fact that one of these manufacturing processes may cause lower ecological impacts than the other depending on part geometry and design. From the life cycle assessment conducted in the study, it was found that FDM performs better than IJP and CNC at maximum utilization. The authors also state that changing the quality level of the part significantly changes the environmental impacts. The findings of this study partly confirmed that additive manufacturing is more sustainable than subtractive manufacturing due to the fact that $3 \mathrm{D}$ printing does not waste as much material. But the authors also state that because of the greater energy use in additive manufacturing processes, the savings in material would be negligible in certain circumstances.

Dudek and Zagorski [22] conducted a study on the energy efficiency and effectiveness of selective laser sintering compared to traditional manufacturing. The authors present the energy 
efficiency and time requirement for producing a typical mechanical part and a complicated element using both laser sintering and traditional manufacturing. The objective of this paper is to provide a decision-making guideline to choose the appropriate technology of manufacturing depending on batch size, element size, complexity, and material requirements. Power usage during the production of a $1,196,500 \mathrm{~mm}^{3}$ part was measured for a selective laser sintering machine with the aid of an energy logger. As per this study, the total energy used for the production of this part was $29 \mathrm{kWh}$ with half being consumed for heating. This research revealed that material costs constitute a major portion of the cost of additive manufacturing, but factors such as build orientation, envelope utilization, build time, energy consumption and labor, minimize the overall cost, and can be considered to be lower when compared to traditional manufacturing. The authors recommend that build volumes within the chamber of the printer should be densely packed to maximize the ratio of part output per build height, which would result in a more energy efficient system.

Wedlund and Bergman [23] developed a decision support model which aids in the selection of either additive manufacturing or subtractive manufacturing for a given metallic part with regards to production costs. For this research study, DMLS and CNC machining were taken into consideration and necessary information related to materials and machines were obtained by interviewing professionals in the field of manufacturing. The model accounts for the material used, geometric complexity, duration of manufacture, quantity produced, surface finish and waste material, in order to generate an accurate depiction of the production costs involved. The authors of this study concluded that additive manufacturing is unable to compete with machining-based production costs incurred during the manufacturing stage of a given metallic part.

Watson and Taminger [24] developed a computational model for determining whether additive manufacturing or subtractive manufacturing is more efficient for manufacturing a given metallic part based on energy consumption. For both types of manufacturing, energy consumption was measured based on the volume fraction of the specific part. The authors generated a critical value which could be used as a benchmark in order to compare the energy efficiency of subtractive or additive manufacturing for producing the part. For volume fractions exceeding the critical value, subtractive manufacturing is more energy efficient, and vice versa. The model reflects the entire 
manufacturing lifecycle of the product ranging from production and transport of feedstock material through processing to post-production scrap for recycling. The authors emphasize on the fact that there only exists limited data pertaining to energy expenditure of manufacturing metallic components, and the data which is already available is highly job specific. This indicates that there exists insufficient material and process related information in order to carry out accurate extrapolation.

\subsection{Sustainability Impacts of Additive Manufacturing and CNC Machining}

\subsubsection{Life Cycle Assessment of Additive Manufacturing}

Abdulrahman et. al [9] studied the sustainability and environmental impact of laser metal deposition techniques, utilizing available literature and life cycle inventory data. The authors emphasize on the fact that additive manufacturing technology possesses the ability to reduce material usage, energy usage and environmental impacts in comparison to traditional machining processes.

Liu et al. [10] conducted a life cycle assessment and analysis of energy consumption in PBF and DED during the manufacture of metal parts. Energy consumption was investigated with respect to the subsystems/operational modes and process parameters of each machine. The environmental impact was compared with conventional manufacturing. The resource consumption due to the atomization of powder material and feedstock was also considered in terms of specific energy. The authors further examined energy consumption reduction strategies such as layer thickness optimization and build volume maximization. In a case study evaluation of $\mathrm{CNC}$ and $\mathrm{AM}$, the authors found that material consumption and energy consumption throughout the life cycle is lower for AM.

A thorough investigation of available life cycle inventory (LCI) data was conducted by Kellens et al. [25] to compare the environmental impact caused by a series of additive manufacturing techniques. In addition to the energy consumption by the $3 \mathrm{D}$ printing unit, the authors also considered the environmental impact of material production and part post treatment aspects as well. The types of additive manufacturing considered in this study were selective laser melting (SLM), selective laser sintering (SLS), electron beam melting (EBM), fused deposition modelling (FDM) and stereolithography (SL.) Kellens et al. explains that the extra material 
preparation required for 3D printing feedstock material results in additional environmental impact compared to traditional manufacturing methods. In this paper, the authors also emphasize on the deficit of current literature pertaining to LCI data on additive manufacturing feedstock materials in terms of environmental performance. The authors conclude that most available studies thus far have focused on energy consumption of 3D printing with less significance given to resource consumption and direct/indirect emissions. As per this study, the specific energy consumption values for 3D printing units are 1 to 2 orders of magnitude higher than conventional machining and injection molding processes. According to the authors, the higher environmental impact caused during the manufacturing phase of 3D printing should be accounted for during the use stage of additive manufactured parts.

Ford and Despeisse [26] conducted an exploratory study of the advantages, challenges and implications of additive manufacturing on sustainability. The sustainability aspect was evaluated in terms of innovation, business models and the configuration of value chains. As stated in this paper, additive manufacturing has the potential to provide numerous sustainability advantages. The authors describe these as; the capability to optimize geometries and create lightweight components that reduce material consumption in manufacturing and energy consumption use; the subsequent reduction in transportation in the supply chain; and inventory waste reduction due to the ability to create spare parts on demand. The authors also state that additive manufacturing provides opportunity for companies to experiment with existing business models, and due to its ability of reproducing parts for remanufacturing and repair from digital files, product life would be extended tremendously. As per this study, it is important to realize that additive manufacturing is also associated with challenges on a sustainability level, which need to be accounted for when transitioning into production systems based on this novel technology. A predictive model for environmental assessment in additive manufacturing processes has been developed by Bourhis et al. [27]. This paper presents a method for electric, fluids and raw material consumption assessment for direct metal deposition type of $3 \mathrm{D}$ printing. The main objective of the authors in developing this model was to aid engineers in the design of optimized parts for additive manufacturing with an environmental point of view. In this study, the environmental impact of a part was determined from the CAD model itself. The authors integrated life cycle assessment data with the model in order to evaluate environmental impacts of the manufacturing stage. This model enables the evaluation of electricity, material and fluids 
consumption during the entire process of manufacturing. In addition, the developed model allows the user to choose the type of 3D printing nozzle which minimizes the environmental impact. Bourhis et al. tested the developed model on an aeronautic part which is currently produced by conventional manufacturing for comparison purposes. The environmental impact was found to be less for the $3 \mathrm{D}$ printed part. The model generated in this research also provides a feedback

loop which allows optimization of the environmental impact. The authors conclude by stating that material consumption has a greater environmental impact than the electrical consumption of additive manufacturing.

\subsubsection{Energy Consumption of Additive Manufacturing}

Faludi et al. [28] analyzed the environmental impacts of selective laser melting by considering the machine and supporting hardware, material used, and electricity used. The material aspect was determined by generating life cycle inventories for feed material and the processing involved, while electricity usage was measured by an in-line power meter. The authors also considered data pertaining to transport and disposal. An important finding of this research was that maximizing printer capacity utilization reduced environmental impacts per part by a factor of 14 to 18 . This research study suggests that printer power usage dominates the energy consumed due to the material usage in selective laser melting processes. The authors also state that auxiliary equipment of the 3D printer typically uses more energy per part than the printer itself. Faludi et al. emphasizes on the fact that machine utilization rates and part removal drastically affects the environmental impacts irrespective of the electricity consumption. As per this study, the post processing of additive manufacturing is a significant contributor towards environmental impact. Based on the results of this study, the authors recommend that SLM machine designers should focus on reduction of power demand both in the printer and auxiliaries while enabling the printer to idle when not in use.

Kellens et al. [29] conducted an environmental impact assessment analysis for selective laser melting (SLM) and selective laser sintering (SLS) processes in order to determine the potential for improvement of these machines. The authors of this paper used the CO2PE! methodology in order to perform comprehensive environmental assessments of the two additive manufacturing processes. Using this methodology, life cycle inventory data was collected and environmental performance pertaining to process emissions and waste material were investigated. In this 
research, consumption of electricity was recorded for productive and nonproductive modes of the two machines. The authors state that the total energy consumption for both types of 3D printers can be minimized by selectively switching on and off the subsystems over the two modes. Another important finding of this research was that by the introduction of external cooling down cycles, the consumption of energy can be reduced immensely. The use of a secondary process container resulted in total machine time reducing by 2 hours and enabling the residual heat from the previous build to be partially recovered. Kellens et al. deduced that energy consumption can be reduced by minimizing the build height or optimizing the part orientation within the $3 \mathrm{D}$ printer, since energy consumption is directly proportional to build volume and time. As per this study a significant factor that contributes toward environmental impact is the nitrogen and compressed air consumption, which can be limited by using a better sealed process chamber. The authors conclude by stating that a well-considered choice of either SLM/SLS equipment along with a flexible/adaptable process chamber would lead to reduced environmental impact.

Peng [30] conducted a comprehensive analysis of energy utilization in 3D printing processes. In this research, energy was divided into two segments; primary and secondary. Energy models which provide methodologies for estimation of energy and optimization of the current production settings were developed for each segment. These models were developed with the objective of facilitating decision making in manufacturing systems. The author considered the energy required to change the material form and properties as primary energy and the energy consumed by ancillary components of the machine as secondary energy. In the model developed for this study, the performance indicators of an additive manufacturing unit are input for environmental assessment. The feedback loop in the program enables modification of part design for minimized environmental impact and optimized energy efficiency, while meeting the required quality standard. The parameters for optimization are first decided based on the initial CAD model and then used in model-based energy evaluation. In this research, Peng also developed an activity-based model representing energy consumption in each activity pertaining to a $3 \mathrm{D}$ printing unit, starting from setup of machine to the re-processing of material after the printing process. The author used discrete event modeling and state transition modeling to partition total energy consumption into machine-component-based segments. Energy consumption was highest for the nozzle heater, drive motors and cooling system. The author 
states that the findings of this research would complement further studies which compare energy utilization of traditional manufacturing with 3D printing processes.

Baumers et al. [31] measured the energy consumption of the two laser sintering processes in order to analyze the energy efficiency of additive manufacturing. The energy inputs for a build consisting of two large prosthetic parts were recorded using power meters to obtain meaningful classifications of energy usage corresponding to job-dependent, time-dependent, geometrydependent and Z-axis height dependent tasks. The build material was selected as Nylon-12 for this particular study. The authors measured the power consumption of the machine during warmup and cool-down procedures. As per this study, the job-dependent energy usage occurs after the build has been initiated and before part scanning commences. Hence, the authors considered this proportion of energy to be independent of the part geometry. Time-dependent energy consumption was identified through the measurement of a baseline power consumption during machine operation and was found to dominate the overall energy consumption of the process. Time-dependent energy consumption accounted for roughly $60 \%$ of the overall energy expenditure for the machines. The majority of this energy was associated with cooling and heating. The energy consumption rates for the two processes were found to be $204.31 \mathrm{MJ} / \mathrm{kg}$ and $237.68 \mathrm{MJ} / \mathrm{kg}$ with process rates of $0.072 \mathrm{~kg} / \mathrm{h}$ and $0.041 \mathrm{~kg} / \mathrm{h}$. According to this paper, process rates smaller than $0.1 \mathrm{~kg} / \mathrm{h}$ tend to consume energy in excess of $100 \mathrm{MJ} / \mathrm{kh}$ of material processed. The authors indicate that reducing the time-dependent energy consumption by means of better thermal insulation and increasing the process speed of the laser sintering process would have a positive impact on energy efficiency.

Baumers et. al [32] analyzed the build time, energy consumption and related costs for direct metal laser sintering (DMLS) by creating a combined estimator which reflects efficient machine operation. The most significant aspect of this experiment is the use of the build volume packing algorithm, which allows the build envelope of the 3D printer to be utilized optimally. For the purposes of the experiment, the authors selected five products which are commercially manufactured using DMLS. Each of these products were manufactured as a single full build with the workspace being optimally packed in order to achieve higher energy efficiency. The experiment was validated by conducting two additional build experiments with each product being manufactured separately. Energy consumption during the build process was measured 
using a digital power meter. In addition, the energy consumption during the removal of the build from the build plate was also measured. The authors conclude by stating that the cost and energy consumption of DMLS is highly dependent on the user's ability to utilize the machine build envelope optimally.

Baumers et al. [33] conducted a comparative study of two metallic additive manufacturing technologies in order to determine their power consumption. The technologies considered were selective laser melting (SLM) and electron beam melting (EBM.) A significant aspect of this research was that explored the effectiveness gained due to packing efficiency of the build platform. Power monitoring of the experiment consisted of two stages. The first step was to measure the power during production of a full build volume, in order to determine the energy consumption of the machine at full capacity. The second step was to monitor the power during a single part build, in order to analyze the gain in efficiency due to packing density and multi part production. The selection of a standardized test part with complex topology allowed the authors to assess the power consumption due to geometric complexity as well. The single part build on the EBM machine resulted in $6.41 \mathrm{kWh}$ whereas the energy consumption of the single build on the SLM resulted in $7.34 \mathrm{kWh}$. Due to the low layer thickness produced by the machines, the parts compose of improved surface finish and tighter dimensional tolerances.

Baumers et al. [34] experimented the effect of product geometric complexity on process energy consumption. Data was collected during the manufacture of a titanium test part using an electron beam melting 3D printer. The electricity consumption during build experiments was measured using a digital multipurpose power meter. By associating a computationally quantifiable convexity-based characteristic to product shape complexity and testing the correlation with energy consumption per printed layer, the authors were able to conclude that process energy is not driven by the complexity of the product. The authors further state that overall part mass is an important contributor towards energy consumption of the process. This research only considers the environmental impact at the process level and does not investigate into other stages of the product life cycle. Additionally, builds used in the experiment consisted only of highly complex geometries. In this research study, Baumers et al. compared the obtained results to CNC machining in terms of generated waste, electricity consumption, cost, etc. 
Meteyer et al. [35] analyzed the energy and material consumption of BJP technology. This research paper presents a methodology to model energy and material consumption for the BJP process, i.e. from filling of the machine to the final sintering stage. The energy consumption due to all sub processes of the BJP machine as well as energy expenditure due to curing and sintering stages were also determined. In this study, the resulting waste powder was reused for subsequent build experiments, indicating minimal powder wastage during BJP processes. The authors state that the consumption of binder and cleaner material is linear with the number of layers printed. For verification of the models, three different experiments were conducted for the printing process, curing and sintering processes, respectively. The builds were of minute volumes and consisted of relatively simple geometries. This research was only focused on the manufacturing stage of the product and does not consider material preparation and disposal aspects.

\subsubsection{Sustainability of CNC Machining}

Dahmus and Gutowski [12] conducted a system level environmental analysis of machining. The environmental impacts due to material removed during machining, material and cutting fluid preparation were analyzed. The authors emphasize on the fact that energy requirement of the material removal process is only a minute fraction compared to the total energy requirement. According to this research study, depending on the material being machined, the material preparation step has a rather high environmental impact. The existing knowledge base of specific cutting energies was used to determine the energy required to remove a certain volume of material. The paper also states that during production machining, the power requirement of auxiliary equipment such as workpiece handling equipment, cutting fluid handling equipment, chip handling equipment, tool changers and computers. The energy requirement of auxiliary equipment was found to exceed the cutting energy in most cases. The authors also state that preparation of cutting fluid can result in hazardous emissions.

Pavanaskar [13] analyzed the energy efficiency of CNC milling by modeling the energy consumption. In this research, algorithms were created to analyze the performance of 3 and 5 axis CNC machines during point milling. The author created a software tool which estimates the energy consumption for a proposed machining operation. Utilizing this software, a method for developing energy efficient toolpaths was proposed. According to the Pavanaskar, machining time dominates the energy consumption of a 5 axis CNC milling machine. Hence a solution 
methodology is presented to optimize machining time.

Li et al. [14] conducted a quantitative analysis of carbon emissions due to CNC based machining systems. The authors assessed the carbon emissions associated with machining a cylindrical turning workpiece by considering the amount of electricity, cutting fluids, wear and tear of cutting tools, material consumption and disposal of waste material. The quantity of carbon emissions was analyzed by varying the cutting speed of the machine. The study indicated that higher cutting speeds does not necessarily result in lower carbon emissions.

Fang et al. [36] developed a model to quantify the sustainability of CNC machining in terms of a sustainable design index. The sustainability indicators considered in this study were energy consumption, pollution emissions, costs, modular design, lightweight design, security, accuracy, and processing capability. The Life Cycle Assessment (LCA) and Analytic Hierarchy Process (AHP) methodologies were utilized to enumerate the sustainability performance of CNC machining. The developed sustainable design index considers factors impacting the economy, society, environment, and technology, and is applicable in CAD environment.

Alvarez et al. [37] conducted a thorough literature review pertaining to the sustainability impacts surrounding CNC machining. Results of the review were used to propose an optimization strategy for CNC machining based on the triple bottom line of sustainability. Sustainability was portrayed as an intersection of the economy, society, and environment. The study conducted by Alvarez et al. focused on enhancing the sustainability knowledge base pertaining CNC machining and mitigating the metabolic rift.

Zhang et al. [38] evaluated the impacts of process planning on the sustainability of CNC machining. The authors described optimization of process planning as an important consideration for the reduction of energy consumption, carbon emissions, and overall increase in sustainability. Sustainability of CNC machining has been evaluated based on energy consumption, relative delay time, and machining costs. Zhang et al. constructed four energy efficient control strategies to reduce energy consumption of CNC machining, and developed a decision-making mechanism using random forests to select the most suitable control strategy. A case study was conducted to verify the developed strategies and resulted in 25\% reduction of energy consumption due to the use of optimal process planning. 


\subsection{Conclusion}

This literature review demonstrates the prominence of sustainability-based AM research. From existing research work, it is quite clear that the utilization of $3 \mathrm{D}$ printing in production systems has the potential of reducing carbon emissions and overall environmental impact. Although several industries have begun the transition towards AM, most manufacturers have been unable to implement this technology in a fruitful manner due to limitations in mass production and material availability. Therefore, a range of further studies need to be conducted to investigate the advantages and challenges associated with the entire life cycle of this technology. At this exploratory stage of research, many studies have been conducted comparing the energy and material consumption of PBF/DED with CNC machining. However, fewer results have been reported for BJP. Furthermore, most research studies do not confine the comparison criteria to product and system parameters equally viable for each type of manufacturing technology. A comprehensive evaluation of sustainability impacts of CNC machining and AM would further expand the AM knowledge base and assist manufacturers in selecting the most beneficial technology in terms of sustainability. 


\section{Research Approach}

As mentioned in section 1.6, this research aims to develop a set of expert systems which would evaluate the sustainability aspects associated with the utilization of CNC machining and AM for the fabrication of metal components. In order to diversify the user base and minimize the computing power required to execute the program, the expert system has been split into two segments. The objective of the first expert system is to aid the user in ascertaining product, process, and system parameters viable for the technologies used for comparative analysis. Upon selecting a suitable product, the second expert system would portray the sustainability performance of each manufacturing process in terms of energy, cost, and auxiliary material usage. For the purposes of this study, BJP and DMLS have been analyzed in comparison to CNC milling, drilling, and turning.

\subsection{Selection of Sustainability Indicators}

Sustainability of AM and CNC machining can be evaluated based on numerous factors. Prior to selecting the most suitable sustainability indicators, the following aspects were considered.

- CNC machines typically idle when parts are transferred from one process to another. Although the load on the machine is considerably lower, switching off the spindle motor during machine idle time can significantly promote process energy efficiency. Sustainability of CNC machining can be improved by effective tool changes and rapid machine setups. Therefore, optimal process planning can be considered to be a major sustainability indicator of $\mathrm{CNC}$ machining. Utilization of machining centers would increase throughput, energy efficiency and overall sustainability due to the combination of machining steps. Flexible manufacturing systems have the capability of adapting to large scale changes in system capacity.

- Near net shape manufacturing enables increased levels of sustainability performance due to the requirement of lesser finishing and post processing steps. Manufacturing processes should be selected based on the capability of delivering optimal dimensional accuracies/surface quality. 
- Appropriate methodologies for the segregation of metal chips (formed during CNC machining) should be incorporated in the process planning stage. Mixing of different metal chip types would hinder recycling processes and would negatively impact sustainability.

- The type of CNC software utilized in processes have a significant impact on sustainability. Operators should be trained to utilize CAD software or CNC software with optimal visualization of tool paths such that rejects/tool failures are minimized.

- $\mathrm{CNC}$ machines typically operate under room temperature conditions, whereas, 3D printers usually require colder/conditioned spaces. Discrepancies in HVAC cooling load due to the utilization of these processes, may have a significant impact on energy consumption.

However due to limitations in resources and the research timeline, only the following sustainability factors have been considered in the evaluation.

1. Economic Impact

Cost effectiveness is a major consideration in the selection of sustainable manufacturing processes. Economic aspects pertaining to labor, material, electricity, and equipment have been analyzed to provide users a realistic depiction of the overall costs incurred during fabrication processes of BJP, DMLS and CNC machining. For most manufacturing systems, cost efficiency is the driving force for the implementation of specific technologies in processes.

\section{Energy Consumption}

The most energy intensive aspects of $\mathrm{CNC}$ machining and $\mathrm{AM}$ are considered to be material processing, and primary/secondary/post processing stages of manufacturing. The energy expenditure of raw material processing, workpiece/production, machine utilization and, finish machining, painting, and post processing steps such as heat treatment, polishing, were considered. Additionally, the energy consumption resulting from recycling and disposal of waste material have been analyzed. For the purposes of this research, it has been assumed that BJP and DMLS are characterized by negligible amounts of waste due to the reuse potential of metal powder. In order to evaluate the environmental impact, detailed calculations were employed to BJP, DMLS and CNC machining, and heat 
treatment processes. Energy consumption of material processing, finishing and recycling have been based on values found in existing literature pertaining to energy intensities (per mass) values for each process/material type.

\section{Auxiliary Material Consumption}

For the purposes of this research, auxiliary material usage of BJP, DMLS and CNC machining has been considered a key indicator of sustainability. Material production and end of life recycling/disposal, worker hazards, and overall process efficiencies pertaining to the utilization of binder fluid, inert gas systems, cutting tools and coolant fluids have been evaluated. Furthermore, the re-use potential of waste material and auxiliary material were further assessed.

\subsection{Evaluation of Feasible Product and System Parameters}

In order to prevent partial results, the proposed expert systems have been designed such that the comparative analysis is carried out within the range of product and system parameters equally suited for both manufacturing technologies. The viability of each technology depends on the type of product being manufactured. Product parameters such as material properties, geometric complexity, dimensions, surface finish and tolerance, as well as system parameters such as cycle time, and production quantity justifiable by unit cost will be considered. Cycle time has been assumed to represent the production capacity of each manufacturing technology.

$\mathrm{CNC}$ offers a vast range of material selection options. Depending on the required hardness, yield strength, chemical and temperature resistance, machinable metal material types include aluminum, stainless steel, alloy steel, mild steel, tool steel and brass. CNC machining produces parts with low tolerances $( \pm 0.125 \mathrm{~mm})$ in comparison to other common manufacturing technologies. Additional finishing steps enable the fabrication of products with higher accuracy $( \pm 0.05 \mathrm{~mm}$ tolerance $)$ and surface finish. Limitations of this technology include the incompetency in producing perfectly square corners and machining internal hidden geometries. Restraints to tool access intensifies the machining process plan, resulting in added human intervention and costs. Parts with complex internal geometries requiring supplementary tooling and fixtures are infeasible for $\mathrm{CNC}$ from an economic standpoint [8]. Furthermore, high temperatures and cutting forces resulting from CNC 
machining operations may result in part deformations. This in turn, limits the minimum thickness of thin features. In terms of unit cost, $\mathrm{CNC}$ machining is more feasible for low to medium sized (1-500 parts) production runs [8].

Product parameters for 3D printing are strictly associated with the type of process utilized. The considered metal additive manufacturing methodologies can be used to print stainless steel, inconel alloy, tungsten carbide, aluminum, maraging steel, cobalt chrome, titanium, nickel alloy. Nonuniform shrinkage can be an issue with metal 3D printing and must be accounted for during the design stage of the product. Binder Jetting (BJP) can print with a tolerance of $\pm 0.2 \mathrm{~mm}$, whereas Direct Metal Laser Sintering (DMLS) is capable of dimensional accuracies up to $\pm 0.127 \mathrm{~mm}$. With post-processing, tolerance could be reduced to $\pm 0.05 \mathrm{~mm}$. Lower layer heights would yield higher resolution, and consequently improved surface finish of the printed part [39]. It is important to note that shape complexity does not necessarily impact the energy consumption of additive manufacturing processes [34]. Fabricating minute details using BJP is infeasible as the preliminary printed part is fragile. Due to the porosity of the printed part, the product may have lower mechanical properties [5]. However, with appropriate post processing steps such as curing, infiltrating and sintering, hot isostatic pressing, high material properties can be achieved. Considering justifiable unit costs, BJP is suited for production quantities of up to 500 parts, whereas DMLS performs better during production runs of up to 100 parts [5].

Table 3.1 depicts the summary of product and system parameters feasible for CNC machining and the considered AM methods. The content in this table will be utilized as logical rules in the design of the expert system to ascertain the equal feasibility region of $\mathrm{AM}$ and $\mathrm{CNC}$ machining. In the first expert system, the user will be required to input details pertaining to the product being manufactured. If the required product characteristics are within the given process and system parameters equally viable for $\mathrm{AM}$ and $\mathrm{CNC}$ machining, the user can proceed to the second expert system for sustainability analysis. 
Table 3.1: Viable System and Product Parameters for CNC Machining and AM [5], [8], [40], [41], [42]

\begin{tabular}{|c|c|c|c|c|}
\hline \multicolumn{2}{|r|}{ Criteria } & \multicolumn{3}{|c|}{ Manufacturing Technology } \\
\hline & & Binder Jetting & DMLS & CNC Machining \\
\hline \multirow[t]{4}{*}{$\begin{array}{l}\text { Product } \\
\text { Parameters }\end{array}$} & Material & $\begin{array}{l}\text { Stainless Steel 304L, Stainless Steel 316, Stainless } \\
\text { Steel 316L, Stainless Steel 17-4, Stainless Steel 420, } \\
\text { Tungsten }\end{array}$ & $\begin{array}{l}\text { AlSi10Mg, Cobalt Chrome (MP1), Nickel Inconel } \\
\text { 625, Nickel Inconel 718, Nickel Alloy HX, Stainless } \\
\text { Steel 316L, Stainless Steel 17-4, Maraging Steel } \\
\text { (MS1), Ti64, Copper C18150 }\end{array}$ & $\begin{array}{l}\text { Stainless Steel 303, Stainless Steel 304, Stainless } \\
\text { Steel 304L, Stainless Steel 316, Stainless Steel } \\
2205 \text { Duplex, Stainless Steel 17-4, Stainless Steel } \\
\text { 420, Alloy Steel 4140, Alloy Steel 4340, Mild } \\
\text { Steel 1018, Mild Steel 1045, Mild Steel A36, tool } \\
\text { Steel D2, Tool Steel A2, Tool Steel O1, Brass } \\
\text { 360, Titanium Grade } 2\end{array}$ \\
\hline & Geometric Features & $\begin{array}{l}\text { Supported Walls }>2 \mathrm{~mm} \\
\text { Unsupported Walls }>3 \mathrm{~mm} \\
\text { Fillets }>1 \mathrm{~mm} \\
\text { Interior Cavities }>1.27 \mathrm{~mm} \\
\text { Embossed and Engraved Details }>0.5 \mathrm{~mm} \\
\text { Escape holes }>5 \mathrm{~mm} \\
\text { Hole diameter }>1.5 \mathrm{~mm} \\
\text { Pin diameter }>2 \mathrm{~mm} \\
\text { Small features }>2 \mathrm{~mm} \\
\text { No support required }\end{array}$ & $\begin{array}{l}\text { Supported Walls }>0.4 \mathrm{~mm} \\
\text { Unsupported Walls }>0.5 \mathrm{~mm} \\
\text { Pin diameter }>1 \mathrm{~mm} \\
\text { Hole diameter }>1.5 \mathrm{~mm} \\
\text { Tall features: height } / \text { width }=8 \\
\text { Embossed and Engraved Details }>0.1 \mathrm{~mm} \\
\text { Small features }>0.6 \mathrm{~mm} \\
\text { Pin diameter }>0.1 \mathrm{~mm} \\
\text { Support required }\end{array}$ & $\begin{array}{l}\text { Tall features: height/width }<4 \\
\text { Cavities and pockets: depth }<4 \mathrm{x} \text { width } \\
\text { Internal edges }>1 / 3 \mathrm{x} \text { cavity depth } \\
\text { Wall thickness }>0.8 \mathrm{~mm} \\
\text { Hole diameter }<4 \mathrm{x} \text { nominal tool diameter } \\
\text { Depth of undercut }<2 \mathrm{x} \text { width } \\
\text { Undercut clearance } 4 \mathrm{x} \text { depth } \\
\text { Small features }>1 \mathrm{~mm}\end{array}$ \\
\hline & Post-processing & Heat treatment, Sanding, Polishing, Machining & $\begin{array}{l}\text { Heat treatment, Support removal, Machining, } \\
\text { Surface Treatment, Polishing }\end{array}$ & $\begin{array}{l}\text { Bead blasting, Heat Treatment, Anodizing, Hard } \\
\text { Coat Anodizing, Powder Coating, Polishing }\end{array}$ \\
\hline & Tolerance & $\begin{array}{l} \pm 0.2 \mathrm{~mm} \\
\pm 0.05 \mathrm{~mm} \text { (after post-processing) }\end{array}$ & $\begin{array}{l} \pm 0.127 \mathrm{~mm} \\
\pm 0.05 \mathrm{~mm} \text { (after post-processing) }\end{array}$ & $\begin{array}{l} \pm 0.125 \mathrm{~mm} \\
\pm 0.05 \mathrm{~mm} \text { (after post-processing) }\end{array}$ \\
\hline $\begin{array}{l}\text { System } \\
\text { Parameters }\end{array}$ & $\begin{array}{l}\text { Production quantity based on } \\
\text { feasible unit cost }\end{array}$ & $1-500$ parts & 1-100 parts & $1-500$ parts \\
\hline
\end{tabular}


Table 3.2: Achievable Material Mechanical Properties for CNC Machining and AM [5], [8], [40], [41], [42]

\begin{tabular}{|c|c|c|c|c|c|c|}
\hline \multirow{2}{*}{\multicolumn{2}{|c|}{ Manufacturing Technology and Considered Mechanical Properties }} & \multicolumn{5}{|c|}{ Material Type } \\
\hline & & Stainless Steel 304L & Stainless Steel 316 & Stainless Steel 316L & Stainless Steel 420 & Stainless Steel 17-4 \\
\hline \multirow{3}{*}{ Binder Jetting } & Hardness (HRB) & 75 & 60 & 71 & 97 & 100 \\
\hline & Yield Strength (ksi) & 29 & 41 & 33 & 66 & 145 \\
\hline & Surface Quality $(\mu \mathrm{m})$ & 3 & 15 & 3 & 15 & 3 \\
\hline \multirow{3}{*}{ Direct Metal Laser Sintering } & Hardness (HRB) & - & - & 75 & - & 100 \\
\hline & Yield Strength (ksi) & - & - & 68 & - & 106 \\
\hline & Surface Quality $(\mu \mathrm{m})$ & - & - & 6 & - & 6 \\
\hline \multirow{3}{*}{ CNC Machining } & Hardness (HRB) & 75 & 75 & 75 & 100 & 100 \\
\hline & Yield Strength (ksi) & 39 & 42 & 42 & 72 & 145 \\
\hline & Surface Quality $(\mu \mathrm{m})$ & 3 & 3 & 3 & 3 & 3 \\
\hline
\end{tabular}




\subsection{Creation of Knowledge Base}

An important aspect of an expert system is its knowledge base. In order to create a database of knowledge pertaining to the feasibility and sustainability of each technology, information has been collected by means of literature reviews and interactions with manufacturing experts. Exhaustive calculation procedures were adopted for determining energy consumption of BJP, DMLS and CNC machining. Factors such as layer thickness, layer time, build orientation, curing and sintering time would be considered for Binder Jetting. In the case of DMLS, impact of build rate of printers and amount of support material on energy consumption has been evaluated. The effect of material removal rates (based on cutting speed, feed and depth) used for CNC milling, turning and drilling, on the resultant energy consumption were analyzed. In addition, energy performance of heat treatment processes have been modeled using temperature profile-based load factors for equipment. Evaluation methods comprising of average process embodied values $(\mathrm{kWh} / \mathrm{lb})$ were employed for the calculation of energy expenditure in material processing, primary processing, finishing and recycling. Cost based calculations for the manufacturing processes includes labor, material, electricity, and equipment. Analysis has utilized methodologies and monetary information found in existing literature. The analysis of sustainability impacts for various auxiliary systems of BJP, DMLS and CNC Machining has been strictly based on findings of existing literature. Information comprised in the knowledge base have been converted to logical rules by means of an expert system shell, such that appropriate inference mechanisms can be utilized to evaluate user input data pertaining to production systems.

\subsection{Weightage and Scoring Methodology for Auxiliary Material}

In order to develop a rating system which depicts the sustainability of each manufacturing process in terms of auxiliary material usage, Analytical Hierarchical Process (AHP) has been utilized [43]. AHP is a method used to solve complex decision problems in which multiple criteria are evaluated

for the selection of an alternative. This algorithm can be used to convert subjective evaluations to numerical values which can be further processed and compared as per the decision-making problem. Additionally, tangible data arising from experiments, measurements and existing literature can be used in the AHP methodology. The objective of AHP would be to conduct pairwise comparisons and score BJP, DMLS and CNC machining in terms of auxiliary material consumption such that a rating would be yielded for each technology. 
The initial step of AHP is to decompose the optimization problem into a hierarchy of criterion and alternatives which can be individually inspected with respect to the goal. The algorithm systematically analyzes each alternative against the criteria using pair-wise comparisons. The pairwise comparisons are represented in form of $\mathrm{n} x \mathrm{n}$ reciprocal matrices, where $\mathrm{n}$ is the number of criteria considered. AHP has the capability of transforming observational/experimental data into numerical values. By determining weight factors for each criterion/sub criterion, all elements within the hierarchy can be assessed alongside the alternatives. A rating system can be created using the calculated weights to depict the suitability of each alternative towards fulfilling the end goal. The relative importance scale introduced by [43] can be used to construct the pairwise comparison matrices. The rating scale is depicted in table 3.3. 
Table 3.3: Relative Importance Scale [43]

\begin{tabular}{|c|c|c|}
\hline $\begin{array}{l}\text { Intensity of } \\
\text { importance }\end{array}$ & Definition & Explanation \\
\hline 1 & Equal importance & Two activities contribute equally to the objective \\
\hline 2 & Weak or slight & \\
\hline 3 & Moderate importance & $\begin{array}{l}\text { Experience and judgement slightly favor one activity } \\
\text { over another }\end{array}$ \\
\hline 4 & Moderate plus & \\
\hline 5 & Strong importance & $\begin{array}{l}\text { Experience and judgement strongly favor one activity } \\
\text { over another }\end{array}$ \\
\hline 6 & Strong plus & \\
\hline 7 & Very strong or demonstrated importance & $\begin{array}{l}\text { An activity is favored very strongly over another; its } \\
\text { dominance demonstrated in practice }\end{array}$ \\
\hline 8 & Very, very strong & \\
\hline 9 & Extreme importance & $\begin{array}{l}\text { The evidence favoring one activity over another is of } \\
\text { the highest possible order of affirmation. }\end{array}$ \\
\hline $\begin{array}{l}\text { Reciprocals of } \\
\text { above }\end{array}$ & $\begin{array}{l}\text { If activity } i \text { has one of the above non-zero numbers assigned to it when compared } \\
\text { with activity } j \text {, then } j \text { has the reciprocal value when compared with } i\end{array}$ & \\
\hline
\end{tabular}


The pairwise comparison matrices will be of the form:

$$
A=\left[\begin{array}{cccc}
1 & a_{12} & \ldots & a_{1 n} \\
a_{21} & 1 & \ldots & a_{2 n} \\
\ldots & a_{j i}=1 / a_{i j} & 1 & \ldots \\
a_{n 1} & \ldots & \ldots & 1
\end{array}\right]
$$

The Eigenvector $(p)$ depicts the relative weights between each criterion calculated by taking the arithmetic mean of all criteria. The priority vectors are obtained from normalized Eigenvectors of the matrix. Since it is normalized, the sum of all values in the priority vector equals 1 . The maximal Eigenvalue $\left(\lambda_{\max }\right)$ is evaluated from the summation of products between each priority vector and the sum of columns in the matrix. The consistency of comparison matrices is analyzed using the consistency index $(\mathrm{CI})$, random consistency index $(\mathrm{RI})$ and consistency ratio $(\mathrm{CR})$.

$\mathrm{CI}=\frac{\lambda \max -n}{\mathrm{n}-1}$

The RI is given by,

\begin{tabular}{|c|c|c|c|c|c|c|c|c|c|c|}
\hline $\mathrm{n}$ & 1 & 2 & 3 & 4 & 5 & 6 & 7 & 8 & 9 & 10 \\
\hline $\mathrm{RI}$ & 0 & 0 & 0.58 & 0.9 & 1.12 & 1.24 & 1.32 & 1.41 & 1.45 & 1.49 \\
\hline
\end{tabular}

$\mathrm{CR}=\frac{\mathrm{CI}}{\mathrm{RI}}$

If the value of $\mathrm{CR}$ is smaller or equal to $10 \%$, consistency of the comparison matrices is acceptable.

Weight factors for each criterion/sub-criterion are assigned using the above method. Afterwards, the alternatives are compared alongside each criterion in the same manner to create a ranking system for the most suitable choice. The ranking for each alternative can be determined using:

$$
g_{i}=\sum_{j} w_{j} \cdot l_{i j}
$$


Where,

$g_{i}=$ global priority of alternative

$w_{j}=$ weight of $\mathrm{j}^{\text {th }}$ criterion

$l_{i j}=$ local priority of alternative with respect to $\mathrm{j}^{\text {th }}$ criterion

The sustainability expert system logical rules have been designed such that all quantitative and qualitative data pertaining to auxiliary material within the knowledge base are converted to the rating scale depicted in table 3.3. The AHP algorithm will be able to choose between AM and CNC machining with respect to the auxiliary material consumption for a user defined product.

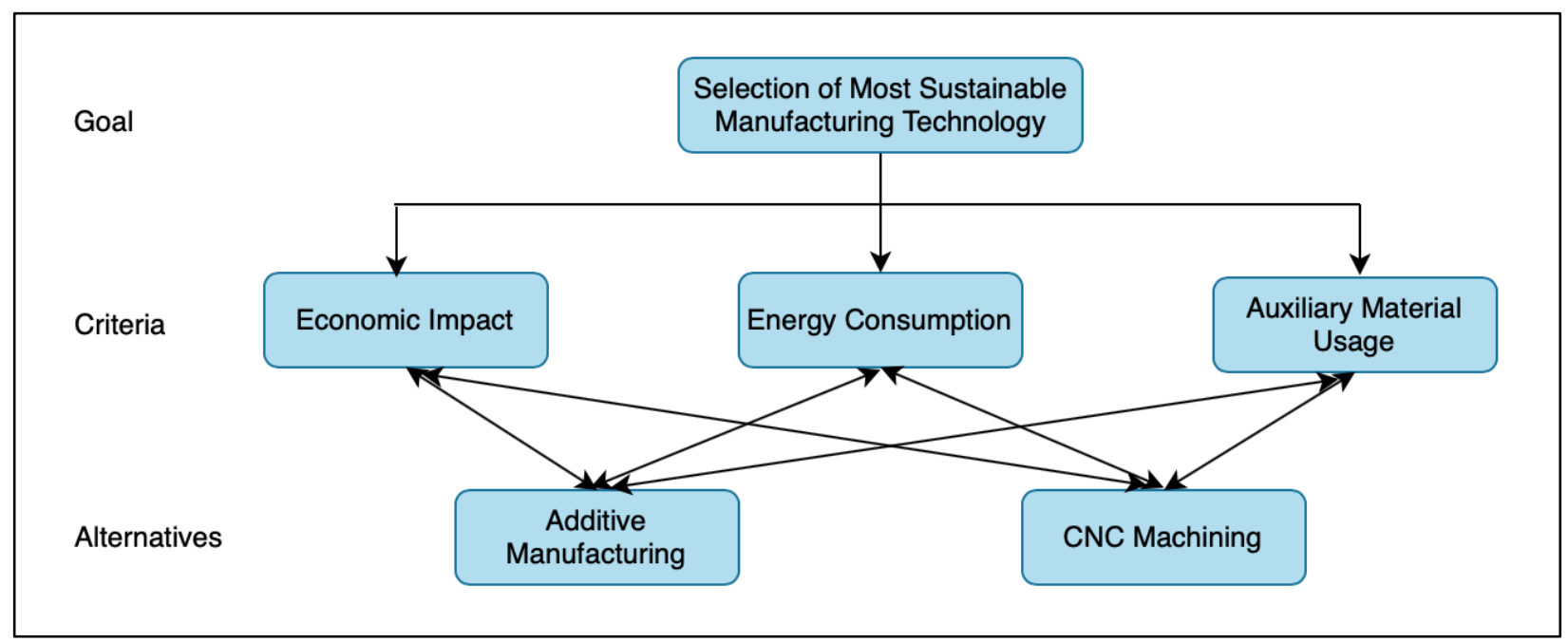

Figure 3.1: Decision Hierarchy of the AHP Process

\subsection{Expert System Shell}

The knowledge automation software Exsys Corvid ${ }^{\circledR}$ has been utilized in this research for the purposes of designing and deploying the required Expert Systems. Corvid ${ }^{\circledR}$ facilitates the development of complex decision support systems which can be executed on a web browser. This is accomplished by using the $\mathrm{Java}^{\circledR}$ applet already existent within web pages. The use of Corvid ${ }^{\circledR}$ is expected to enhance accessibility/portability of the expert systems and enable streamlined access to users.

The Exsys Corvid ${ }^{\circledR}$ program provides an object-oriented structure which also incorporates a simple logical rule building procedure (in terms of IF, AND, OR, THEN statements), which can emulate the thinking process of a human expert. The program allows incorporation of a vast range 
of variable types such as dynamic lists, statics lists, numeric values, strings, dates, collections and confidence levels. The logic building platform enables organization of blocks (consisting of rules and trees with related functions) which can be executed at a user defined order. The command block builder allows the developer to select the method of inferencing (backward or forward chaining) utilized by the Corvid $\AA$ inference engine to derive necessary variables which serve as final outputs of the system. Aspects of the expert system shell utilized for the purposes of this research have been detailed below.

\subsubsection{Corvid $®$ Variables}

Variables are the driving force behind the infrastructure of Corvid ${ }^{\circledR}$ expert systems. Variables can be used to hold information during program deployment, define the final outcome of the system and develop logical rules within logic blocks and command blocks. The Variable Edit Window can be used to add variables and design the structure of prompts within the system. Variables can also be set as a backward chaining goal. The flexibility provided by Corvid ${ }^{\circledR}$ to utilize variables for multiple purposes, facilitates the development of systems with increased functionality. Each variable can be assigned with a unique name and prompt. Prompts are descriptions for each variable, which will be displayed when requesting system user input. Suitable application of the prompts feature will enable development of systems which can support users with varying levels of expertise. During program execution, Corvid ${ }^{\circledR}$ uses a Java ${ }^{\circledR}$ Runtime Applet to ask the user for required information as per the logical rules and inferencing method. Additionally, variables can consist of data deriving from external sources.

\subsubsection{Corvid® Logic Blocks}

The concept of Logic Blocks is unique to Corvid ${ }^{\circledR}$, and is useful in grouping related logical rules within a system. The logic can be developed in terms of tree diagrams or individual rules. Logic blocks can be additionally used to improve comprehensibility by means of separating preceding rules into segments. By setting an appropriate firing order for blocks, the overall goal of the system can be achieved. Due to the partition of logic, the main set of rules can be distinctly presented, such that improvements/modifications to the code can be easily achieved. Blocks can be created/edited using the Corvid ${ }^{\circledR}$ Logic Block window. A range of outputs can be achieved by 
carefully designing the logic trees with suitable indentations for rules. Logic trees can be designed such that the system would be capable of handling a vast range of user inputs, including errors.

\subsubsection{Corvid $®$ Command Blocks}

Command Blocks control system operation by utilizing inference mechanisms to derive predefined variables. Essentially, Command Blocks control the variables which need derivation, and logic blocks to be utilized to achieve the system goal. Command Blocks additionally execute the procedure for displaying results. Commands can be designed in a manner which applies conditional inferencing to variables, or such that all required confidence variables are derived. WHILE and FOR loops can be used within Command Blocks for conditional inferencing purposes. Command Blocks can be developed and modified in the Corvid ${ }^{\circledR}$ Command Block Window. This window clearly depicts the command structure of the program and enables the user to easily make enhancements/alterations.

\subsection{Conclusion}

The need for AI in decision support systems pertaining to the selection of AM and CNC Machining is quite apparent. A set of expert systems have been developed to assist product development teams in the selection of BJP, DMLS or CNC Machining for metal manufacturing processes based on feasibility and sustainability. Comprehensive knowledge bases pertaining to feasible product/process/system parameters, economic impact, energy consumption and auxiliary material usage, were created to aid the design of the expert systems. Exsys Corvid ${ }^{\circledR}$ has been utilized to design appropriate logical rules and inference mechanisms, with adequate access to data/information arising from existing literature. In addition, AHP has been utilized in developing a rating-based methodology for the evaluation of auxiliary material consumption inherent to BJP, DMLS and CNC Machining. 


\section{System Design}

The main objectives of this research study encompass the design and development of two expert systems which can enhance decision making capabilities in the selection of metal additive manufacturing (BJP or DMLS) and CNC machining. The first expert system (MSUSTAIN1) is capable of ascertaining the region of feasibility for CNC machining and BJP/DMLS based on product, process, and system level attributes. Once this region of feasibility has been established, the second expert system (MSUSTAIN2) can be utilized to obtain ratings for sustainability impacts emanating from the manufacturing process of a user defined product. The expert systems have been built using Exsys Corvid $\AA$.

Exsys Corvid ${ }^{\circledR}$ is a powerful tool for developing interactive expert systems. The software converts expert knowledge and decision-making logic to organized structures, which enable the inbuilt inference engine to dynamically carry out interactive consultations and provide advice to users. The decision to use Exsys Corvid ${ }^{\circledR}$ for the purposes of this research study revolves around its userfriendly controls, ability to easily build user interfaces and efficiency of the inference engine to fire logical rules at a high rate. Once the decision-making logic is designed and the appropriate inference mechanisms are selected via the command block, the software automatically generates the required procedures and files in order to run the system on a web server. Since all systems built using Corvid ${ }^{\circledR}$ can be fielded through a web browser-based applet, the portability of the programs is enhanced and can be accessed via most operating systems and platforms.

The expert systems have been designed in a manner which requires minimal technical expertise on the user end pertaining to domains external to the product, process, and system parameters inherent within the manufacturing system. Cost and energy consumption pertaining to the manufacturing processes have been enumerated based on algorithms available in literature. Analytical Hierarchy Process (AHP) has been incorporated into the expert system logic blocks such that relative ratings are assigned based on auxiliary material usage of each process.

\subsection{Knowledge Base Development}

Development of an expert system requires the creation of a comprehensive knowledgebase, to which, logical rules and inference mechanisms can be applied. As per the requirements of this 
research study, knowledge base creation has been accomplished by means of obtaining qualitative/quantitative data through literature reviews and expert opinions. The developed database consists of knowledge pertaining to the feasibility regions of product/process/system parameters, energy consumption during manufacturing and materials processing, costs resulting from fabrication, and the impact of auxiliary material consumption on sustainability of metal 3D printing and $\mathrm{CNC}$ machining.

\subsubsection{Viable Product, Process and System Parameters}

As described in section 3.2, Binder Jetting (BJP), Direct Metal Laser Sintering (DMLS) and CNC machining comprise of feasibility criteria inherent to their processes. Depending on the process capabilities, each type of manufacturing technology fabricates metal parts with specific product characteristics and system throughput ranges. It was considered essential to identify the product parameters (material, geometric complexity, surface quality, hardness, strength, dimensional accuracy) and system parameters (production quantity considering overall unit cost, cycle time based on process parameters) equally viable for each considered technology. The determination of feasible regions for product parameters and the calculation procedures for the evaluation of system parameters are detailed below.

It is important to note that the process capabilities of BJP, DMLS and CNC machining in manufacturing components with the desired product characteristics vary depending on the type of metal selected. Through extensive literature reviews, it was discovered that the material types valid for comparison of these technologies are variants of stainless steel (in the form of solid metal powder and billets.)

Geometric complexity is an important consideration during the selection of additive manufacturing and CNC machining for a particular product. Although the cost and resources for CNC machining exponentially increase with geometric complexity, the sensitivity of $3 \mathrm{D}$ printing cost to intricate geometric details remains fairly constant due to its additive nature of manufacturing. Most research studies to date do not evaluate these technology types based on equally viable product geometric complexities. As a general rule of thumb, components with higher geometric complexities should be fabricated using additive manufacturing, and components with lower complexities are more appropriate for $\mathrm{CNC}$ machining. However, there exists ambiguity in deciding which geometric features can be considered low or high in terms of complexity [44]. developed a methodology in 
which geometric complexity can be estimated utilizing the ratio between volume of the component and number of facets representing the CAD model. For this research study, the procedure described by [44] in combination with a complexity factor (as introduced by [23]) has been utilized to approximate the geometric complexity viable for additive manufacturing and CNC machining. Since geometric complexity has negligible impact on the resources required for additive manufacturing, the complexity factor is only applicable to products manufactured using CNC machining.

As described by [44], higher volume to facets ratios depict lower geometric complexity, whereas lower ratios illustrate higher complexities. Based on the information provided in related to complexity ratio values of traditional and additive manufacturing in [45], the following scale has been adopted to this research study.

Table 4.1: Geometric Complexity Ratios

\begin{tabular}{|c|c|}
\hline Ratio & Geometric Complexity \\
\hline Volume/Facets $\geq 3$ & Low \\
\hline $1.5 \leq$ Volume/Facets $<3$ & Medium \\
\hline $0.5 \leq$ Volume/Facets $<1.5$ & Medium-high \\
\hline Volume/Facets $<0.5$ & High \\
\hline
\end{tabular}

[23] formulated a complexity factor, ranging from 1 - 10 to account for the variation in machining time due to the product geometric complexity. According to [23], machining time increases as an exponential function with respect to the complexity factor. Based on the research of [23] and the analysis of breakeven point in terms of geometric complexity, the volume to number of facets ratios and the corresponding complexity factors for CNC machining have been modified in the following manner for the purposes of this research study. The assignment of complexity factors to volume/facets ratio was based on estimation of machine time difference due to each complexity level. 
Table 4.2: Geometric Complexity Factors for CNC machining

\begin{tabular}{|c|c|}
\hline Ratio & Complexity factor \\
\hline Volume/Facets $\geq 3$ & 2.5 \\
\hline $1.5 \leq$ Volume/Facets $<3$ & 5 \\
\hline $0.5 \leq$ Volume/Facets $<1.5$ & 7.5 \\
\hline Volume/Facets $<0.5$ & 10 \\
\hline
\end{tabular}

It is important to understand that the exact geometric complexity of products viable for both CNC machining and additive manufacturing is challenging to ascertain. However, by using subjective knowledge arising from existing literature such as [5], [8] and the research study of [23], the equally viable geometric complexity factor (considering the overall cost per unit) has been approximated to attain the value of 5 .

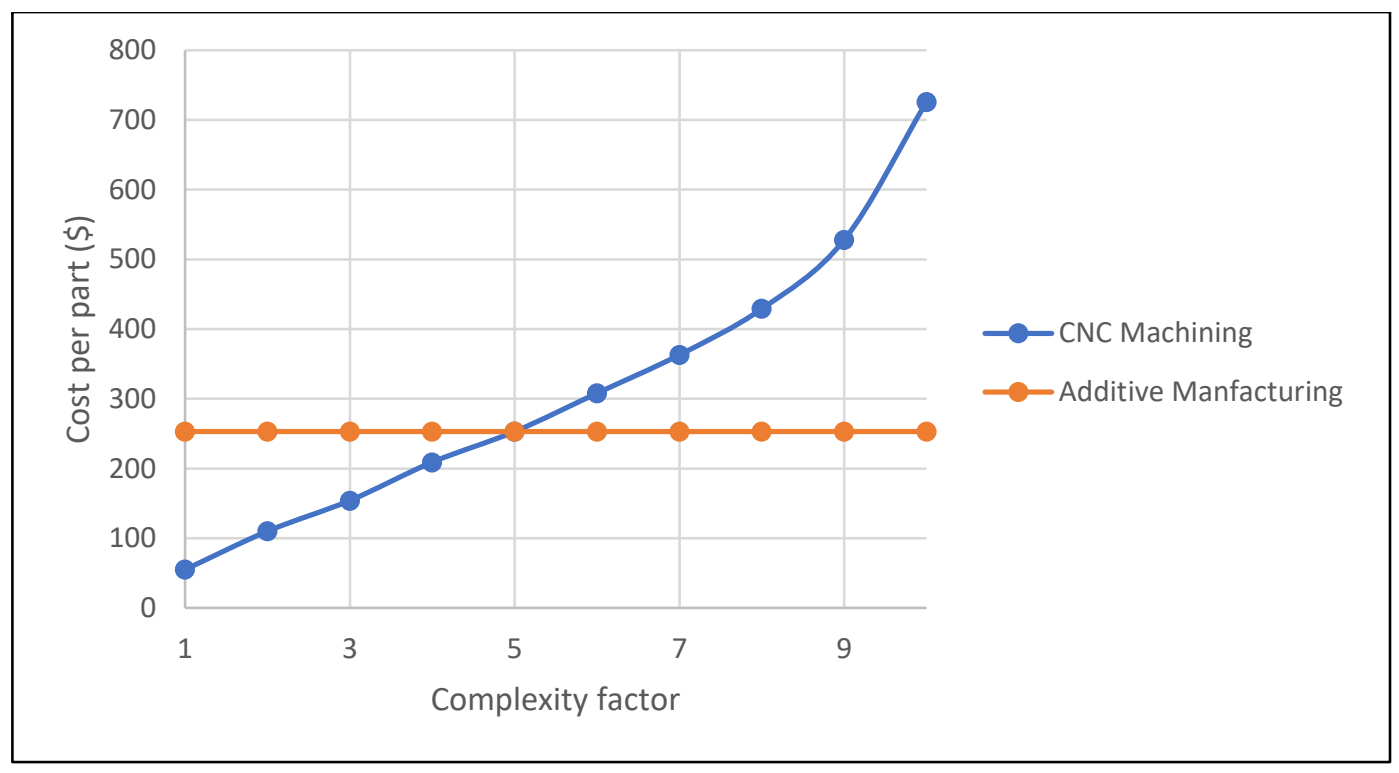

Figure 4.1: Average Breakeven Point for Geometric Complexity Factor [23]

The equally viable product parameters attainable by BJP, DMLS and CNC machining accounting for mechanical properties associated with each material type variation are tabulated below. 
Table 4.3: Product Parameters Equally Feasible for BJP and CNC Machining

\begin{tabular}{|c|c|}
\hline Material Type & $\begin{array}{l}\text { Equally Viable Product Parameters for BJP and } \\
\text { CNC Machining }\end{array}$ \\
\hline Stainless Steel 304L & $\begin{array}{l}\text { Geometric complexity = medium } \\
\text { Surface Quality } \geq 3 \mu \mathrm{m} \\
\text { Hardness } \leq 75 \mathrm{HRB} \\
\text { Strength } \leq 29 \mathrm{ksi} \\
\text { Tolerance } \geq 0.2 \mathrm{~mm}\end{array}$ \\
\hline Stainless Steel 316 & $\begin{array}{l}\text { Geometric complexity }=\text { medium } \\
\text { Surface Quality } \geq 15 \mu \mathrm{m} \\
\text { Hardness } \leq 60 \mathrm{HRB} \\
\text { Strength } \leq 41 \mathrm{ksi} \\
\text { Tolerance } \geq 0.2 \mathrm{~mm}\end{array}$ \\
\hline Stainless Steel 316L & $\begin{array}{l}\text { Geometric complexity = medium } \\
\text { Surface Quality } \geq 3 \mu \mathrm{m} \\
\text { Hardness } \leq 71 \mathrm{HRB} \\
\text { Strength } \leq 33 \mathrm{ksi} \\
\text { Tolerance } \geq 0.2 \mathrm{~mm}\end{array}$ \\
\hline Stainless Steel 420 & $\begin{array}{l}\text { Geometric complexity }=\text { medium } \\
\text { Surface Quality } \geq 15 \mu \mathrm{m} \\
\text { Hardness } \leq 97 \mathrm{HRB} \\
\text { Strength } \leq 66 \mathrm{ksi} \\
\text { Tolerance } \geq 0.2 \mathrm{~mm}\end{array}$ \\
\hline Stainless Steel 17-4 & $\begin{array}{l}\text { Geometric complexity }=\text { medium } \\
\text { Surface Quality } \geq 3 \mu \mathrm{m} \\
\text { Hardness } \leq 100 \mathrm{HRB} \\
\text { Strength } \leq 145 \mathrm{ksi} \\
\text { Tolerance } \geq 0.2 \mathrm{~mm}\end{array}$ \\
\hline
\end{tabular}


Table 4.4: Product Parameters Equally Feasible for DMLS and CNC Machining

\begin{tabular}{|l|l|}
\hline \multicolumn{1}{|c|}{ Material Type } & $\begin{array}{l}\text { Equally Viable Product Parameters for } \\
\text { DMLS and CNC Machining }\end{array}$ \\
\hline Stainless Steel 316L & $\begin{array}{l}\text { Geometric complexity }=\text { medium } \\
\text { Surface Quality } \geq 6 \mu \mathrm{m} \\
\text { Hardness } \leq 75 \mathrm{HRB} \\
\text { Strength } \leq 42 \mathrm{ksi} \\
\text { Tolerance } \geq 0.127 \mathrm{~mm}\end{array}$ \\
\hline Stainless Steel 17-4 & $\begin{array}{l}\text { Geometric complexity }=\text { medium } \\
\text { Surface Quality } \geq 6 \mu \mathrm{m} \\
\text { Hardness } \leq 100 \mathrm{HRB} \\
\text { Strength } \leq 106 \mathrm{ksi} \\
\text { Tolerance } \geq 0.0 .127 \mathrm{~mm}\end{array}$ \\
\hline
\end{tabular}

It is important to note that the feasible material types were selected based on existing machine capabilities and specifications for BJP, DMLS and CNC machining. With most stainless-steel materials, $\mathrm{CNC}$ machining is capable of fabricating components with higher performance (in terms of quality and mechanical properties.) In production setups where either BJP has to be compared to CNC machining, or DMLS to CNC machining, the customer expectations of component quality and mechanical properties are important considerations in selecting the most optimal technology. Therefore, the ranges for surface quality, hardness, strength and tolerance depicted in tables 4.3 and 4.4 describe the maximum possible component performance levels which allow for the impartial comparison of BJP, DMLS and CNC machining. If the required mechanical properties and quality of a component exceed the competency of current additive manufacturing technology, the manufacturing facility should opt for $\mathrm{CNC}$ machining.

It is imperative to select process parameters for BJP, DMLS and CNC machining such that the machines operate at optimal capacity levels to achieve the desired product features and production quantity. Production quantity/time required by the customer should be feasible by both manufacturing technologies in terms of cost per unit part and cycle time. According to the 
information provided by [46], the following relationship between manufacturing technology type, geometric complexity and cost per part was formulated.

Table 4.5: Optimal Production Quantities for BJP, DMLS, CNC Machining Based on Geometric Complexity and Unit Cost

\begin{tabular}{|l|l|l|l|}
\hline \multirow{2}{*}{$\begin{array}{l}\text { Feasible Production Quantity } \\
\text { Accounting for Unit Cost }\end{array}$} & \multicolumn{3}{|c|}{ Geometric Complexity } \\
\cline { 2 - 4 } & \multicolumn{1}{|c|}{ Low } & \multicolumn{1}{|c|}{ Medium } & \multicolumn{1}{|c|}{ High } \\
\hline$<100$ parts & CNC & CNC \\
Machining & $\begin{array}{l}\text { machining, } \\
\text { BJP, DMLS }\end{array}$ & BJP, DMLS \\
\hline$<500$ parts & CNC & $\begin{array}{l}\text { CNC } \\
\text { machining, } \\
\text { MJP }\end{array}$ & BJP \\
\hline
\end{tabular}

As depicted in table 4.5, CNC machining and BJP are comparable when production quantities less than 500 parts (of medium complexity) are required, and CNC machining and DMLS are comparable when the customer requirement is for less than 100 parts (of medium complexity.) In scenarios where production quantity demanded by the customer exceeds the above-mentioned limits, manufacturing technologies such as injection molding should be considered.

In addition to considering production quantities justified by unit cost, it is crucial to verify if the selected process parameters of each technology are capable of achieving the required cycle time. For the purposes of this research, machine capacities have been determined using the machine assignment algorithm described in [47].

$$
T_{c}=\left\{\begin{array}{cc}
(a+t) & m \leq \mathrm{n}^{\prime} \\
m(a+b) & m>n^{\prime}
\end{array}\right.
$$

Where,

$\mathrm{T}_{\mathrm{c}} \quad=$ repeating cycle time 
a = concurrent activity time (loading/unloading a machine)

$\mathrm{b} \quad=$ independent operator activity time (inspecting/packing)

$\mathrm{t}=$ machine activity/process time (machining time/printing time)

n' $\quad=(\mathrm{a}+\mathrm{t}) /(\mathrm{a}+\mathrm{b})=$ ideal number of identical machines to assign an operator

$\mathrm{m} \quad=$ number of identical machines assigned to an operator

For CNC machining, BJP and DMLS to be equally viable on a system level, the cycle times of the processes need to be equal or less than the required cycle time as per the customer demands. Required cycle time $\left(\mathrm{T}_{\mathrm{c}(\text { required })}\right)$ has been calculated as follows:

$$
T_{c(\text { required })}=\frac{t_{\text {required }}}{P}
$$

Where,

$\mathrm{t}_{\text {required }}=$ process time to meet the required lead time (as per customer demand)

$\mathrm{P} \quad=$ production quantity demanded by customer

Process time calculations for each manufacturing method has been adopted from the work of [23] , [35]. However, the CNC machining time calculation has been modified in order to account for the impact of cutting speed, feed rate and depth of cut required by each operation (milling, drilling and turning) on cycle time. For the purposes of this research, machining time has been considered as a suitable indicator of $\mathrm{CNC}$ toolpath for parts with varying geometric features.

$$
t_{C N C(\text { milling })}=\frac{V_{\text {milling }}\left(1+\frac{e^{\alpha}}{100}\right)}{\left(Q_{\text {milling }} * 60\right)}
$$

Where,

$\mathrm{t}_{\mathrm{CNC} \text { (milling) }}=$ time taken for the milling operation (hours)

$\mathrm{V}_{\text {milling }} \quad=$ volume removed by the milling process $\left(\mathrm{mm}^{3}\right)$ 
$\mathrm{Q}_{\text {milling }}=$ material removal rate of the milling process $\left(\mathrm{mm}^{3} / \mathrm{min}\right)$

$\alpha \quad=$ geometric complexity

$$
t_{C N C(\text { drilling })}=\frac{V_{\text {drilling }}}{\left(Q_{\text {drilling }} * 60\right)}
$$

$\mathrm{t}_{\mathrm{CNC}(\mathrm{drilling})}=$ time taken for the drilling operation (hours)

$\mathrm{V}_{\text {drilling }} \quad=$ volume removed by the drilling process $\left(\mathrm{mm}^{3}\right)$

Q drilling = material removal rate of the drilling process $\left(\mathrm{mm}^{3} / \mathrm{min}\right)$

$$
t_{C N C(\text { turning })}=\frac{V_{\text {turning }}}{\left(Q_{\text {turning }} * 60\right)}
$$

$\mathrm{t}_{\mathrm{CNC}(\text { turning) }}=$ time taken for the turning operation (hours)

$\mathrm{V}_{\text {turning }} \quad=$ volume removed by the turning process $\left(\mathrm{mm}^{3}\right)$

Q $\quad=$ materinial removal rate of the turning process $\left(\mathrm{mm}^{3} / \mathrm{min}\right)$

As CNC milling time exponentially increases with complex geometric features, the previously mentioned complexity factor has been incorporated to the machining time calculation for milling processes. Furthermore, cutting speed, feed rate and depth of cut has been integrated into the material removal rate pertaining to each operation. For parts requiring more than one of the abovementioned operations, the machining time for each operation needs to be summed accordingly.

Build time of the BJP process includes the time for printing, curing and sintering. It's important to incorporate the curing and sintering time into the process time of BJP since the as printed parts are highly porous and lack the mechanical properties required by functional components. In order to account for the impact of build orientation on print time of binder jetted parts, the process time calculation considers the height of the component as per the print angle used in the build envelope. As binder jetted parts are transferred to the curing and sintering oven in the same build tray used in the printer (with a crucible setup for sintering), the number of simultaneous builds was deemed to play an important role in the overall process time for a production run consisting of multiple 
parts. Build volume optimization is crucial for BJP as the cycle time can be significantly decreased by appropriately selecting the number of simultaneous builds. For the purposes of this research, the cycle time calculation of binder jetted parts considers the printer, curing oven and sintering oven as one machine.

$$
t_{B J}=\frac{h_{\text {component }} *\left(t_{\text {layer }} / 3600\right)}{h_{\text {layer }}}+\left(t_{\text {curing }} / N\right)+\left(t_{\text {sintering }} / N\right)
$$

Where,

$$
\begin{array}{ll}
\mathrm{t}_{\mathrm{BJP}} & =\text { time for the binder jetting process (hours) } \\
\mathrm{t}_{\text {curing }} & =\text { curing time (hours) } \\
\mathrm{t}_{\text {sintering }} & =\text { sintering time (hours) } \\
\mathrm{h}_{\text {component }} & =\text { height of component as per the build orientation (mm) } \\
\mathrm{h}_{\text {layer }} & =\text { height of print layer (mm) } \\
\mathrm{t}_{\text {layer }} & =\text { time taken to print one layer (secs) } \\
\mathrm{N} & =\text { Number of simultaneous builds }
\end{array}
$$

In determining the build time for Direct Metal Laser Sintering, it was considered imperative to account for the amount of support material used. As illustrated by the work of [23], the amount of support material has been represented as a percentage of the component volume.

$$
t_{D M L S}=\frac{V(1+s)}{(v * 60)}
$$

Where,

tDMLS $\quad=$ process time for direct metal laser sintering (hours)

$\mathrm{V} \quad=$ component volume $\left(\mathrm{mm}^{3}\right)$

$\mathrm{S} \quad=$ support material as a percentage of component volume 


$$
v \quad=\text { build rate of printer }\left(\mathrm{mm}^{3} / \mathrm{min}\right)
$$

\subsubsection{Energy Consumption}

Selecting manufacturing technologies which have a lesser burden on the environment is of utmost importance in the domain of sustainability. Although it is imperative to consider environmental emissions at each individual stage of the manufacturing life cycle, the main focus of this research study has been to evaluate the energy consumption resulting from fabrication and material processing stages of products.

The evaluation of material processing stage energy consumption was adopted from the life cycle energy assessment methodology developed by [48]. As described in section 4.1.1, the material types which are equally viable for CNC machining, Binder Jetting and Direct Metal Laser Sintering as per the currently available machine specifications, are variants of stainless steel. In scenarios where CNC machining and BJP are compared on a sustainability basis, the material types considered are stainless steel 304L, stainless steel 316, stainless steel 316L, stainless steel 420 and stainless steel 17-4. For the cases involving CNC machining and DMLS, under consideration are stainless steel 316L and stainless steel 17-4. The material preparation phases required for CNC machining are the initial mining of raw materials, conversion to primary metal, and the processing required to convert the initial stainless-steel material to workpieces. In the case of BJP and DMLS, following the initial mining and conversion to initial metal material, atomization is required to achieve the required powder metal. The atomization process contributes immensely towards the overall energy consumption of additive manufacturing, and therefore essential to be considered in the energy consumption calculation. The average material embodied energy values (Btu/lb) for stainless steel billets and stainless-steel powder have been ascertained from existing literature [48], [10]. For the purposes of this research, the material embodied values for all variants of stainlesssteel billets have been generalized and assumed to identical, as with stainless-steel variants of metal powder. However, in the determination of total material processing energy for CNC machining, the energy expenditure due to workpiece fabrication needs to be considered. In this study, the primary processing steps required for workpiece fabrication have been restricted to casting, rolling and forging. Since CNC machining results in a substantial amount of material waste, the impact of recycling the metal chips on energy consumption has been incorporated into this research study. As recycled material is combined with virgin material, the embodied energy 
for recycled stainless steel based on the waste recovery percentage of the facility has been folded into the material processing energy of CNC machining. The lessened burden on virgin material production due to waste material recycling is also an important consideration. Due to the fact that BJP and DMLS only utilize the amount of metal powder required by the component being built, material wastage is minimal. In most cases, the unused powder is reused in subsequent builds. The number of reuses for each metal powder may vary depending on the process parameters being used. Therefore, the impact of additive manufacturing waste material on energy consumption has been assumed to be negligible.

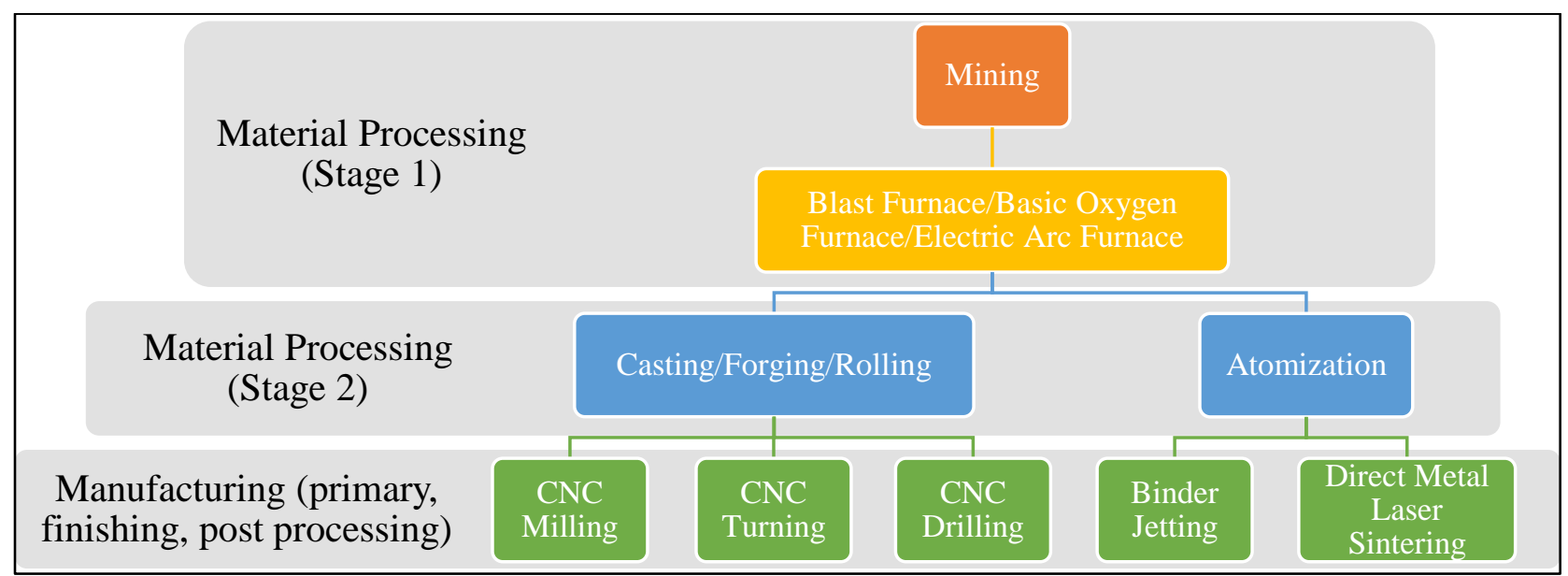

Figure 4.2: Material and Manufacturing Aspects Considered for Evaluation of Energy Consumption The calculation procedures for determining energy consumption of each manufacturing technology are depicted below.

\subsubsection{Material Processing Energy}

$$
\begin{aligned}
E_{\text {material }(\mathrm{CNC})} & =\left(M_{\text {billet }}-M_{\text {waste }} * W\right) * E_{\text {embodied }(\text { billet })}+\left(E_{\text {primary }} * M_{\text {billet }}\right)+\left(E_{\text {recycling }}\right. \\
& \left.* M_{\text {waste }} * W\right)
\end{aligned}
$$

Where,

$\mathrm{E}_{\text {material }(\mathrm{CNC})} \quad=$ material processing energy for $\mathrm{CNC}$ machining $(\mathrm{kWh})$

$E_{\text {embodied(billet) }}=$ material embodied energy for stainless steel $(\mathrm{kWh} / \mathrm{lb})$

M $\quad=$ masilet $\quad=$ of billet used for $\mathrm{CNC}$ machining $(\mathrm{lb})$

$\mathrm{E}_{\text {primary }} \quad=$ embodied energy for workpiece fabrication $(\mathrm{kWh} / \mathrm{lb})$

$\mathrm{E}_{\text {recycling }} \quad=$ embodied energy for recycling the resultant waste $(\mathrm{kWh} / \mathrm{lb})$

$\mathrm{W} \quad=$ percentage waste recovered/recycled at facility 
$* \mathrm{M}_{\text {waste }} \quad=$ mass of the resultant $\mathrm{CNC}$ machining waste (lb)

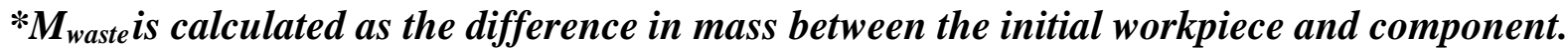

Table 4.6: Material Embodied Energy for Stainless Steel Billet [48]

\begin{tabular}{|c|c|}
\hline $\begin{array}{l}\text { Material Embodied } \\
\text { Energy - Virgin }(\mathbf{k W h} / \mathbf{l b})\end{array}$ & $\begin{array}{l}\text { Material Embodied } \\
\text { Energy }- \text { Recycled }(\mathbf{k W h} / \mathbf{l b})\end{array}$ \\
\hline 10.644 & 1.512 \\
\hline
\end{tabular}

$$
\boldsymbol{E}_{\text {material }(\mathrm{DMLS})}=\boldsymbol{E}_{\text {material }(B J)}=\boldsymbol{M}_{\text {component }} * \boldsymbol{E}_{\text {embodied }(\text { powder })}
$$

Where,

$\mathrm{E}_{\text {material(DMLS) }}=$ material processing energy for DMLS $(\mathrm{kWh} / \mathrm{lb})$

$\mathrm{E}_{\text {material(BJP) }} \quad=$ material processing energy for DMLS $(\mathrm{kWh} / \mathrm{lb})$

$\mathrm{M}_{\mathrm{component}} \quad=$ mass of printed component (lb)

$\mathrm{E}_{\text {embodied(powder) }}=$ material embodied energy for stainless steel $(\mathrm{kWh} / \mathrm{lb})$

Table 4.7: Material Embodied Energy for Stainless Steel Powder [48], [10]

\begin{tabular}{|c|}
\hline $\begin{array}{l}\text { Material Embodied } \\
\text { Energy }- \text { Powder }(\mathbf{k W h} / \mathbf{l b})\end{array}$ \\
\hline 12.22 \\
\hline
\end{tabular}

From the values depicted in tables 4.6 and 4.7 , it is clear that the atomization process has a significant impact on the material processing energy consumption.

\subsubsection{Manufacturing Process Energy}

In determination of manufacturing process related energy consumption, it was considered imperative that minimal empirical data is required. As the proposed expert system is meant to be used by manufacturing/design personnel, the capability of the model to estimate the energy consumption using minimal input data from the user is essential. In order to overcome this challenge, extensive literature reviews were conducted to ascertain an average load factor which can be generalized for each type of BJP, DMLS and CNC machine used for fabrication of metal parts. 
The results of [32] research study on energy and cost estimation of DMLS has been adopted for the estimation of load factor for DMLS machines. According to current data logging experiments by [32], it can be estimated that the EOSINT M270 DMLS machine operates at roughly $43 \%$ load factor during single and combined-build experiments. For the purposes of this research, DMLS load factor has been generalized using the results of [32]. The energy consumption for DMLS has been calculated using the generalized load factor, time for the build [23] and rated power of the machine.

$$
\begin{array}{ll} 
& E_{D M L S}=P_{D M L S} * L F_{D M L S} *\left(\frac{V(1+s)}{(v * 60)}+t_{j o b(D M L S)}\right) \\
\mathrm{E}_{\mathrm{DMLS}} & =\text { energy consumption of DMLS process }(\mathrm{kWh}) \\
\mathrm{P}_{\mathrm{DMLS}} & =\text { rated power of DMLS machine }(\mathrm{kW}) \\
\mathrm{LF} & =\text { load factor, } \% \\
\mathrm{~V} & =\text { component volume }\left(\mathrm{mm}^{3}\right) \\
\mathrm{s} & =\text { support material as a percentage of component volume } \\
v & \left.=\text { build rate of printer ( } \mathrm{mm}^{3} / \mathrm{min}\right) \\
\mathrm{t}_{\mathrm{job}(\mathrm{DMLS})} & =\text { start up time for DMLS machine (hours) }
\end{array}
$$

[49] has stated that, at a constant saturation level, operating the infrared heater power of the BJP printer between 55\% and 65\% yields structures with required dimensional accuracies and appropriate characteristics sufficient for curing. For the purposes of this research, the heater power has been considered to have a direct correlation with the input power of the BJP printer. For the energy consumption calculation of BJP printers, 55\% load factor has been used as a generalized value as operators would tend to utilize the heater power between $55 \%$ and $65 \%$. Additionally, energy consumption of the curing and sintering processes has been considered by the estimation of load factor for each oven based on the temperature profile utilized. As mentioned in section 4.1.1, build volume optimization is a key concept in BJP processes. To conduct a realistic 
simulation, energy consumption for a single build has been calculated based on machine/oven capacities and the number of simultaneous builds.

$$
\begin{gathered}
E_{B J}=\left(P_{B J} * L F_{B J} *\left(t_{B J}+t_{j o b(B J)}\right)\right)+\left(\frac{T_{\text {average }(\text { curing })}}{T_{\text {rated }(\text { curing })}} * P_{\text {rated }(\text { curing })} *\left(t_{\text {curing }} / N\right)\right) \\
+\left(\frac{T_{\text {average }(\text { sintering })}}{T_{\text {rated }(\text { sintering })}} *\left(t_{\text {sintering }} / N\right)\right)
\end{gathered}
$$

Where,

$\mathrm{t}_{\mathrm{BJP}}=$ time for the binder jetting process (hours)

$\mathrm{t}_{\mathrm{job}(\mathrm{BJP})}=$ start up time for BJP machine (hours)

$\mathrm{LF}_{\mathrm{BJP}} \quad=$ load factor for binder jetting printer

$\mathrm{P}_{\mathrm{BJP}} \quad=$ rated power of binder jetting printer $(\mathrm{kW})$

$\mathrm{T}_{\text {average(curing) }}=$ average temperature used in the curing process ${ }^{\circ} \mathrm{F}$

$\mathrm{T}_{\text {rated(curing) }} \quad=$ maximum rated temperature of curing oven ${ }^{\circ} \mathrm{F}$

$\mathrm{P}_{\text {rated(curing) }} \quad=$ rated power of curing oven $(\mathrm{kW})$

$\mathrm{t}_{\text {curing }} \quad=$ curing time (hours)

$\mathrm{T}_{\text {average(sintering) }}=$ average temperature used in the sintering process ${ }^{\circ} \mathrm{F}$

$\mathrm{T}_{\text {rated(sintering) }}=$ maximum rated temperature of sintering oven ${ }^{\circ} \mathrm{F}$

$\mathrm{P}_{\text {rated(sintering) }} \quad=$ rated power of sintering oven $(\mathrm{kW})$

$\mathrm{t}_{\text {sintering }} \quad=$ sintering time (hours)

$\mathrm{N}=$ Number of simultaneous builds

In the case of CNC machining, the load factor for machines has been determined based on Industrial Assessment Center (IAC) experience of energy assessments conducted for metal 
manufacturing facilities. Additionally, it is important to note that a major portion of energy consumption related to $\mathrm{CNC}$ machines arises from fixed utilization rates of subsystems such as the computer, lights and fans [13]. According to data obtained from numerous manufacturing facilities, the average load factor for metal CNC machining has been generalized to be roughly $80 \%$.

$$
\begin{aligned}
& E_{C N C(\text { milling })}=P_{C N C} * L F_{C N C} *\left(t_{C N C(\text { milling })}+t_{j o b(C N C)}\right) \\
& E_{C N C \text { (turning })}=P_{C N C} * L F_{C N C} *\left(t_{C N C \text { (turning })}+t_{j o b(C N C)}\right) \\
& E_{C N C \text { (turning })}=P_{C N C} * L F_{C N C} *\left(t_{C N C(\text { turning })}+t_{j o b(C N C)}\right)
\end{aligned}
$$

Where,

$$
\begin{array}{ll}
\mathrm{E}_{\mathrm{CNC}(\text { milling) }} & =\text { energy consumption of the CNC milling process }(\mathrm{kWh}) \\
\mathrm{E}_{\mathrm{CNC} \text { (turning) }} & =\text { energy consumption of the } \mathrm{CNC} \text { turning process }(\mathrm{kWh}) \\
\mathrm{E}_{\mathrm{CNC} \text { (drilling) }} & =\text { energy consumption of the } \mathrm{CNC} \text { drilling process }(\mathrm{kWh}) \\
\mathrm{P}_{\mathrm{CNC}} & =\text { rated power of the CNC machine }(\mathrm{kW}) \\
\mathrm{LF}_{\mathrm{CNC}} & =\text { load factor of CNC machine } \% \\
\mathrm{t}_{\mathrm{CNC}(\text { milling) }} & =\text { machining time for the CNC milling process (hours) } \\
\mathrm{t}_{\mathrm{CNC}(\text { turning) }} & =\text { machining time for the CNC turning process (hours) } \\
\mathrm{t}_{\mathrm{CNC}(\text { drilling) }} & =\text { machining time for the CNC drilling process (hours) } \\
\mathrm{t}_{\mathrm{job}(\mathrm{CNC})} & =\text { start up time for CNC machine (hours) }
\end{array}
$$

It is important to note that, energy consumption values need to be appropriately summed based on machining operations required by the component. In such cases, startup time for the CNC machine needs to be considered only once.

During the analysis of energy consumption during the manufacturing processes, secondary finishing processes such as finish machining and painting have been considered. The calculation procedure for secondary processing energy $\left(\mathrm{E}_{\text {secondary }}\right)$ has been adopted from [48].

$$
\begin{gathered}
E_{D M L S(\text { painting })}=E_{B J(\text { painting })}=E_{C N C(\text { painting })}=\left(M_{\text {initial }}\right) * E_{(\text {painting })} \\
E_{D M L S(\text { finishmachining })}=E_{B J(\text { finishmachining })}=\left(M_{\text {initial }}-M_{\text {final }}\right) * E_{(\text {finishmachining })}
\end{gathered}
$$




$$
* E_{C N C(\text { finishmachining })}=\left(0.1 * \frac{M_{\text {billet }}-M_{\text {component }}}{M_{\text {billet }}}\right) * E_{(\text {finishmachining })}
$$

*Assumption: finish machining process for CNC machining removes $10 \%$ of initial mass difference.

Where,

EMLS(painting)

$\mathrm{E}_{\mathrm{BJP} \text { (painting) }}$

$\mathrm{E}_{\mathrm{CNC}(\text { painting) }}$

$M_{\text {initial }}$

$\mathrm{M}_{\text {final }}$

M billet

$\mathbf{M}_{\text {component }}$

$\mathrm{E}_{\text {(painting) }}$

$\mathrm{E}_{\text {(finishmachining) }}$

EDMLS(finishmachining)

EBJP(finishmachining)

ECNC(finishmachining)
$=$ Energy consumption of painting process for DMLS $(\mathrm{kWh})$

$=$ Energy consumption of painting process for $\mathrm{BJP}(\mathrm{kWh})$

$=$ Energy consumption of painting process for $\mathrm{CNC}(\mathrm{kWh})$

$=$ Mass of initially printed component for DMLS/BJP (lb)

= Mass of component after secondary processing DMLS/BJP (lb)

$=$ Mass of billet used in CNC machining (lb)

$=$ Mass of component for CNC machining (lb)

$=$ Embodied energy value for painting $(\mathrm{kWh} / \mathrm{lb})$

$=$ Embodied energy value for finish machining $(\mathrm{kWh} / \mathrm{lb})$

$=$ Energy consumption of finish machining for DMLS $(\mathrm{kWh})$

$=$ Energy consumption of finish machining for BJP $(\mathrm{kWh})$

$=$ Energy consumption of finish machining for $\mathrm{CNC}(\mathrm{kWh})$

Table 4.8: Embodied Energy of Secondary Processing Steps [48]

\begin{tabular}{|c|c|}
\hline Finish Machining (kWh/lb) & Painting (kWh/lb) \\
\hline 1.01 & 6.93 \\
\hline
\end{tabular}

In addition to secondary processing, the energy consumption of post processing (heat treatment) steps have been considered in this research. The scenarios in which heat treatment options are viable needed to be evaluated prior to energy consumption calculations. It is important to 
understand that the type of heat treatment required varies depending on the material type and utilized manufacturing methodology. In the case of CNC machining heat treatment can be applied either before or after the process. However, heat treatment prior to CNC machining consists of high variability in the utilized processes and their inherent process parameters. Since this information can be rather ambiguous to most facility personnel, the impact of prior heat treatment on energy consumption has not been considered. Post CNC machining heat treatments are applied to enhance the mechanical properties (such as hardness, strength) of the material as required by its end use. Due to the application of heat, the microstructure and chemical composition of the material changes, resulting in a toughened component. Usually, parts are heated to a high temperature and allowed to cool down naturally until the desired microstructure is obtained. Heat treatment for additive manufacturing is only done following the printing process. Components of certain material types fabricated using DMLS require heat treatment to relieve thermal stresses prompted by the printing process. In these cases, lack of heat treatment may result in warped components. Porosity is considered characteristic to binder jetted components even after undergoing curing, sintering and infiltration. Therefore, appropriate heat treatment procedures are necessary to attain the required material density. The heat treatment processes viable/appropriate for components of each material type manufactured using CNC machining, BJP and DMLS are tabulated below.

Table 4.9: Heat Treatment Processes Viable for CNC, BJP and DMLS Based on Material Type [50], [41], [42], [40]

\begin{tabular}{|l|l|l|l|}
\hline Material Type & CNC Machining & Binder Jetting & Direct Metal Laser Sintering \\
\hline Stainless Steel 304L & Annealing & Hot isostatic pressing & - \\
\hline Stainless Steel 316 & Annealing & Hot isostatic pressing & - \\
\hline Stainless Steel 316L & Annealing & Hot isostatic pressing & Not necessary \\
\hline Stainless Steel 420 & Annealing & Hot isostatic pressing & - \\
\hline Stainless Steel 17-4 & Not suitable & Hot isostatic pressing & $\begin{array}{l}\text { Annealing in argon, hot } \\
\text { isostatic pressing }\end{array}$ \\
\hline
\end{tabular}


For the purposes of this research, it was deemed unnecessary to thermodynamically model the heat treatment equipment. Instead, energy consumption of heat treatment processes has been calculated by using rated power of the ovens, time of heat treatment processes and a load factor based on the temperature profile. Due to insulation and temperature feedback sensors of the heat treatment furnaces, the sensors would not operate constantly at maximum loads levels. Therefore, a linear relationship has been assumed for power and ratio of zone temperature to rated oven temperature. It is important to note that the hydroelectric intensifier has not been considered in the energy calculation of hot isostatic pressing. Furthermore, it has been assumed that all heat treatment equipment is electric. Therefore, energy consumption of hot isostatic pressing and annealing can be calculated as follows.

$$
E_{\text {postprocessing }}=P_{\text {postprocessing }} * \frac{T_{\text {zone }(\mathrm{avg})}}{T_{\text {rated }}} * t_{\text {postprocessing }}
$$

Where,

$\mathrm{E}_{\text {postprocessing }}=$ energy consumption of heat treatment process $(\mathrm{kWh})$

$\mathrm{P}_{\text {postprocessing }}=$ rated power of the heat treatment equipment $(\mathrm{kW})$

$\mathrm{T}_{\text {zone(avg) }}=$ average zone temperature used in the heat treatment equipment $\left({ }^{\circ} \mathrm{F}\right)$

$\mathrm{T}_{\text {rated }}=$ maximum rated temperature of the heat treatment equipment $\left({ }^{\circ} \mathrm{F}\right)$

$\mathrm{t}_{\text {postprocessing }}=$ time taken for the heat treatment process (hours)

The total energy consumption for CNC machining, Binder Jetting and Direct Metal Laser Sintering can be summarized as:

$$
\begin{gathered}
E_{\text {total }(C N C)}=E_{C N C}+E_{\text {secondary }(C N C)}+E_{\text {postprocessing }(C N C)} \\
E_{\text {total }(B J)}=E_{B J}+E_{\text {secondary }(B J)}+E_{\text {postprocessing }(B J)} \\
E_{\text {total }(D M L S)}=E_{D M L S}+E_{\text {secondary }(D M L S)}+E_{\text {postprocessing }(D M L S)}
\end{gathered}
$$




\subsubsection{Economic Impact}

The economic aspects surrounding the manufacturing processes of additive manufacturing and CNC machining are of paramount importance in the evaluation of sustainability. In selecting the most sustainable approach to manufacturing a product, cost effectiveness of the build dictates the decision-making process for most manufacturers. However, it is vital to consider all resources expended during the manufacturing process to conduct a comprehensive cost evaluation of the technologies. In this research study, the economics pertaining to each manufacturing technique comprise of equipment cost, material cost, labor cost and cost due to energy consumption of the processes.

For the purposes of this research study, it was considered important to include depreciation of equipment, installation and maintenance costs, and tax rate for equipment in determining the overall hourly cost rate for each machine. In order to account for the reduction in taxable income, the Modified Accelerated Cost Recovery System (MACRS) [51] depreciation system has been adopted in calculating the equipment cost. The overall costs associated with each manufacturing method have been calculated as described below.

Operator involvement for a build entails concurrent activity time, independent activity time and programming time required for the machine. Programming time for $\mathrm{CNC}$ and additive manufacturing has been estimated as a function of product geometric complexity [23]. Therefore, total operator cost for CNC machining, BJP and DMLS can be calculated as follows.

$$
\begin{gathered}
L_{C N C}=(a+b+(20 * \alpha)) * L_{\text {cost }} \\
L_{B J}=(a+b+(10 * \alpha)) * L_{\text {cost }} \\
L_{D M L S}=(a+b+(10 * \alpha)) * L_{\text {cost }}
\end{gathered}
$$

Where,

a $\quad=$ concurrent activity time

$\mathrm{b} \quad=$ independent operator activity time

$\alpha \quad=$ geometric complexity factor 
$\mathrm{L}_{\mathrm{cost}} \quad=$ hourly labor cost at facility $(\$ /$ hour $)$

$\mathrm{L}_{\mathrm{CNC}}=$ total labor cost for $\mathrm{CNC}$ machining $(\$)$

$\mathrm{L}_{\mathrm{BJP}} \quad=$ total labor cost for $\mathrm{BJP}(\$)$

$\mathrm{L}_{\mathrm{DMLS}}=$ total labor cost for DMLS $(\$)$

Material costs have been calculated as,

$$
\begin{gathered}
M_{B J}=M_{D M L S}=M_{\text {component }} * M_{\text {cost }(\text { powder })} \\
M_{C N C}=M_{\text {billet }} * M_{\text {cost }(\text { billet })}
\end{gathered}
$$

Where,

$\mathrm{M}_{\mathrm{BJP}} \quad=$ total material cost incurred during the BJP build (\$)

M $\quad=$ total material cost incurred during the DMLS build (\$)

M $\quad=$ total material cost incurred during the $\mathrm{CNC}$ machining build (\$)

$\mathrm{M}_{\text {component }} \quad=$ mass of BJP/DMLS component (lb)

$\mathrm{M}_{\mathrm{billet}} \quad=$ mass of billet used in CNC machining process (lb)

$\mathrm{M}_{\text {cost(powder) }} \quad=$ cost of metal powder $(\$ / \mathrm{lb})$

$\mathrm{M}_{\text {cost(billet) }} \quad=$ cost of metal billet $(\$ / \mathrm{lb})$

Electricity costs for the manufacturing processes have been quantified in the following manner:

$$
\begin{gathered}
E_{\operatorname{cost}(B J)}=E_{\text {total }(B J)} * E_{\text {cost }} \\
E_{\operatorname{cost}(D M L S)}=E_{\text {total }(D M L S)} * E_{\text {cost }} \\
E_{\text {cost }(C N C)}=E_{\text {total }(C N C)} * E_{\text {cost }}
\end{gathered}
$$

Where, 
$\mathrm{E}_{\mathrm{cost}(\mathrm{BJP})}=$ electricity cost incurred for the BJP process $(\$)$

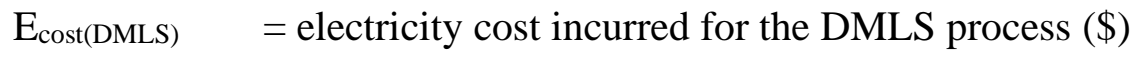

$\mathrm{E}_{\mathrm{cost}(\mathrm{CNC})}=$ electricity cost incurred for the $\mathrm{CNC}$ machining process $(\$)$

$\mathrm{E}_{\text {total(BJP) }} \quad=$ total energy consumption of BJP $(\mathrm{kWh})$

$\mathrm{E}_{\text {total(DMLS) }} \quad=$ total energy consumption of DMLS $(\mathrm{kWh})$

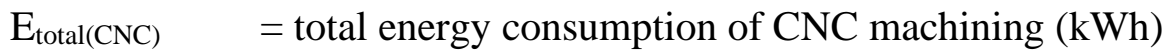

$\mathrm{E}_{\mathrm{cost}} \quad=$ blended electricity cost at the facility $(\$ / \mathrm{kWh})$

In order to calculate the equipment cost accounting for reduction in taxable income, a 10 year class life has been assumed for CNC machining, BJP and DMLS equipment. It has been assumed that the manufacturing facilities have significant taxable incomes which exceed the depreciation amount of equipment. The equipment costs pertaining to each manufacturing method have been calculated as hourly rates, and multiplied by the process times to estimate the machine cost incurred per build.

$$
\begin{aligned}
C_{\text {cost }}=(( & \left(C_{\text {capital }}+C_{\text {capital }} * C_{\text {installation }}\right)+\left(C_{\text {capital }} * C_{\text {maintenance }}\left(1+C_{\text {increase }}\right)^{10}\right) \\
& -\left(C_{\text {capital }}(0.1 * R+0.18 R+0.144 \mathrm{R}+0.1152 \mathrm{R}+0.0922 \mathrm{R}+0.0737 \mathrm{R}\right. \\
& +0.0655 \mathrm{R}+0.0655 \mathrm{R}+0.0656 \mathrm{R}+0.0655 \mathrm{R}+0.0328 \mathrm{R}))) / 10) /(8760 * \mathrm{UF})
\end{aligned}
$$

Where,

$$
\begin{array}{ll}
\mathrm{C}_{\text {cost }} & =\text { hourly cost of machine }(\$ / \text { hour }) \\
\mathrm{C}_{\text {capital }} & =\text { capital cost of equipment }(\$) \\
\mathrm{C}_{\text {installation }} & =\text { installation cost as a percentage of capital cost } \\
\mathrm{C}_{\text {maintenance }} & =\text { maintenance cost as a percentage of capital cost } \\
\mathrm{C}_{\text {increase }} & =\text { percentage annual increase in maintenance cost }
\end{array}
$$


$\mathrm{R} \quad=$ tax rate for manufacturing equipment

UF = utilization factor of equipment on an annual basis

To calculate the machine cost incurred per build, the following equations have been used.

$$
\begin{gathered}
C_{C N C}=C_{\operatorname{cost}(C N C)} * t_{C N C} \\
C_{B J}=C_{\operatorname{cost}(B J)} * t_{B J} \\
C_{D M L S}=C_{\operatorname{cost}(D M L S)} * t_{D M L S}
\end{gathered}
$$

Where,

$\mathrm{C}_{\mathrm{CNC}}=$ total $\mathrm{CNC}$ machine cost for the build $(\$)$

$\mathrm{C}_{\mathrm{BJP}} \quad=$ total DMLS machine cost for the build $(\$)$

$\mathrm{C}_{\mathrm{DMLS}} \quad=$ total BJP machine cost for the build $(\$)$

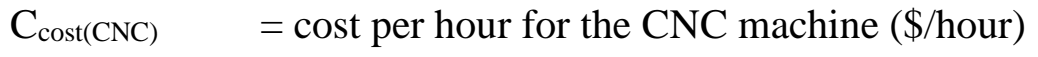

$\mathrm{C}_{\operatorname{cost}(\mathrm{BJP})}=$ cost per hour for the BJP machine $(\$ /$ hour $)$

$\mathrm{C}_{\text {cost(DMLS) }}=$ cost per hour for the DMLS machine $(\$ /$ hour $)$

$\mathrm{t}_{\mathrm{CNC}} \quad=$ process time for $\mathrm{CNC}$ machining (hour)

$\mathrm{t}_{\mathrm{BJP}} \quad=$ process time for BJP $($ hour $)$

$\mathrm{t}_{\mathrm{DMLS}} \quad=$ process time for DMLS (hour)

In the machine cost calculation for BJP, the capital costs of the curing and sintering ovens have also been integrated into the above formulas. The total economic impact of the manufacturing processes (CNC machining, BJP, DMLS) have been estimated by combining material, labor, electricity and machine costs pertaining to the fabricated component. 


\subsubsection{Impact of Auxiliary Material on Sustainability}

Consumption of auxiliary material is a key differentiator between additive manufacturing and CNC machining. The evaluation of sustainability impact caused due to processing, recycling and usage of auxiliary materials would aid decision makers in selection of the most optimal technology for manufacturing processes.

Intuitively, $\mathrm{CNC}$ machining consumes a larger proportion of auxiliary material due to the nature of its process. The auxiliary systems with the highest sustainability impact in $\mathrm{CNC}$ machining have been considered as cutting tools and cutting fluid. Although, compressed air is used in blowing off the resultant metal chips, it has been considered to have a negligible impact on sustainability due to the low flow rates used in processes.

In this research, the considered cutting tool types for machining stainless steel are carbide and ceramic, due to their significant usage in industry. Interest in ceramic tools has increased over the recent past due to its high resistance to heat/wear and tear. By the selection of appropriate coatings, cutting speed can be reduced by substantial amounts when compared to carbide tools [52]. In a generalized sense, all ceramic tools increase the machinability of materials by increasing the temperature of the cutting area such that plasticization occurs [53]. It is important to note that ceramic cutting tools have a much higher resource efficiency than carbide tools during high-speed machining of hard materials in dry conditions [52]. According to [53], dry machining is recommended for milling operations with ceramic materials. Due to the avoidance in cutting fluid, dry machining would result in a lessened burden on the environment, and impact on worker safety due to decreased exposure to harmful chemicals. However, turning processes would require the use of cutting fluid. In cases where dry machining is not viable, minimum lubrication is utilized by the use of ceramic tools. With appropriate whisker reinforced ceramics, machinability of stainless steel can be increased drastically in comparison to carbide [53]. However, ceramic tools require precious resources, and higher energy expenditure during production and recycling due to added processing steps such as sintering and other heat treatment methodologies [52]. In the case of carbide tools, upon reaching tool life, roughly 40 percent of the recycled material is used for the production of new cutting tools, and the remainder is used for mining tools. Usage of chemical recycling processes allows almost $100 \%$ of disposed carbide cutting tools to be reused for the production of new tools. Therefore, carbide tools go through either open loop or closed loop 
recycling during their end of life phase. It has been proven that cutting tools manufactured using recycled tool material results in $75 \%$ less energy consumption than that of virgin material-based production [54].

Based on the CNC machining process parameters required for cutting stainless steel material, light to medium duty oils, emulsifiable oils, and light to heavy duty synthetic oils may be utilized. Since the compositions of these cutting fluids can be highly variant, the types have been generalized as cutting oils and water miscible fluids for the purposes of this research. Oil-based cutting fluids were predominantly used for machining till the recent past. However, due to concerns regarding worker safety, occupational hazards and challenges/expenditures in treatment procedures, water miscible fluids have become more popular in manufacturing processes. Water miscible cutting fluids can be recirculated for numerous times, reducing the need for disposal and recycling, when compared to cutting oils [55]. According to the Metal Products and Machinery rule enacted by the EPA in 2003, oily water discharges arising from cutting fluid have been limited. Due to these regulations, the processing required for discharging cutting oil is significant compared to water miscible fluids [55]. It is important to note that the biological oxygen demand of water miscible fluids require special wastewater treatment operations and therefore can be energy intensive in certain scenarios.

During Binder Jetting processes, the auxiliary material usage composes of binder fluid and cleaning fluid. In this research, only the sustainability impact of binder fluid has been considered. Binder fluid materials suited for stainless steel are either solvent based (with low viscosity) or water based. Since all binder material is consumed during the print process, there is no requirement for recycling or disposal. It is important to note that the sustainability impact of bronze (used for infiltration), compressed air and crucible setups have been considered to be negligible. The auxiliary material consumption of DMLS is only due to inert gas utilization and compressed air. Since compressed air is used at low flow rates, its impact on sustainability has been neglected. Most DMLS systems utilize argon or nitrogen for the creation of an inert environment so that oxidization is minimized during the sintering process. In more sophisticated systems, a nitrogen generator equipped within the DMLS system is used to create the required inert gas atmosphere. Since these generators extract nitrogen from air, the sustainability impact has been considered to be minimal. No unfavorable effects on the environment are expected due to the use of argon. It is 
important to note that sustainability impact due to flow rates of the auxiliary materials used in BJP and DMLS have not been taken into consideration as they are highly variable among machines and processes.

\subsection{Application of Analytical Hierarchy Process to Knowledge Base}

The primary objective of the second expert system is to provide users with advice pertaining to the sustainability indicators of each technology. As described in section 3.4, Analytical Hierarchy Process (AHP) has been used to develop a rating system for the evaluation of auxiliary material usage. It was imperative to utilize the AHP algorithm in a manner which enables easy integration into the logical rules of the expert system. In order to accomplish this task, AHP was used to assign priority vectors to each criterion and alternative based on the possible impact on sustainability due to the considered manufacturing processes. The knowledge base described in section 4.1.4 has been used in conjunction with the scale of relative importance (table 3.3) [43] to designate ratings for each technology as per their auxiliary material consumption.

The first step in the application of AHP to the knowledgebase was to create the pairwise comparison/judgement matrix for the sustainability indicators. Weights calculated for the sustainability indicators depict the relative importance of each towards accomplishing manufacturing sustainability. According to Industrial Assessment Center (IAC) experience and interactions with manufacturing facilities, relative scores were assigned for cost, energy and auxiliary material consumption. The following priority weights for the sustainability criteria were obtained by normalizing the principal eigen vectors as described in section 3.4.

Table 4.10: Judgement Matrix for Criteria

\begin{tabular}{ccccc}
\hline Criteria & Cost & Energy & Auxiliary Material & Priority Vector \\
\hline Cost & 1 & 5 & 7 & 0.6758 \\
Energy & $1 / 5$ & 1 & 7 & 0.2595 \\
Auxiliary Material & $1 / 7$ & $1 / 7$ & 1 & 0.0647 \\
\hline Sum & 1.34 & 6.14 & 15 & 1.00 \\
\hline
\end{tabular}

As depicted in table 4.10, cost effectiveness of a process plays a significant role in its sustainability within manufacturing systems. Although other factors such as energy and material efficiency are important, manufacturing facilities would tend to prioritize on overall cost of processes and 
profitability. Intuitively, the costs of energy and material are folded into the overall cost of a build. With the increased focus on energy efficiency practices and implementation of ISO 50001 within manufacturing facilities, the score for energy has been assigned higher than auxiliary material in the judgement matrix. According to the methodology utilized in this research, the calculation of judgement matrix weights for sustainability indicators is only required in the initial phase of the algorithm. Upon calculation of these weights/priority vectors, the values are a directly incorporated into the logic block rules of the expert system.

Next step of the AHP is the evaluation of manufacturing processes (BJP/CNC Machining, DMLS/CNC Machining) considering auxiliary material usage. It is important to note that, tangible data arising from experiments, literature, monetary information, calculations and other measurements pertaining to each criterion have been used to score the possible alternatives, as adopted from [56]. This approach eliminates the need for consistency index evaluation as required by the Analytical Hierarchy Process. During the evaluation of each manufacturing process in regard to the auxiliary material criteria, it was imperative to accurately allocate relative rankings based on the subjective knowledge described in 4.1.4. The judgement-based rankings have been assigned considering the associated environmental impact and hazards to worker safety during production, use, disposal and recycling each auxiliary system.

As evident from the information in 4.1.4, CNC machining has a higher sustainability impact due to its significant usage of auxiliary materials over BJP and DMLS. The values from the scale of importance have been varied to accommodate for the impact on sustainability due to the use of various manufacturing process parameters. Weights of the judgement-based matrices are predominantly based on the type of cutting fluid and cutting tool utilized in the CNC process. Additionally, regrinding/reusing of cutting tools has been considered to have a favorable impact on sustainability. For simplicity, a range of manufacturing scenarios in which process parameters may vary in terms of auxiliary systems have been considered for the allocation of weights. As per the information in 4.1.4, it is clear that DMLS is the most sustainable technology in terms of auxiliary material usage. Therefore, the scores have been assigned in a manner which reflects better performance. The following priority weights have been calculated by the normalization of eigen vectors. 
Scenario 1: Ceramic tools used with minimal coolant fluid or dry machining. Tools are reground upon breaking or reaching tool life.

Table 4.11: Comparison Matrix for BJP, CNC in terms of Auxiliary Material (Scenario 1)

\begin{tabular}{cccc}
\hline Auxiliary Material & Binder Jetting & CNC Machining & Priority Vector \\
\hline Binder Jetting & 1 & 3 & 0.75 \\
CNC Machining & $1 / 3$ & 1 & 0.25 \\
\hline Sum & 1.33 & 4 & 1.00 \\
\hline
\end{tabular}

Table 4.12: Comparison Matrix for DMLS, CNC in terms of Auxiliary Material (Scenario 1)

\begin{tabular}{cccc}
\hline Auxiliary Material & Direct Metal Laser Sintering & CNC Machining & Priority Vector \\
\hline Direct Metal Laser Sintering & 1 & 4 & 0.8 \\
CNC Machining & $1 / 4$ & 1 & 0.2 \\
\hline Sum & 1.25 & 5 & 1.00 \\
\hline
\end{tabular}

Scenario 2: Ceramic tools used with minimal coolant fluid or dry machining. Tools are not reground upon breaking or reaching tool life.

Scenario 3: Carbide tools used with water miscible fluids. Tools are reground upon breaking or reaching tool life.

Table 4.13: Comparison Matrix for BJP, CNC in terms of Auxiliary Material (Scenario 2,3)

\begin{tabular}{cccc}
\hline Auxiliary Material & Binder Jetting & CNC Machining & Priority Vector \\
\hline Binder Jetting & 1 & 4 & 0.8 \\
CNC Machining & $1 / 4$ & 1 & 0.2 \\
\hline Sum & 1.25 & 5 & 1.00 \\
\hline
\end{tabular}

Table 4.14: Comparison Matrix for DMLS, CNC in terms of Auxiliary Material (Scenario 2,3)

\begin{tabular}{cccc}
\hline Auxiliary Material & Direct Metal Laser Sintering & CNC Machining & Priority Vector \\
\hline Direct Metal Laser Sintering & 1 & 5 & 0.83 \\
CNC Machining & $1 / 5$ & 1 & 0.17 \\
\hline Sum & 1.2 & 6 & 1.00 \\
\hline
\end{tabular}

Scenario 4: Carbide tools used with water miscible fluids. Tools are not reground upon breaking or reaching tool life. 
Scenario 5: Carbide tools used with cutting oil. Tools are reground upon breaking or reaching tool life.

Table 4.15: Comparison Matrix for BJP, CNC in terms of Auxiliary Material (Scenario 4,5)

\begin{tabular}{cccc}
\hline Auxiliary Material & Binder Jetting & CNC Machining & Priority Vector \\
\hline Binder Jetting & 1 & 5 & 0.83 \\
CNC Machining & $1 / 5$ & 1 & 0.17 \\
\hline Sum & 1.2 & 6 & 1.00 \\
\hline
\end{tabular}

Table 4.16: Comparison Matrix for DMLS, CNC in terms of Auxiliary Material (Scenario 4,5)

\begin{tabular}{cccc}
\hline Auxiliary Material & Direct Metal Laser Sintering & CNC Machining & Priority Vector \\
\hline Direct Metal Laser Sintering & 1 & 6 & 0.86 \\
CNC Machining & $1 / 6$ & 1 & 0.14 \\
\hline Sum & 1.17 & 7 & 1.00 \\
\hline
\end{tabular}

Scenario 6: Carbide tools are used with cutting oil. Tools are not reground upon breaking or reaching tool life.

Table 4.17: Comparison Matrix for BJP, CNC in terms of Auxiliary Material (Scenario 6)

\begin{tabular}{cccc}
\hline Auxiliary Material & Binder Jetting & CNC Machining & Priority Vector \\
\hline Binder Jetting & 1 & 6 & 0.86 \\
CNC Machining & $1 / 6$ & 1 & 0.14 \\
\hline Sum & 1.17 & 7 & 1.00 \\
\hline
\end{tabular}

Table 4.18: Comparison Matrix for DMLS, CNC in terms of Auxiliary Material (Scenario 6)

\begin{tabular}{cccc}
\hline Auxiliary Material & Direct Metal Laser Sintering & CNC Machining & Priority Vector \\
\hline Direct Metal Laser Sintering & 1 & 7 & 0.875 \\
CNC Machining & $1 / 7$ & 1 & 0.125 \\
\hline Sum & 1.14 & 8 & 1.00 \\
\hline
\end{tabular}

The auxiliary material weights for each manufacturing technology have been computed based on the methodology described in section 3.4. However, for the purposes of this research, the ratings have been modified to be represented on a scale ranging from 1 to 5 . 


\subsection{Design of Expert Systems}

Expert Systems are particularly beneficial due to their ability of incorporating fuzziness arising from multiple sources of human expertise into automated computer programs based on confidence levels. Since MSUSTAIN1 and MSUSTAIN2 both consist of discrete and deterministic data, or in other words, crisp information, 100\% confidence levels have been assumed for all rules in the systems. The design aspects pertaining to variables, logic blocks and command blocks of the developed expert systems are described in the following sections. Furthermore, the logical rules pertaining to each system have been detailed in Appendix C and Appendix D.

\subsubsection{MSUSTAIN1 Expert System}

The main purpose of MSUSTAIN1 is to analyze if the considered manufacturing techniques are feasible for fabricating a user defined metal component based on product, process and system parameters. The developed system achieves this goal by evaluating user input according to logical rules built using the knowledgebase described in 4.1.1. The system consists of 253 nodes, and includes static lists, numeric values and confidences. The system has been built in a manner which derives confidence variables (with appropriately assigned prompts) such that the user is advised in situations where the product, process or system parameters are not viable for both technologies under consideration. In addition, the provided advice contains feasibility regions which would facilitate an impartial comparison of the sustainability indicators. User input data comprise of information which are specific to the manufacturing facilities or would originate from the associated CAD models. As per the design of the system, the user can opt to evaluate either Binder Jetting and CNC Machining, or Direct Metal Laser Sintering and CNC Machining for the specific component being manufactured. The system first determines if the user defined component satisfies the product parameters equally viable for the two manufacturing technologies under consideration. If the product parameters are satisfied, the system then proceeds to evaluate the capability of each technology in achieving the system level requirements based on utilized process parameters. For CNC machining time, the user has been given the option to enter specific cutting speeds, feeds and depths for each operation, or input the time as simulated by CAD software. If all product, process and system criteria for both technologies are met, the system informs the user, and advises to proceed to MSUSTAIN2. 
For simplicity of developing logical rules, four separate logic blocks were designed. These were thought of as 3 sub-blocks which carry out the necessary calculations (for geometric complexity factor, CNC machining time, and cycle time based on 4.1.1) and feed the information to a main block which evaluates the product, process and system parameters. Backward chaining has been used in the command block to derive confidence variables containing appropriate advice. The decision to use backward chaining was taken due to its efficient method of firing only the required rules.

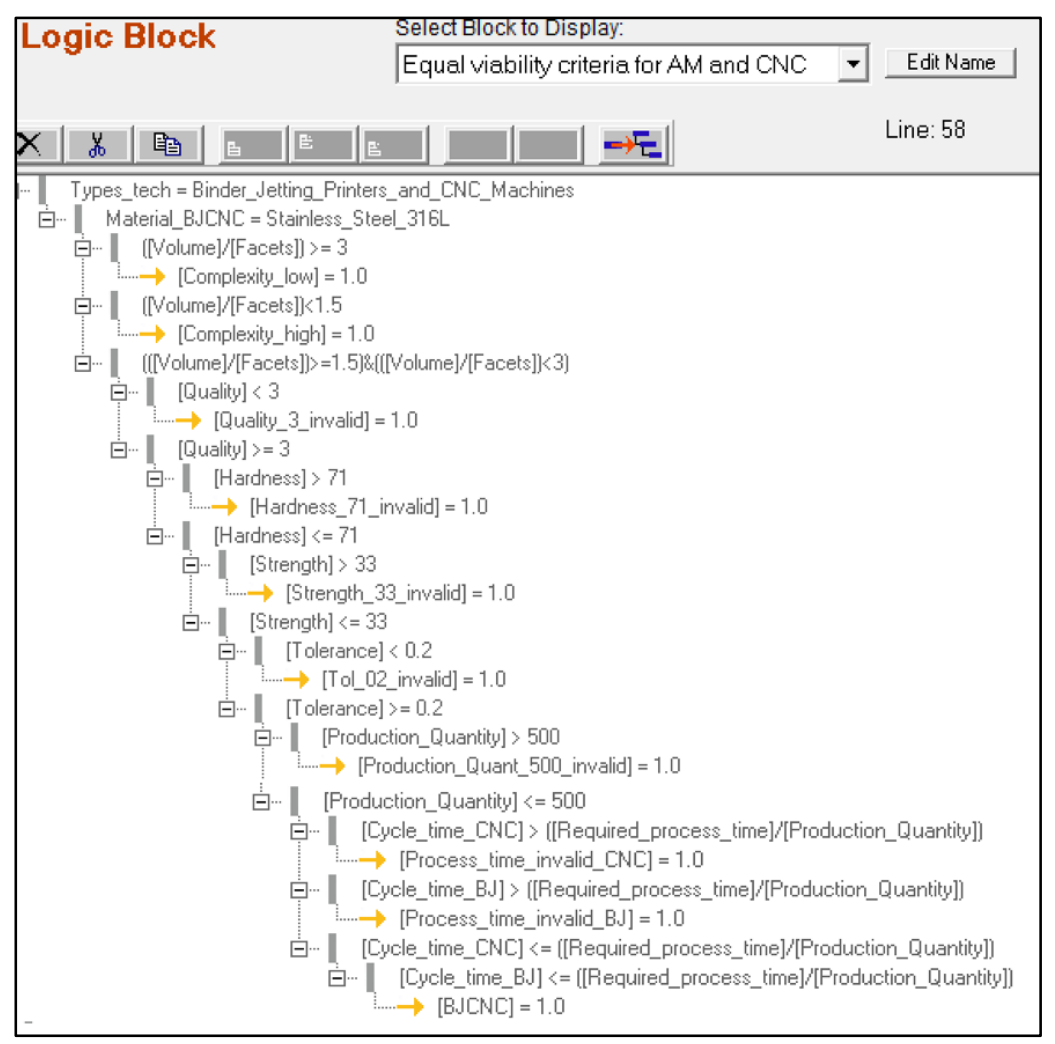

Figure 4.3: Design of Main Logic Block Rules for SS316L, BJP vs CNC

Figure 4.3 depicts the standard logic tree structure utilized in MSUSTAIN1 for deriving various confidence variables corresponding to user defined product, process and system parameters. All derived variables are associated with $100 \%$ confidence levels and include appropriate prompts to serve as advice. The logic structure has been designed such that the user inputs pertaining to geometric complexity, surface quality, hardness, yield strength, tolerance, production quantity and cycle time are individually checked against feasibility regions described in 4.1.1. If all parameters are within the viability criteria for each manufacturing technology, the user is advised to proceed 
to MSUSTAIN2. However, if a certain parameter is outside of the scope of these regions, the user is informed, and requested to alter the input accordingly (as shown in figure 4.4.)

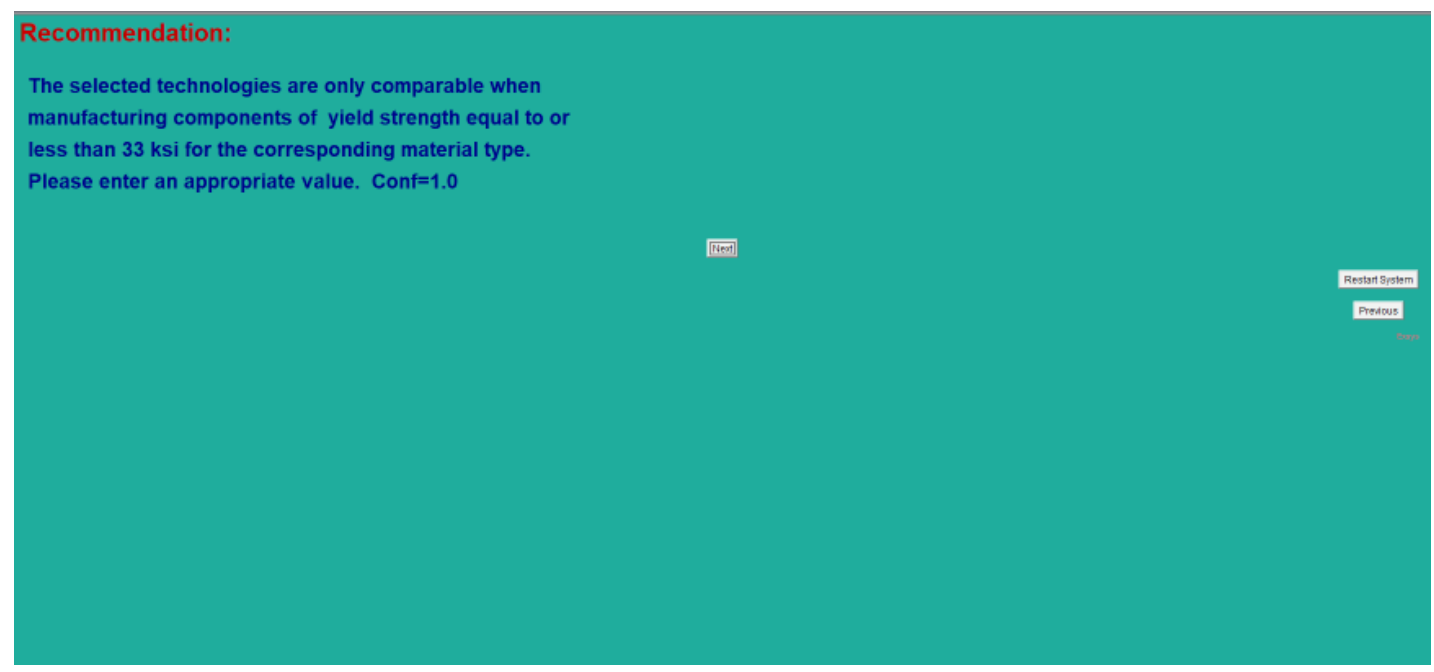

Figure 4.4: Example of Invalid Product Parameter Input by User

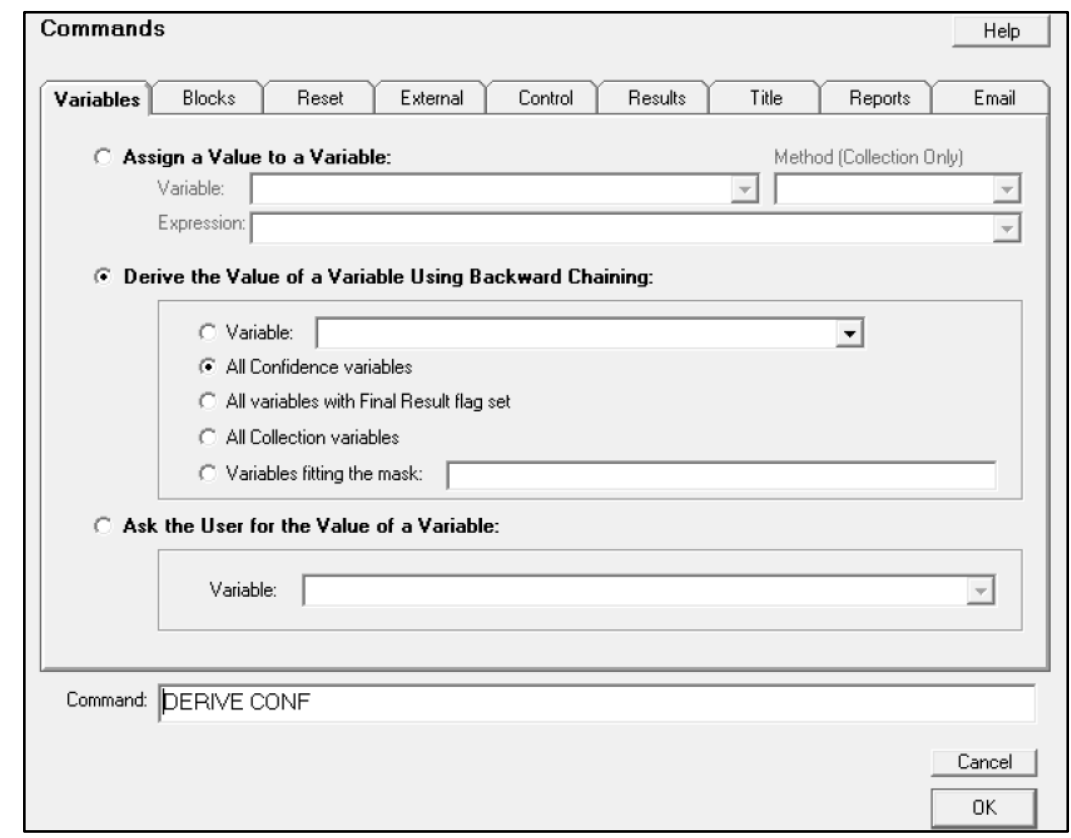

Figure 4.5: Assignment of Backward Chaining to Derive Confidence Variables

Figure 4.5 portrays the assignment of backward chaining to derive all confidence variables, using the Corvid ${ }^{\circledR}$ Command Block Window. As the main goal of the system is to derive confidence variables according to user input, the inference engine iteratively flows through the necessary consequents and antecedents in the logical rules/blocks to induce the desired output. 


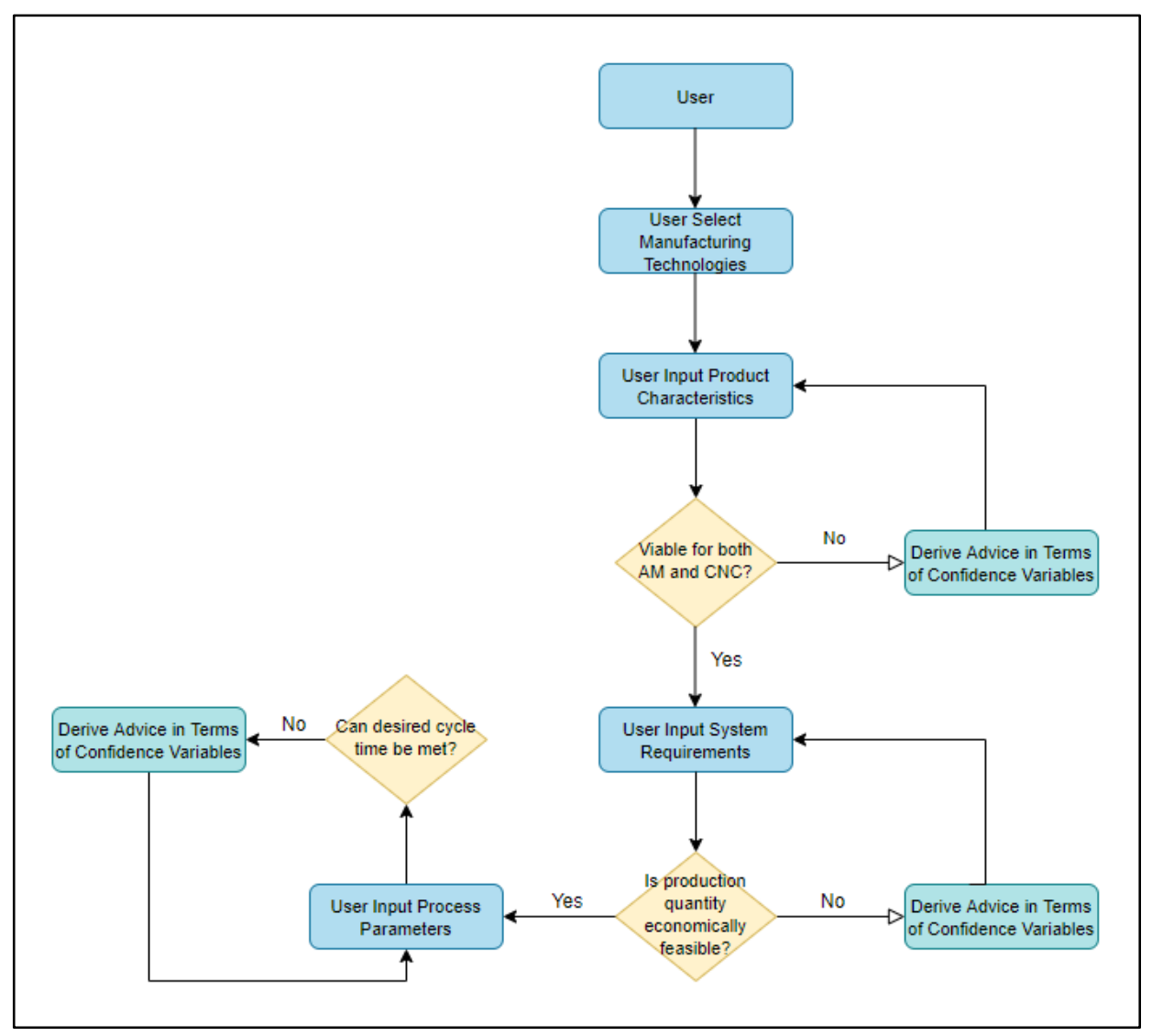

Figure 4.6: Algorithm for the MSUSTAIN1

\subsubsection{MSUSTAIN2 Expert System}

When the component has been determined to be viable for both additive manufacturing and CNC machining using MSUSTAIN1, MSUSTAIN2 would be capable of analyzing/comparing the sustainability impacts surrounding the fabrication processes under consideration. As with MSUSTAIN1, the system evaluates user input pertaining to the production of the component based on quantitative/qualitative information found in section 4.1. For the purposes of this research, it has been assumed that the sustainability impact surrounding a component increases linearly with the production quantity. Therefore, the impacts on sustainability due to economics, environmental emissions and auxiliary material consumption have been analyzed for a single part using the expert system. The methodology utilized is similar in structure to MSUSTAIN1. The system has been built using 314 nodes and consists of crisp information (100\% confidence levels.) The necessary equations and algorithms have been incorporated into the logic blocks such that the user is informed of the cost (\$), energy consumption (kWh) and sustainability rating (on a scale of 1 to 5) for auxiliary material. The expert system logic has been separated into 11 blocks which carry out 
specific functions such as calculation of energy consumption for primary, finishing and post processing, cost evaluation and derivation of auxiliary material weights using AHP. The logic block consisting of AHP follows the methodology described in section 4.2. Contrary from MSUSTAIN1, MSUSTAIN2 does not require the derivation of confidence variables. Instead, the command block has been designed to derive values for energy $(\mathrm{kWh})$, cost $(\$)$ and auxiliary material weights using AHP.

To be consistent with MSUSTAIN1, the user has to initially choose between BJP and CNC machining, or DMLS and CNC machining for the sustainability comparison. The system then inquires the user regarding product and process parameters required by each manufacturing technique. The logic blocks consider a vast range of inputs pertaining to (and not restricted to) CNC machining operations, layer characteristics of the additive manufacturing process, finishing/post processing steps, and cost aspects (for equipment, material, labor, electricity.) It is important to note that a geometric complexity factor of 5 is utilized for all builds, as per the information described in 4.1.1. Additionally, the system gives users the option to either provide equipment-based costs from documentation available at the manufacturing facility or allow the program to estimate costs according to average values found in literature. Variables have been designed with appropriate prompts, such that advice is provided to the user in situations deemed necessary. As an example, during the inquiry for the requirement of post processing, the system provides information pertaining to circumstances in which heat treatment should be utilized, and the feasible types as per the material used.

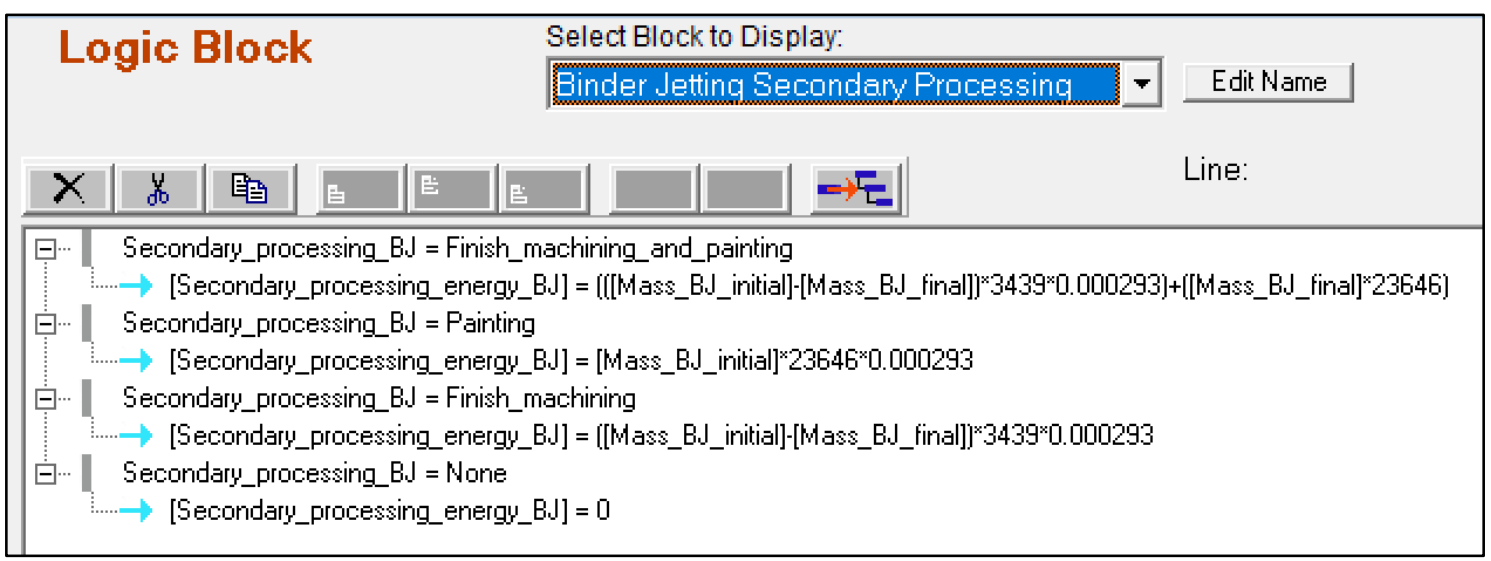

Figure 4.7: Logic Block Sample for Energy Consumption of BJP Finishing Processes 


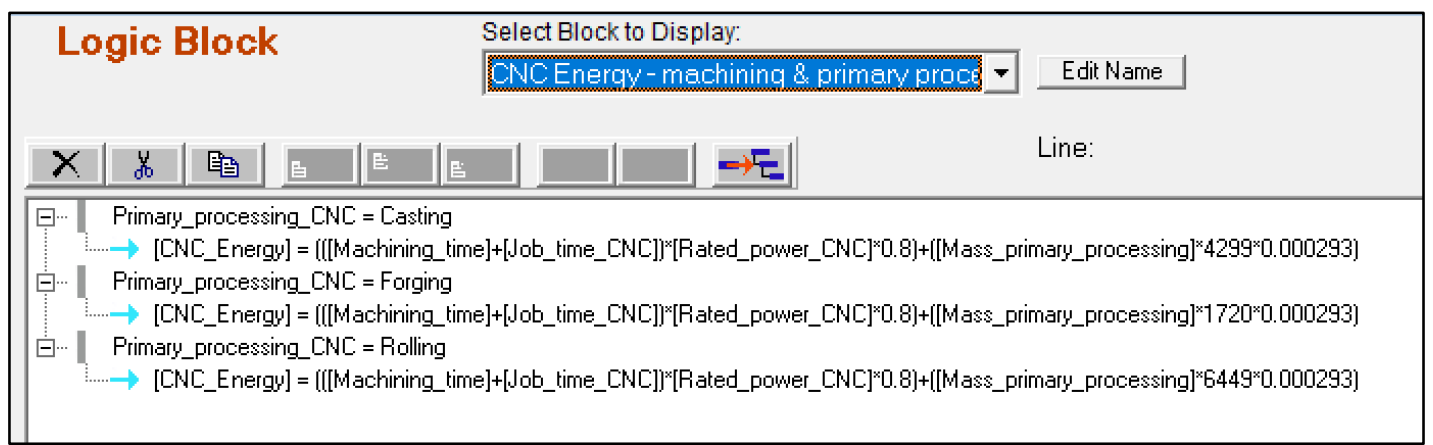

\section{Figure 4.8: Logic Block Sample for Energy Consumption of CNC process}

Figure 4.7 and 4.8 depict the structure of logical rules for the calculation of BJP secondary processing energy, and CNC machining energy consumption based on the utilized primary process. As described earlier, these sub-blocks (along with the others) carry out the necessary calculations required for the analysis. The backward chaining process would fire these logical rules in an appropriate sequence.

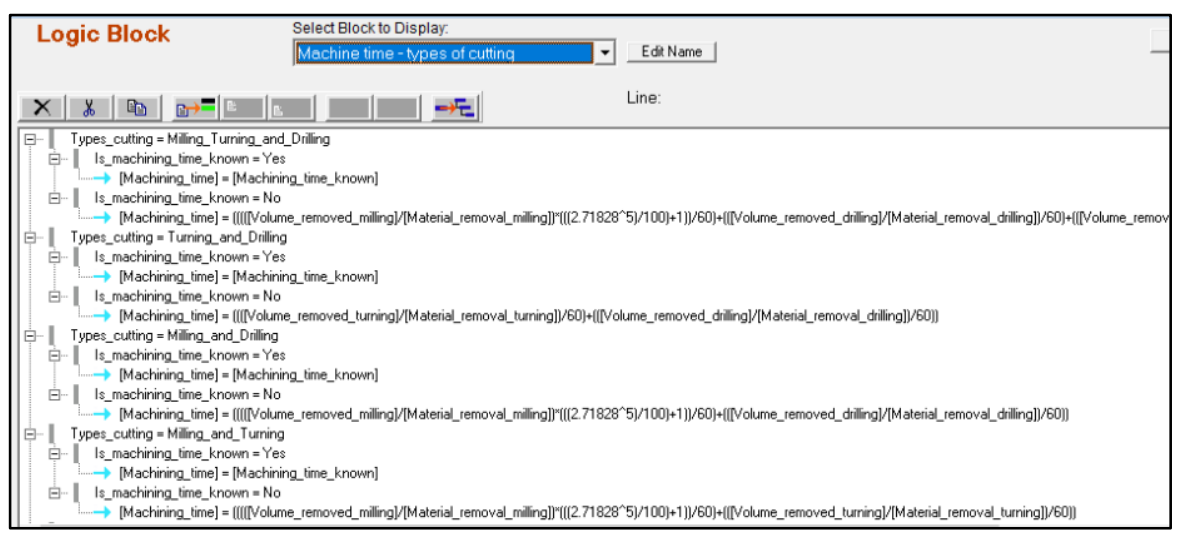

Figure 4.9: Logic Block Sample for Machining Time Calculation

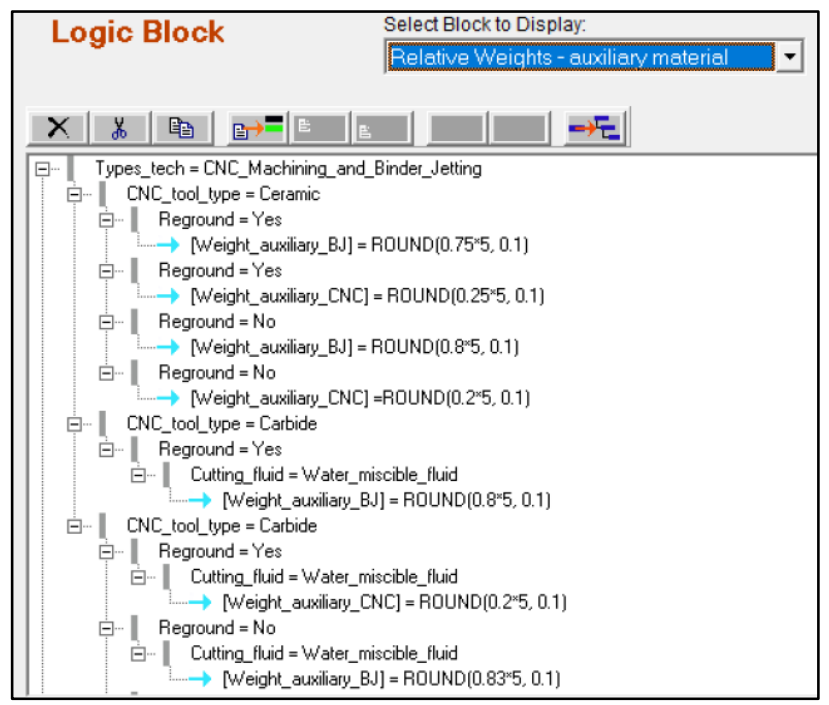

Figure 4.10: Logic Block Sample of Weights Calculation for Auxiliary Material 
Figure 4.9 and 4.10 portray samples of the logical rules used for deriving the sustainability performance for each manufacturing technology as described in 4.1 and 4.2. Upon obtaining information pertaining to the product from the user, the system evaluates the logical rules within the sub-blocks (containing derivations for cost, energy and auxiliary material usage) and uses the "Relative Weights - Auxiliary Material” block to enumerate the sustainability of each process.

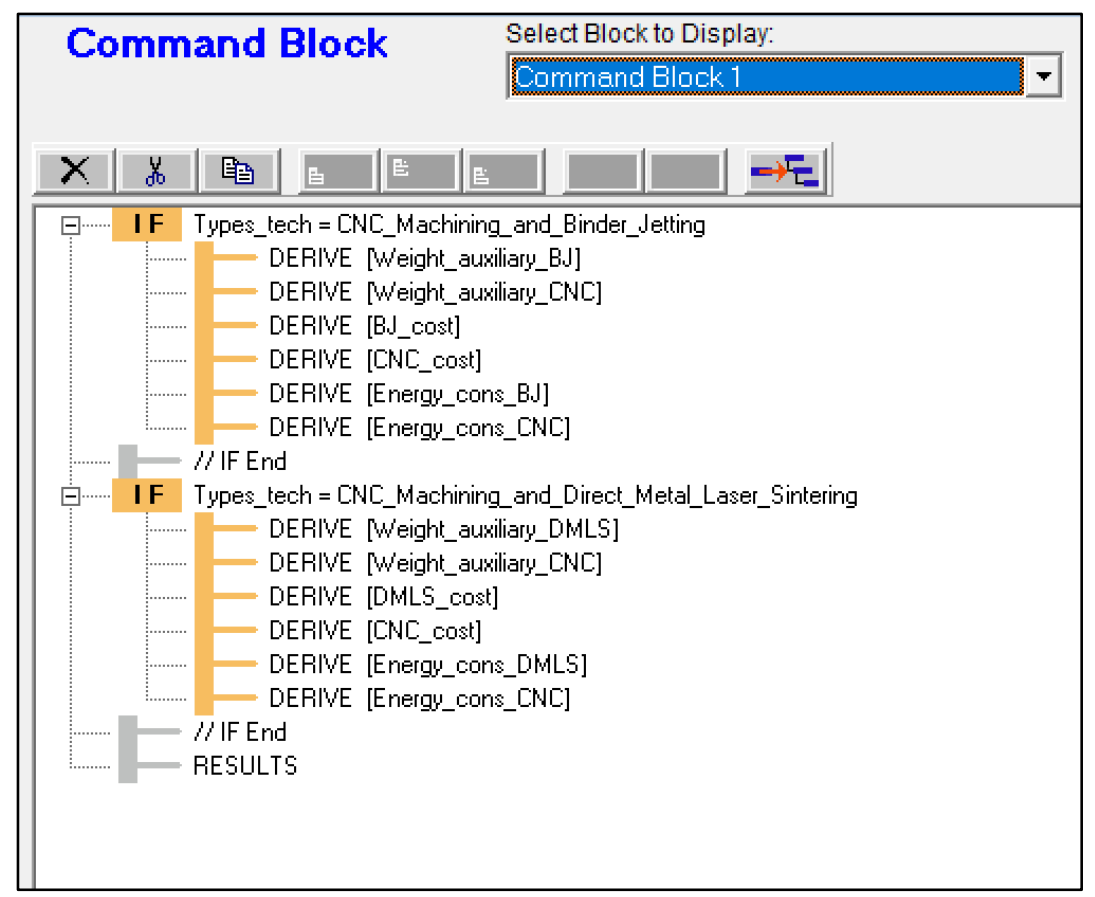

Figure 4.11: Command Block Structure for MSUSTAIN2

Figure 4.11 depicts the structure of the Corvid ${ }^{\circledR}$ Command Block Window for MSUSTAIN2. Conditional inferencing has been utilized to derive sustainability performance values based on the type of technologies being compared. The goal of the system has been defined such that variables corresponding to the values of sustainability indicators are derived using backward chaining. 


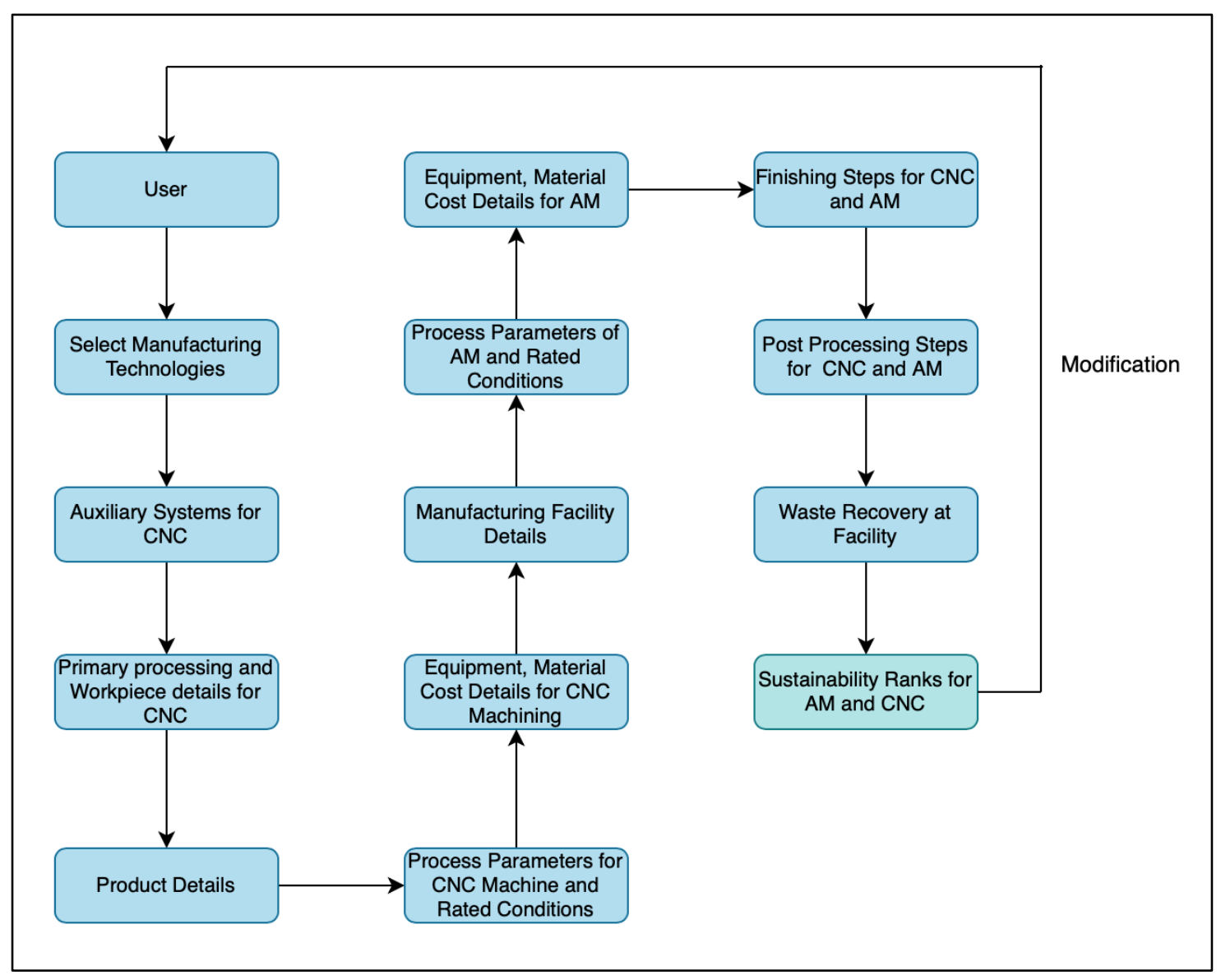

Figure 4.12: Algorithm for MSUSTAIN2

\subsection{Conclusion}

Two expert systems were created using Exsys Corvid® to aid decision makers in selecting additive manufacturing (BJP/DMLS) or CNC machining for the fabrication of metal components. The first expert system ascertains the region of feasibility for both $\mathrm{AM}$ and $\mathrm{CNC}$ based on product, process and system parameters. Whereas the second expert system compares both manufacturing technologies in terms of overall cost, energy and auxiliary material, and displays an overall sustainability rating. The initial phase of design for the expert systems was the creation of a comprehensive knowledgebase which includes quantitative/qualitative subjective knowledge pertaining to the research objectives. Afterwards, appropriate logical rules were designed for each expert system such that user input related to each product, process and system can be vigilantly evaluated. Both expert systems have been designed to utilize backward chaining as the inferencing method. Analytical Hierarchy Process was used for weightage and development of the scoring system for sustainability indicators. 


\section{Verification and Analysis of Model}

Further analysis and verification are required to test the robustness of the knowledgebase and logical rules built into the expert systems. For this purpose, the expert systems have been utilized to evaluate the sustainability aspects pertaining to fabrication of a stainless-steel component by means of CNC machining and Binder Jetting. Details of the case study are discussed in the following sections.

\subsection{Case Study}

In order to test the accuracy of the expert systems, it was considered imperative to fabricate a test part using CNC machining and Binder Jetting and compare output results of the programs to actual data retrieved during manufacturing. For this purpose, electrical data was logged during the manufacturing processes such that calculations employed within the expert systems can be validated. Data obtained during the processes were beneficial in the evaluation of energy consumption and material usage. It is important to note that the fabrication processes were carried out as per the availability of resources during the timeline of the research project. Secondary/tertiary processing steps such as finishing, and heat treatment have not been considered in the case study due to limitations in equipment.

\subsubsection{Characteristics of Manufactured Component}

The component selected was a reduced scale model representing the control arm of a vehicle suspension system. Control arms fasten suspension members to the chassis and manage the motion of the wheels so that it synchronizes with that of the body of the car. These components, along with bushings, allow the vehicle to turn its wheel and pivot. Figure 5.1 depicts the front, isometric, top, and side views of the fabricated object modeled using Autodesk Fusion 360®. 


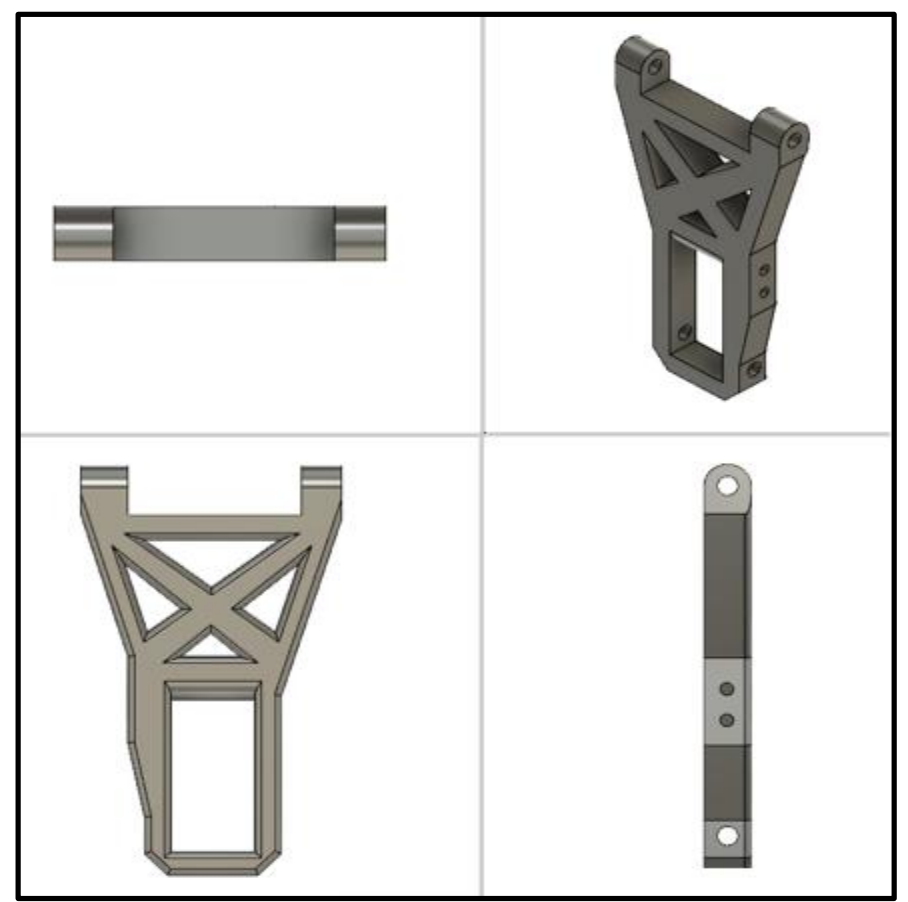

Figure 5.1: Autodesk Fusion 360® Model of Component

A vital factor to be considered when manufacturing automotive components is the selection of material with appropriate mechanical properties. Stainless Steel (SS) 316L was selected due its high strength and corrosion resistance. SS 316L is reasonably easy to machine below 30 HRC [57] and extensively used in Binder Jetting (BJP) processes. It is important to note that tool life, cutting speed and surface finish should all be considered when evaluating the degree of machinability [58]. Table 5.1 summarizes the properties of the manufactured control arm component.

Table 5.1: Control Arm Material Properties, Dimensions and Tolerances

\begin{tabular}{|c|c|}
\hline Material & $\begin{array}{c}\text { Stainless Steel 316L powder - BJP } \\
\text { Stainless Steel 316L annealed bar - CNC }\end{array}$ \\
\hline Mass & $61 \mathrm{~g}$ \\
\hline Volume & $7,600 \mathrm{~mm}^{3}$ \\
\hline \multirow{3}{*}{ Features and dimensions } & Chamfers: $3.50 \mathrm{~mm} \times 3.50 \mathrm{~mm}$ \\
\cline { 2 - 2 } & Fillets: $\varnothing 1.5 \mathrm{~mm}$ \\
\cline { 2 - 2 } & Counterbore: $\varnothing 3 \pm 0.2 \mathrm{~mm}, \varnothing 5.20 \pm 0.2 \mathrm{~mm}$ \\
\cline { 2 - 2 } & Rectangular slot: $12.50 \pm 0.2 \mathrm{~mm} \times 24.70 \pm 0.2 \mathrm{~mm}$ \\
\cline { 2 - 2 } & Small holes: $2.00 \pm 0.2 \mathrm{~mm}, 3.00 \pm 0.2 \mathrm{~mm}$ \\
\cline { 2 - 2 } & Notch: $26.00 \pm 0.2 \mathrm{~mm}$ \\
\hline
\end{tabular}




\subsubsection{Manufacturing Process of Control Arm using Binder Jetting}

The fabrication process of the control arm was carried out on an ExOne Innovent BJP printer, and consisted of two iterations. During the first experimental run, the component was manufactured as a batch of one part. For the second experiment, the build volume was optimized within the platform to accommodate a production run of 6 parts.

As mentioned in earlier sections, the BJP process involves a series of stages. The initial printed "green structure" needs to be cured to enhance the binding process. This allows the produced part to be removed from the print bed and transferred to the sintering oven. Due to the porosity of the part yielded from the BJP printing process, an infiltration step is required to achieve the required density and hardness. In this pilot study, the component was bronze infiltrated during the sintering process. A simplified depiction of the BJP process is shown in figure 5.2.

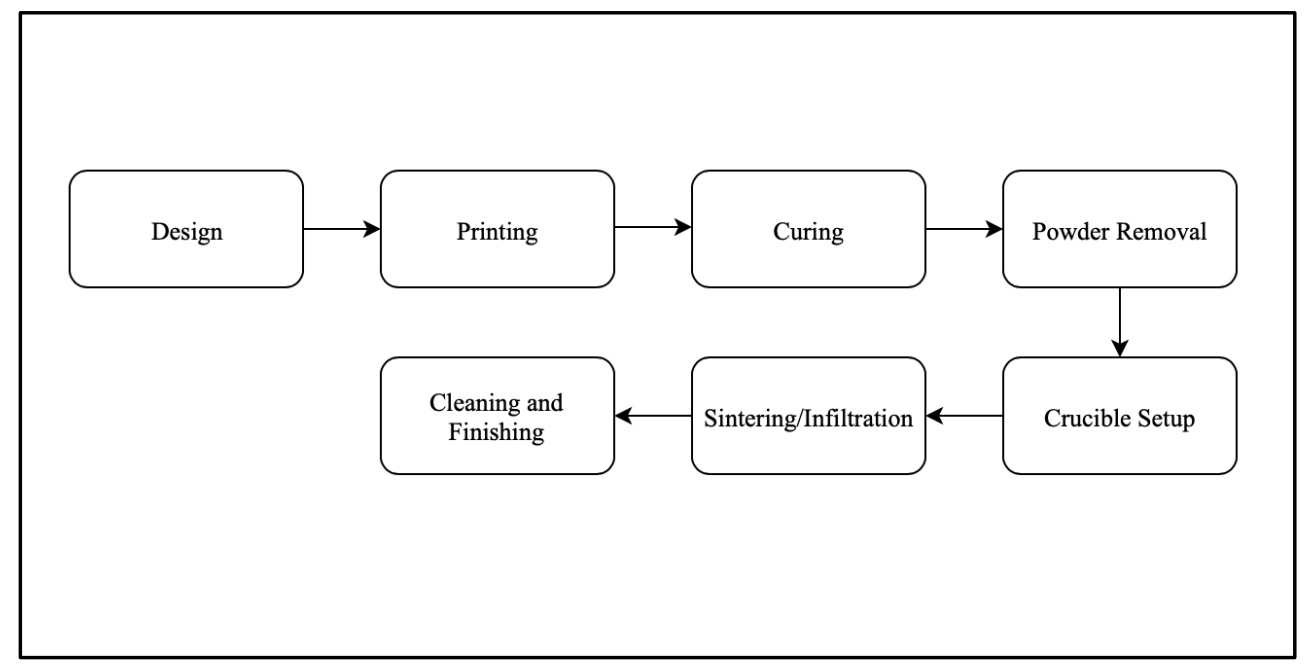

Figure 5.2: BJP Process

The process parameters used to manufacture the control arm are summarized in table 5.2. 
Table 5.2: Process Parameters Used for BJP

\begin{tabular}{|c|c|c|}
\hline Stage & \multicolumn{2}{|c|}{ Process Parameters } \\
\hline Printing & \multicolumn{2}{|c|}{$\begin{array}{c}\text { Build envelope: } 160 \text { x } 65 \text { x } 65 \mathrm{~mm} \\
\text { Layer thickness: } 0.1 \mathrm{~mm} \\
\text { Layer time: } 46 \mathrm{sec} / \mathrm{layer} \\
\text { Drying time: } 15 \mathrm{sec} \\
\text { Target bed temperature: } 65^{\circ} \mathrm{C}\end{array}$} \\
\hline Stage & \multicolumn{2}{|c|}{ Process Parameters } \\
\hline Curing & \multicolumn{2}{|c|}{$\begin{array}{c}\text { Oven temperature: } 200^{\circ} \mathrm{C} \\
\text { Time: } 10 \text { hours }\end{array}$} \\
\hline Sintering/Bronze Infiltration & $\begin{array}{l}\text { 1) } 122^{\circ} \mathrm{F}: 150 \mathrm{~min} \\
\text { 2) } 392^{\circ} \mathrm{C}: 100 \mathrm{~min} \\
\text { 3) } 572^{\circ} \mathrm{C}: 100 \mathrm{~min} \\
\text { 7) } 129\end{array}$ & $\begin{array}{l}\text { 4) } 1112^{\circ} \mathrm{F}: 230 \mathrm{~min} \\
\text { 5) } 1832^{\circ} \mathrm{F}: 60 \mathrm{~min} \\
\text { 6) } 2048^{\circ} \mathrm{F}: 200 \mathrm{~min} \\
80 \mathrm{~min}\end{array}$ \\
\hline
\end{tabular}

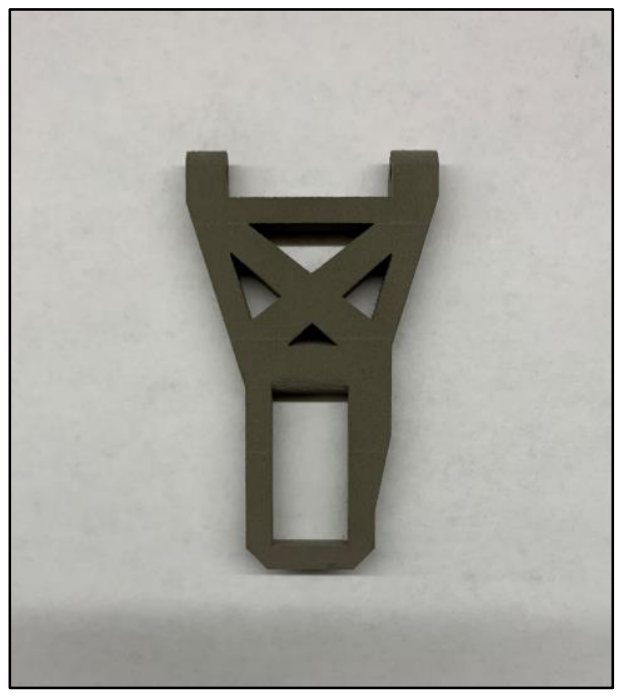

Figure 5.3: "Green Structure" Yielded from BJP Process

\subsubsection{Energy and Material Consumption of the BJP Process}

In order to determine the energy consumption of the BJP process, it was required to record real time electrical data during each stage of fabrication. This was achieved by the use of a series of instruments such as current transducers, data loggers and a hand-held multimeter. The current drawn by the printer and curing oven were recorded using the combination of a HOBO data logger 
and Onset CTV-E 20-amp current transducer. The device was clamped on the wire carrying input line current of each system's single-phase connection. Data were collected for each iteration of the experiment. Figure 5.4 depicts the electrical data monitoring setup.



Figure 5.4: Current Data Collection Procedure

The input power consumed by the ExOne Innovent BJP printer during iteration 1 of the experiment can be calculated as shown below,

$$
\mathrm{P}_{\text {print }, 1}=\mathrm{V}_{\text {print }} \times \mathrm{I}_{\text {print }, 1} / \mathrm{k}_{1}
$$

Where,

$$
\begin{array}{ll}
\mathrm{V} & =\text { Voltage supplied }(\mathrm{V}), 220 \mathrm{~V} \\
\mathrm{I}_{\text {print }, 1} & =\text { Average Current drawn (Amps), } 2.7 \text { (measured) } \\
\mathrm{k}_{1} & =\text { Conversion constant, } 1 \mathrm{~kW}=1,000 \mathrm{~W}
\end{array}
$$

The power consumption for the printer is given by,

$$
\begin{aligned}
P_{\text {print }, 1} & =220 \times 2.7 / 1,000 \\
& =0.6 \mathrm{~kW}
\end{aligned}
$$

The build time is calculated as,

$$
\mathrm{T}_{\text {print }, 1}=\mathrm{N}_{\mathrm{L}, 1} \times \mathrm{L}_{\mathrm{T}} / \mathrm{k}_{2}
$$


Where,

$$
\begin{array}{ll}
\mathrm{N}_{\mathrm{L}, 1} & =\text { No. of layers, } 74 \text { (as per model) } \\
\mathrm{L}_{\mathrm{T}} & =\text { Time per layer, } 46(\mathrm{sec}) \\
\mathrm{k}_{2} & =\text { Conversion constant, } 1 \mathrm{~h}=3,600 \mathrm{sec}
\end{array}
$$

Build time of the model is given by,

$$
\begin{aligned}
\mathrm{T}_{\text {print }, 1} & =74 \times 46 /(3,600) \\
& =0.9 \mathrm{~h}
\end{aligned}
$$

Therefore, the energy consumed during the build of 1 part can be calculated as,

$$
\begin{aligned}
\mathrm{E}_{\text {print }, 1} & =\mathrm{P}_{\text {print }, 1} \times \mathrm{T}_{\text {print }, 1} \\
& =0.6 \times 0.9 \\
& =0.5 \mathrm{kWh}
\end{aligned}
$$

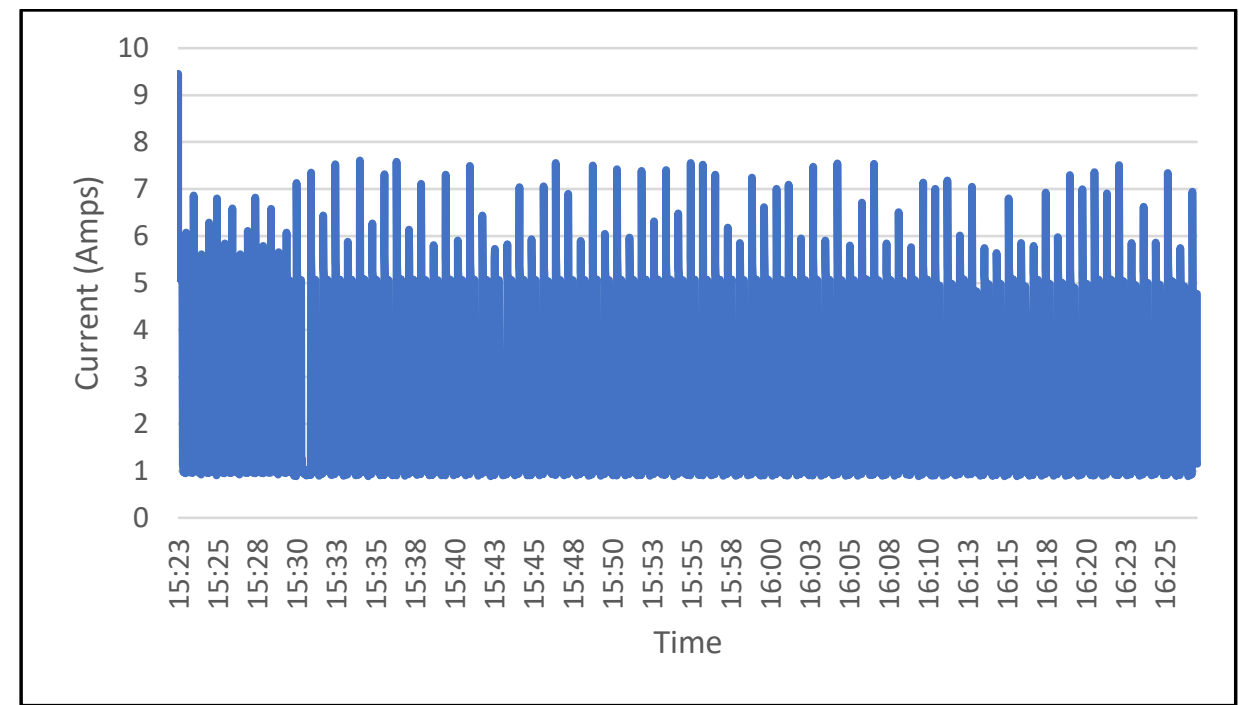

Figure 5.5: Current Draw of the Printer During Build of 1 part

The input power consumed by the curing oven during iteration 1 of the experiment can be calculated as shown below,

$$
\mathrm{P}_{\text {cure }, 1}=\mathrm{V}_{\text {cure }} \times \mathrm{I}_{\text {cure }, 1} / \eta_{\text {cure }} \times \mathrm{k}_{1}
$$


Where,

$$
\begin{array}{ll}
\mathrm{V}_{\text {cure }} & =\text { Voltage supplied (V), } 115 \mathrm{~V} \\
\mathrm{I}_{\text {cure, } 1} & =\text { Average Current drawn (Amps), } 4.6 \text { (measured) } \\
\eta_{\text {cure }} & =\text { Efficiency of Curing Oven, } 0.95 \text { (assumed) } \\
\mathrm{k}_{1} & =\text { Conversion constant, } 1 \mathrm{~kW}=1,000 \mathrm{~W}
\end{array}
$$

The power consumption of the curing oven is given by,

$$
\begin{aligned}
\mathrm{P}_{\text {cure }, 1} & =115 \times 4.6 /(0.95 \times 1,000) \\
& =0.6 \mathrm{~kW}
\end{aligned}
$$

The energy consumed during the curing process of 1 part can be calculated as,

$$
\begin{aligned}
\mathrm{E}_{\text {cure }, 1} & =\mathrm{P}_{\text {cure }, 1} \times \mathrm{T}_{\text {cure }, 1} \\
& =0.6 \times 10 \\
& =6.0 \mathrm{kWh}
\end{aligned}
$$

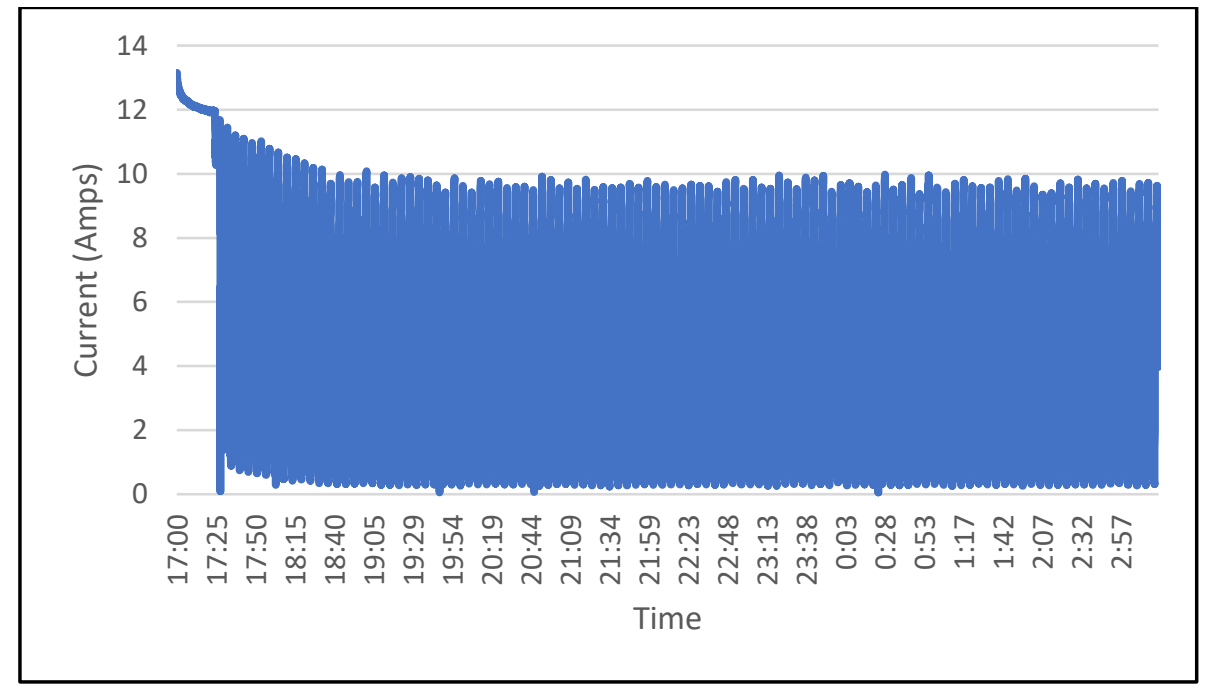

Figure 5.6: Current Draw of the Curing Oven during Build of 1 Part

In order to calculate the energy consumption during the sintering process, the utilized heat profile (table 5.2) of the oven needs to be taken into consideration.

$\mathrm{E}_{\text {sinter }, 1}=\mathrm{V}_{\text {sinter }, 1} \times \mathrm{I}_{\text {sinter }, 1} \times \mathrm{LF}_{\text {sinter }} \times \mathrm{T}_{\text {sinter }} /\left(\eta_{\text {sinter }} \times \mathrm{k}_{1}\right)$ 
Where,

$$
\begin{array}{ll}
\mathrm{V}_{\text {sinter }, 1} & =\text { Voltage supplied }(\mathrm{V}), 240 \mathrm{~V} \\
\mathrm{I}_{\text {cure, } 1} & =\text { Current drawn (Amps), } 35 \\
\mathrm{LF}_{\text {sinter }} & =\text { Load factor, } 35 \% \text { (based on heat profile) } \\
\mathrm{T}_{\text {sinter }} & =\text { Sintering time, } 15 \text { hours } \\
\eta_{\text {sinter }} & =\text { Efficiency of Sintering Oven, } 0.95 \text { (assumed) } \\
\mathrm{k}_{1} & =\text { Conversion constant, } 1 \mathrm{~kW}=1,000 \mathrm{~W}
\end{array}
$$

The energy consumption of the sintering process is given by,

$$
\begin{aligned}
\mathrm{E}_{\text {sinter }, 1} & =240 \times 35 \times 0.35 \times 15 /(0.95 \times 1,000) \\
& =46.4 \mathrm{kWh}
\end{aligned}
$$

Therefore, the total energy consumption of the BJP process during the production of a single part (iteration 1) of the control arm is,

$$
\begin{aligned}
\mathrm{E}_{\text {total }} & =\mathrm{E}_{\text {print }, 1}+\mathrm{E}_{\text {cure }, 1}+\mathrm{E}_{\text {sinter }, 1} \\
& =52.9 \mathrm{kWh}
\end{aligned}
$$

During the second iteration of the experiment, the energy consumption of the curing and sintering processes remained identical to that of the former. Understandably, energy consumption of the printer is dependent on the build time of the component. Therefore, the energy consumption during the production run of 6 parts (iteration 2) can be calculated as depicted in the following sequence of steps.

$$
\mathrm{P}_{\text {print }, 2}=\mathrm{V}_{\text {print }} \mathrm{X} \mathrm{I}_{\text {print }, 2} / \mathrm{k}_{1}
$$

Where,

$$
\begin{array}{ll}
\mathrm{V} & =\text { Voltage supplied }(\mathrm{V}), 220 \mathrm{~V} \\
\mathrm{I}_{\text {print }, 2} & =\text { Average Current drawn (Amps), } 2.5 \text { (measured) } \\
\mathrm{k}_{1} & =\text { Conversion constant, } 1 \mathrm{~kW}=1,000 \mathrm{~W}
\end{array}
$$


The power consumption for the printer is given by,

$$
\begin{aligned}
\mathrm{P}_{\text {print }, 2} & =220 \times 2.5 / 1,000 \\
& =0.6 \mathrm{~kW}
\end{aligned}
$$

The build time is calculated as,

$$
\mathrm{T}_{\text {print }, 2}=\mathrm{N}_{\mathrm{L}, 2} \times \mathrm{L}_{\mathrm{T}} / \mathrm{k}_{2}
$$

Where,

$$
\begin{array}{ll}
\mathrm{N}_{\mathrm{L}, 2} & =\text { No. of layers, } 325 \text { (as per model) } \\
\mathrm{L}_{\mathrm{T}} & =\text { Time per layer, } 46(\mathrm{sec}) \\
\mathrm{k}_{2} & =\text { Conversion constant, } 1 \mathrm{~h}=3,600 \mathrm{sec}
\end{array}
$$

Build time of the production run is given by,

$$
\begin{aligned}
\mathrm{T}_{\text {print }, 2} & =325 \times 46 /(3,600) \\
& =4.2 \mathrm{~h}
\end{aligned}
$$

Therefore, the energy consumed during the build of 6 parts can be calculated as,

$$
\begin{aligned}
\mathrm{E}_{\text {print }, 2} & =\mathrm{P}_{\text {print }, 2} \times \mathrm{T}_{\text {print }, 2} \\
& =0.6 \times 4.2 \\
& =2.5 \mathrm{kWh}
\end{aligned}
$$




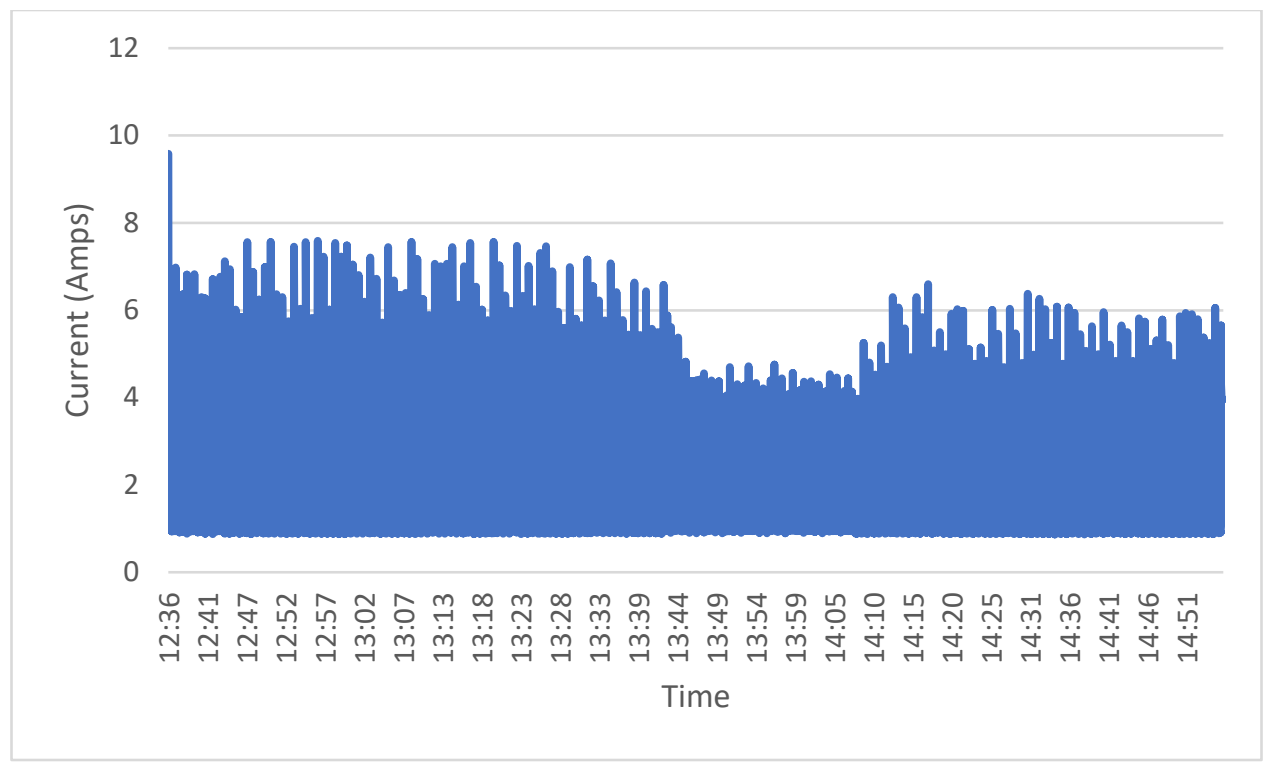

Figure 5.7: Current Draw of the Printer during Build of 6 Parts

The summary of energy consumption during each iteration of the process is shown in table 5.3.

Table 5.3: Energy consumption of BJP process

\begin{tabular}{|c|c|c|}
\hline \multirow{2}{*}{ Stage of BJP Process } & \multicolumn{2}{|c|}{ Energy Consumption (kWh) } \\
\cline { 2 - 3 } & Iteration 1 (1 Part) & Iteration 2 (6 Parts) \\
\hline Printing & 0.5 & 2.5 \\
\hline Curing & 6 & 6 \\
\hline Sintering & 46.4 & 46.4 \\
\hline Total & $\mathbf{5 2 . 9}$ & $\mathbf{5 4 . 9}$ \\
\hline Energy Intensity / Part & $\mathbf{5 2 . 9}$ & $\mathbf{9 . 1 5}$ \\
\hline
\end{tabular}

Data collected from the manufacturing processes indicate that the energy intensity per part can be significantly reduced by build volume optimization of the printer.

Unlike PBF/DED processes in which high energy beams are used and powder material is susceptible to high probabilities of oxidation, BJP uses low temperature infrared heating. Oxidation of 3D printing metal powder limits the number of reuses due to its effect on surface quality. Hence, waste powder material generated in the printing process of BJP can be reutilized for a significant number of subsequent builds. During the powder removal stage of the process, a 
sieve is used to collect all the redundant powder content resulting from the build. During this pilot study, all waste powder produced from the first iteration was combined with new powder for the next production run. From existing literature, it is understood that there is no significant change in mechanical properties due to the reuse of powder [35]. It can be concluded that only the material which is required for the build is utilized during printing and material wastage is negligible. Therefore, material usage during the build can be estimated as being equal to the volume of the component. In this case, $7,600 \mathrm{~mm}^{3}$.

\subsubsection{Manufacturing Process of Control Arm Using CNC}

In order to determine the CNC machining process plan and create suitable toolpaths, the manufacturing suite of Autodesk Fusion 360 was used. Machining parameters such as spindle speed, cutting speed and feed rate were selected based on optimality for cutting SS 316L [59]. Water miscible fluid in the flood setting was used during the build experiment. The process plan and machining parameters are summarized in table 5.4.

Table 5.4: CNC Machining Process Plan

\begin{tabular}{|c|c|c|c|c|}
\hline Stage & Tool & $\begin{array}{c}\text { Spindle } \\
\text { Speed (rpm) }\end{array}$ & $\begin{array}{c}\text { Cutting Speed } \\
(\mathbf{f t} / \mathbf{m i n})\end{array}$ & $\begin{array}{c}\text { Feed Rate } \\
(\mathbf{i n} / \mathbf{m i n})\end{array}$ \\
\hline Top face milling & $\varnothing 0.39$ in - Flat & 1460 & 150.48 & 4.38 \\
\hline Bottom face milling & $\varnothing 0.39$ in - Flat & 1460 & 150.48 & 4.38 \\
\hline $\begin{array}{c}\text { Adaptive milling } \\
\text { (front/back/sides) }\end{array}$ & $\varnothing 0.39$ in - Flat & 1460 & 150.48 & 4.38 \\
\hline Milling of pockets & $\varnothing 0.11811$ in - Flat & 4850 & 149.96 & 4.85 \\
\hline Adaptive milling & $\varnothing 0.11811$ in - Flat & 4850 & 149.96 & 4.85 \\
\hline Contouring & $\varnothing 0.11811$ in - Flat & 4850 & 149.96 & 4.85 \\
\hline Drilling stage 1 & $\varnothing 1 / 8$ in center drill & 2440 & 79.848 & 3.904 \\
\hline Drilling stage 2 & $\varnothing 1 / 8$ in center drill & 2440 & 79.848 & 3.904 \\
\hline Deep drilling stage 1 & $\varnothing 0.079$ in drill & 1930 & 39.916 & 4.246 \\
\hline Deep drilling stage 2 & $\varnothing 0.118$ in drill & 1290 & 39.851 & 4.773 \\
\hline
\end{tabular}




\begin{tabular}{|c|c|c|c|c|}
\hline Deep drilling stage 3 & $\varnothing 0.118$ in drill & 1290 & 39.851 & 4.773 \\
\hline Bore & $\varnothing 0.118$ in flat & 4850 & 149.967 & 4.85 \\
\hline Adaptive milling & $\varnothing 1 / 8$ in - ball & 4850 & 149.96 & 4.85 \\
\hline Adaptive milling & $\varnothing 1 / 8$ in - ball & 4850 & 149.96 & 4.85 \\
\hline Contour & $\varnothing 1 / 8$ in - ball & 4850 & 149.96 & 4.85 \\
\hline Contour & $\varnothing 1 / 8$ in - ball & 4850 & 149.96 & 4.85 \\
\hline
\end{tabular}

Prior to machining the stainless-steel work piece, a test run had to be conducted to analyze the suitability of process parameters. The test run was conducted using Acetal Resin as the stock material. The energy consumption of the machine during the fabrication process was monitored using a HOBO data logger and Onset CTV-E 20-amp current transducer. The resulting data served as a benchmark for comparing the current draw of the machine during the fabrication of the stainless-steel part. It was found that the input current into the machine during both iterations remained fairly identical. Due to limitations of the CNC machine, the process plan needed to be altered. In order to make a realistic comparison and analysis, the machining time simulation from the CAD software has been used to calculate the energy consumption. The new process plan consisted of the following steps.

Table 5.5: Modification of CNC process plan

\begin{tabular}{|c|c|c|c|}
\hline Stage & Tool & $\begin{array}{c}\text { Spindle Speed } \\
\text { (rpm) }\end{array}$ & $\begin{array}{c}\text { Cutting Feed } \\
\text { Rate } \\
\text { (in/min) }\end{array}$ \\
\hline Top face milling & $\begin{array}{c}\varnothing 0.375 \text { in - Flat (Carbide 4 } \\
\text { flute) }\end{array}$ & 1346 & 7.53 \\
\hline Bottom face milling & $\begin{array}{c}\varnothing 0.375 \text { in - Flat (Carbide 4 } \\
\text { flute) }\end{array}$ & 1346 & 7.53 \\
\hline $\begin{array}{c}\text { Adaptive milling stage 1 } \\
\text { (front/back/sides) }\end{array}$ & $\begin{array}{c}\varnothing 0.125 \text { in - Flat (Carbide 4 } \\
\text { flute) }\end{array}$ & 1346 & 7.53 \\
\hline Pocket milling stage 1 & $\begin{array}{c}\varnothing 0.125 \text { in - Flat (Carbide 4 } \\
\text { flute) }\end{array}$ & 4030 & 8.06 \\
\hline
\end{tabular}




\begin{tabular}{|c|c|c|c|}
\hline Adaptive milling stage 2 & $\begin{array}{c}\varnothing 0.125 \text { in - Flat (Carbide 4 } \\
\text { flute) }\end{array}$ & 4030 & 8.06 \\
\hline Pocket milling stage 2 & $\begin{array}{c}\varnothing 0.125 \text { in - Flat (Carbide 4 } \\
\text { flute) }\end{array}$ & 4030 & 8.06 \\
\hline Adaptive milling stage 3 & $\begin{array}{c}\varnothing 0.125 \text { in - Flat (Carbide 4 } \\
\text { flute) }\end{array}$ & 4030 & 8.06 \\
\hline Contour & $\begin{array}{c}\varnothing 0.125 \text { in - Flat (Carbide 4 } \\
\text { flute) }\end{array}$ & 4030 & 8.06 \\
\hline Adaptive milling stage 4 & $\begin{array}{c}\varnothing 0.125 \text { in - Ball (Carbide 4 } \\
\text { flute) }\end{array}$ & 4030 & 8.06 \\
\hline Contour & $\begin{array}{c}\varnothing 0.125 \text { in - Ball (Carbide 4 } \\
\text { flute) }\end{array}$ & 4030 & 8.06 \\
\hline
\end{tabular}

\subsubsection{Energy and Material Consumption of CNC Process}

The stainless-steel part was manufactured using a Tormach 1100M four-axis CNC mill. Machining time was found to be 3.65 hours and the average current draw during the build experiment was 4.48 amps.

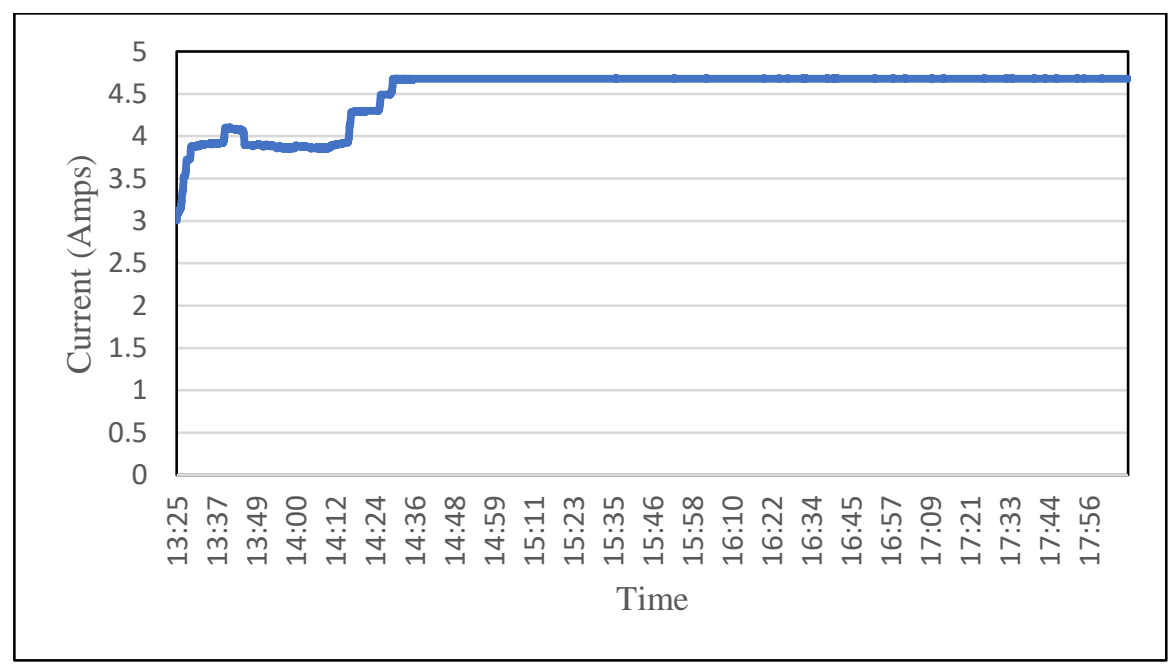

Figure 5.8: Data logged during fabrication 
The energy consumption during the production of a single unit of the control arm can be calculated as follows.

$\mathrm{E}_{\mathrm{CNC}}=\mathrm{V}_{\mathrm{CNC}} \mathrm{x} \mathrm{I}_{\mathrm{CNC}} \times \mathrm{T}_{\mathrm{CNC}} / \mathrm{k}_{1}$

Where,

$\mathrm{V}_{\mathrm{CNC}} \quad=$ Voltage supplied $(\mathrm{V}), 240 \mathrm{~V}$

ICNC $\quad=$ Current drawn (Amps), 4.48

$\mathrm{T}_{\mathrm{CNC}}=\mathrm{CNC}$ machining time (estimated by simulation), 3.65 hours

Therefore, the energy consumption of the $\mathrm{CNC}$ process is given by,

$$
\begin{aligned}
\mathrm{E}_{\mathrm{CNC}} & =240 \times 4.48 \times 3.65 /(1,000) \\
& =3.9 \mathrm{kWh}
\end{aligned}
$$

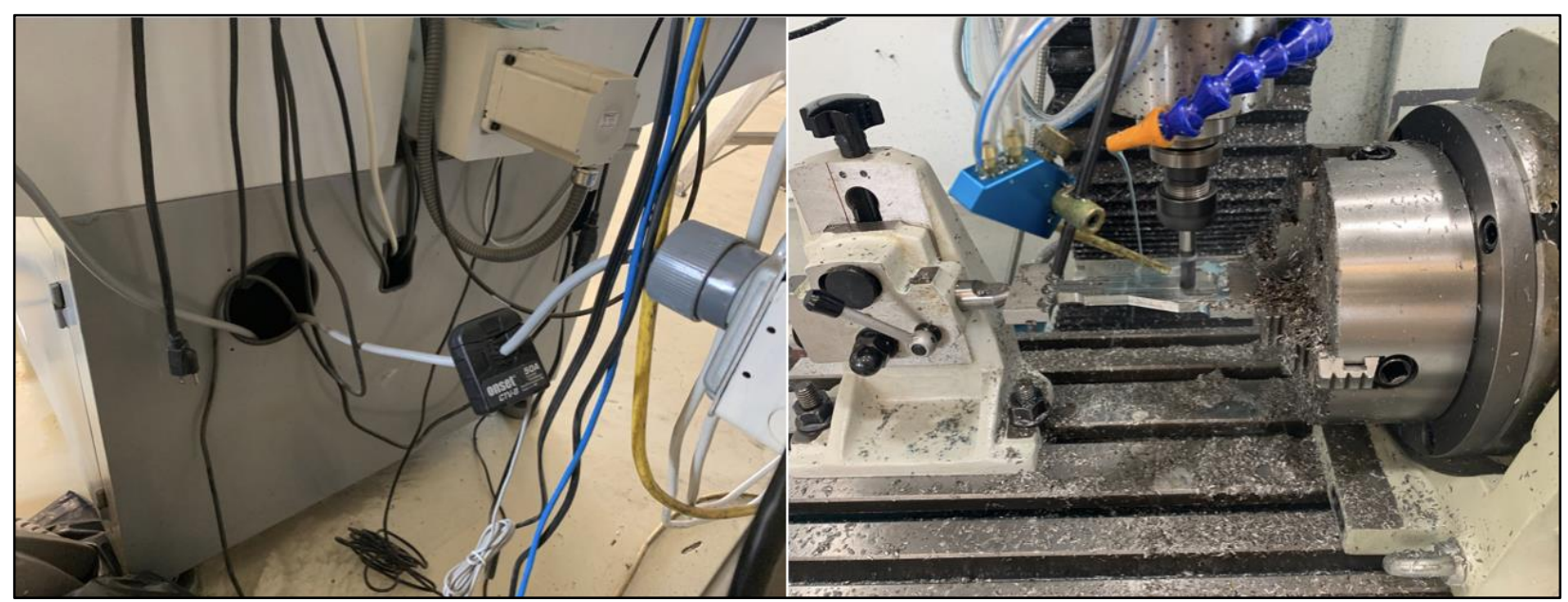

Figure 5.9: CNC machining, data logging

As described in earlier sections, $\mathrm{CNC}$ machining processes result in a large amount of waste material due to the generation of chips. Dimensions of the workpiece were selected such that minimal waste material is generated during production. Material allowances required by the process were also considered. 
Table 5.6: Dimensions and Volume of Workpiece

\begin{tabular}{|c|c|}
\hline \multicolumn{2}{|c|}{ Workpiece Properties } \\
\hline Dimensions (mm) & Volume $\left(\mathbf{m m}^{\mathbf{3}}\right.$ ) \\
\hline Width (X): 50.8 & \\
Depth (Y): 9.525 & 147,484 \\
Height (Z): 304.8 & \\
\hline
\end{tabular}

The volume of waste material (chips) generated can be calculated as follows.

$$
\mathrm{V}_{\text {chips }} \quad=\mathrm{V}_{\text {workpiece }}-\mathrm{V}_{\text {component }}
$$

Where,

$$
\begin{aligned}
& V_{\text {workpiece }}=\text { Volume of Workpiece }\left(\mathrm{mm}^{3}\right), 147,484 \\
& V_{\text {component }}=\text { Volume of Component }\left(\mathrm{mm}^{3}\right), 7,600
\end{aligned}
$$

Hence, the volume of waste material is given by,

$$
\begin{aligned}
V_{\text {chips }} & =147,484-7,600 \\
& =139,884 \mathrm{~mm}^{3}
\end{aligned}
$$

The mass of waste material generated can be calculated as,

$$
\mathrm{m}_{\text {chips }} \quad=\rho \times \mathrm{V}_{\text {chips }}
$$

Where,

$$
\begin{array}{ll}
\rho & =\text { Density of SS316 }\left(\mathrm{g} / \mathrm{mm}^{3}\right), 8.03 \times 10^{-3} \\
V_{\text {chips }} & =\text { Volume of chips, } 139,884 \mathrm{~mm}^{3}
\end{array}
$$

Therefore, the mass of waste material is given by,

$$
\begin{aligned}
\mathrm{m}_{\text {chips }} & =8.03 \times 10^{-3} \times 139,884 \\
& =1123.3 \mathrm{~g}
\end{aligned}
$$




\subsubsection{Comparison of Energy, Waste Material and Carbon Emissions}

Based on the results obtained from the pilot study, a comparison of the energy, waste material and carbon emissions of the manufacturing process was conducted. In order to determine the associated carbon emissions, the average annual $\mathrm{CO}_{2}$ emissions factor for electricity generated (0.9904 $\mathrm{lbsCO}_{2} / \mathrm{kWh}$ ) [60] within the United States was considered. A summary of the results is tabulated below.

Table 5.7: Summary of Energy, Material Consumption and Carbon Emissions

\begin{tabular}{|c|c|c|c|c|}
\hline $\begin{array}{c}\text { Manufacturing } \\
\text { Process }\end{array}$ & $\begin{array}{c}\text { Production } \\
\text { Units }\end{array}$ & $\begin{array}{c}\text { Energy } \\
\text { Consumption } \\
(\mathbf{k W h})\end{array}$ & $\begin{array}{c}\text { Carbon } \\
\text { Emissions } \\
\left(\mathbf{l b s C O}_{2}\right)\end{array}$ & $\begin{array}{c}\text { Waste } \\
\text { Material (lb) }\end{array}$ \\
\hline Binder Jetting & 1 & 9.15 & 9.06 & 0 \\
\hline CNC Machining & 1 & 3.9 & 3.86 & 2.48 \\
\hline
\end{tabular}

\subsubsection{Analysis and Verification of Case Study}

The expert systems were used to evaluate the fabrication of the control arm using Binder Jetting and CNC machining. The product and process parameters for both expert systems will be reflective of the information provided in the previous sections pertaining to the fabrication of the control arm. However, due to the requirement of cycle time calculation in MSUSTAIN1, concurrent activity time, independent operator activity time, number of machines assigned per operator, required process time, and required production quantity have been assumed based on a hypothetical manufacturing scenario. Input data utilized in the two expert systems are tabulated below. 
Table 5.8: Input Product Parameters for Viability ES

\begin{tabular}{|c|c|}
\hline Input Parameter & Value \\
\hline Material Type & Stainless Steel 316L \\
\hline Volume of component $\left(\mathrm{mm}^{3}\right)$ & 7600 \\
\hline Number of facets in CAD model & 4380 \\
\hline Surface quality $(\mu \mathrm{m})$ & 5 \\
\hline Hardness $(\mathrm{HRB})$ & 60 \\
\hline Strength (ksi) & 30 \\
\hline Tolerance/dimensional accuracy $(\mathrm{mm})$ & \pm 0.2 \\
\hline
\end{tabular}

Table 5.9: Input System Parameters for Viability ES

\begin{tabular}{|c|c|}
\hline Input Parameter & Value \\
\hline Production quantity & 50 \\
\hline Required process time (hours) & 336 \\
\hline
\end{tabular}

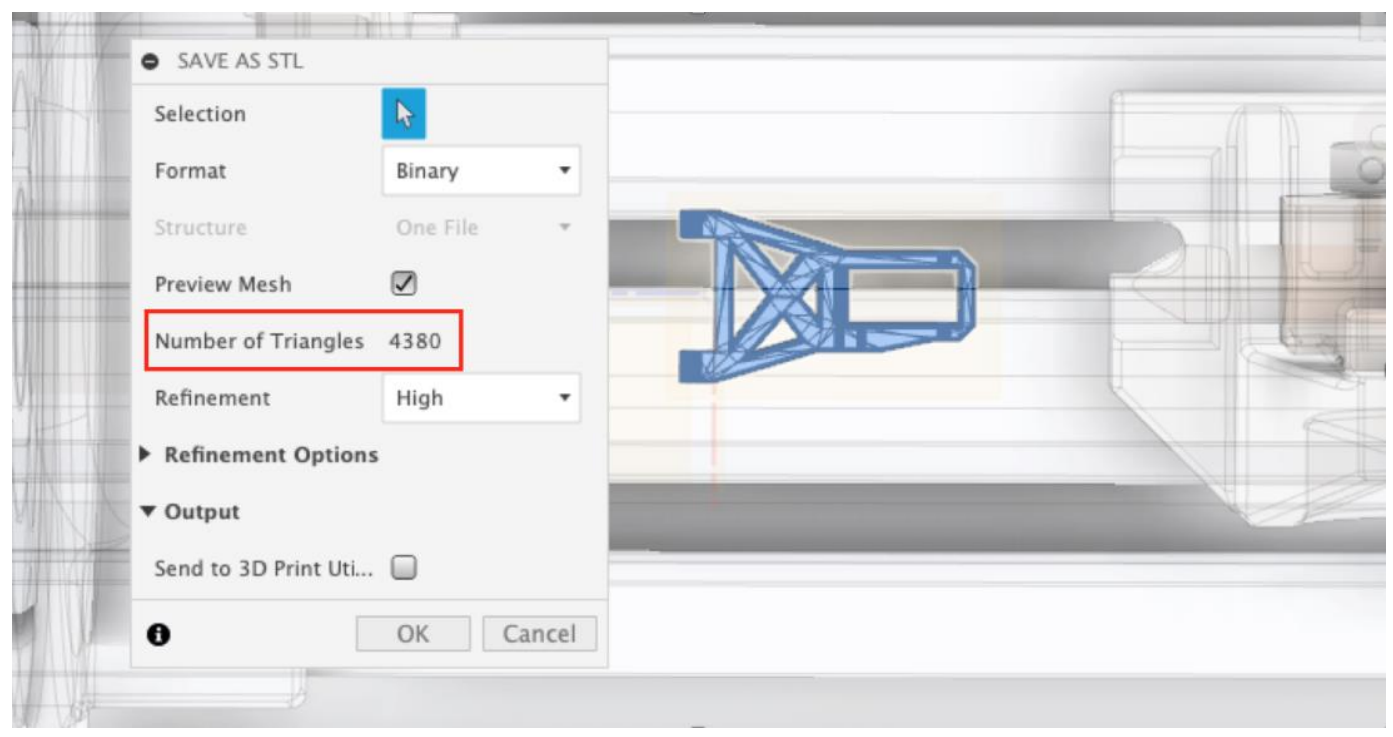

Figure 5.10: Determination of Number of Facets in CAD Model 
Table 5.10: BJP Parameters - Viability ES

\begin{tabular}{|c|c|}
\hline Input Parameter & Value \\
\hline Concurrent activity time (mins) & 15 \\
\hline Independent operator activity time (mins) & 14.4 \\
\hline Number of machines assigned per operator & 8 \\
\hline Number of simultaneous builds & 6 \\
\hline Layer height (mm) & 0.1 \\
\hline Leight of component as per build orientation & 7.005 \\
\hline (mm) & 10 \\
\hline Curing time (hours) & 46 \\
\hline
\end{tabular}

Table 5.11: CNC Parameters - Viability ES

\begin{tabular}{|c|c|}
\hline Input Parameter & Value \\
\hline Concurrent activity time (mins) & 6 \\
\hline $\begin{array}{c}\text { Independent operator activity time } \\
\text { (mins) }\end{array}$ & 2.4 \\
\hline $\begin{array}{c}\text { Number of machines assigned per } \\
\text { operator }\end{array}$ & 8 \\
\hline $\begin{array}{c}\text { Machining time as per CAD model } \\
\text { (hours) }\end{array}$ & 3.65 \\
\hline
\end{tabular}


Table 5.12: BJP Inputs - Sustainability ES

\begin{tabular}{|c|c|}
\hline Input Parameter & Value \\
\hline Component mass (lb) & 0.134 \\
\hline Rated power of printer $(\mathrm{kW})$ & 1.8 \\
\hline Rated power of curing oven $(\mathrm{kW})$ & 1.8 \\
\hline Rated power of sintering oven $(\mathrm{kW})$ & 8.4 \\
\hline Number of simultaneous builds & 6 \\
\hline Layer height (mm) & 0.1 \\
\hline Height of component as per build orientation (mm) & 7.005 \\
\hline Layer time (secs) & 46 \\
\hline Curing time (hours) & 10 \\
\hline Sintering time (hours) & 15 \\
\hline Average temperature for curing $\left({ }^{\circ} \mathrm{F}\right)$ & 250 \\
\hline Average temperature for sintering $\left({ }^{\circ} \mathrm{F}\right)$ & 1080 \\
\hline Maximum rated temperature for curing oven $\left({ }^{\circ} \mathrm{F}\right)$ & 600 \\
\hline Maximum rated temperature for sintering oven $\left({ }^{\circ} \mathrm{F}\right)$ & 3100 \\
\hline Utilization factor for printer (\%) & 0.5 \\
\hline Utilization factor for curing oven (\%) & 0.5 \\
\hline Utilization factor for sintering oven (\%) & 0.5 \\
\hline Startup time (hours) & 0.5 \\
\hline Printer cost (\$) & 80,000 \\
\hline Curing oven cost $(\$)$ & 6,100 \\
\hline Sintering oven cost (\$) & 8,000 \\
\hline Material cost $(\$ / \mathrm{lb})$ & 173 \\
\hline Binder Fluid & $\begin{array}{l}\text { Water- } \\
\text { based }\end{array}$ \\
\hline
\end{tabular}

Table 5.13: CNC Inputs - Sustainability ES

\begin{tabular}{|c|c|}
\hline Input Parameter & Value \\
\hline Component mass (lb) & 0.134 \\
\hline Workpiece mass (lb) & 2.51 \\
\hline Rated power of CNC machine $(\mathrm{kW})$ & 1.5 \\
\hline Primary processing type & Rolling \\
\hline $\begin{array}{l}\text { Utilization factor of CNC machine } \\
\qquad(\%)\end{array}$ & 0.5 \\
\hline $\begin{array}{c}\text { Machining time as per CAD model } \\
\text { (hours) }\end{array}$ & 3.65 \\
\hline Startup time (hours) & 0.5 \\
\hline Waste recovered fraction $(\%)$ & 0.5 \\
\hline CNC machine cost $(\$)$ & 25,000 \\
\hline Material cost $(\$ / \mathrm{lb})$ & 38 \\
\hline Machining operation required & $\begin{array}{l}\text { Milling \& } \\
\text { Drilling }\end{array}$ \\
\hline Cutting fluid & Water miscible \\
\hline Cutting tool & Carbide \\
\hline Cutting tool reground & No \\
\hline
\end{tabular}


Table 5.14: Facility Costs - Sustainability ES

\begin{tabular}{|c|c|}
\hline Labor cost (\$/hour) & 50 \\
\hline Installation cost (\%) & 0.25 \\
\hline Maintenance cost (\%) & 0.05 \\
\hline Annual increase in maintenance cost (\%) & 0.1 \\
\hline Tax rate of equipment (\%) & 0.15 \\
\hline
\end{tabular}

By evaluating the input data based on the built-in logical rules, MSUSTAIN1 was capable of yielding the following results.

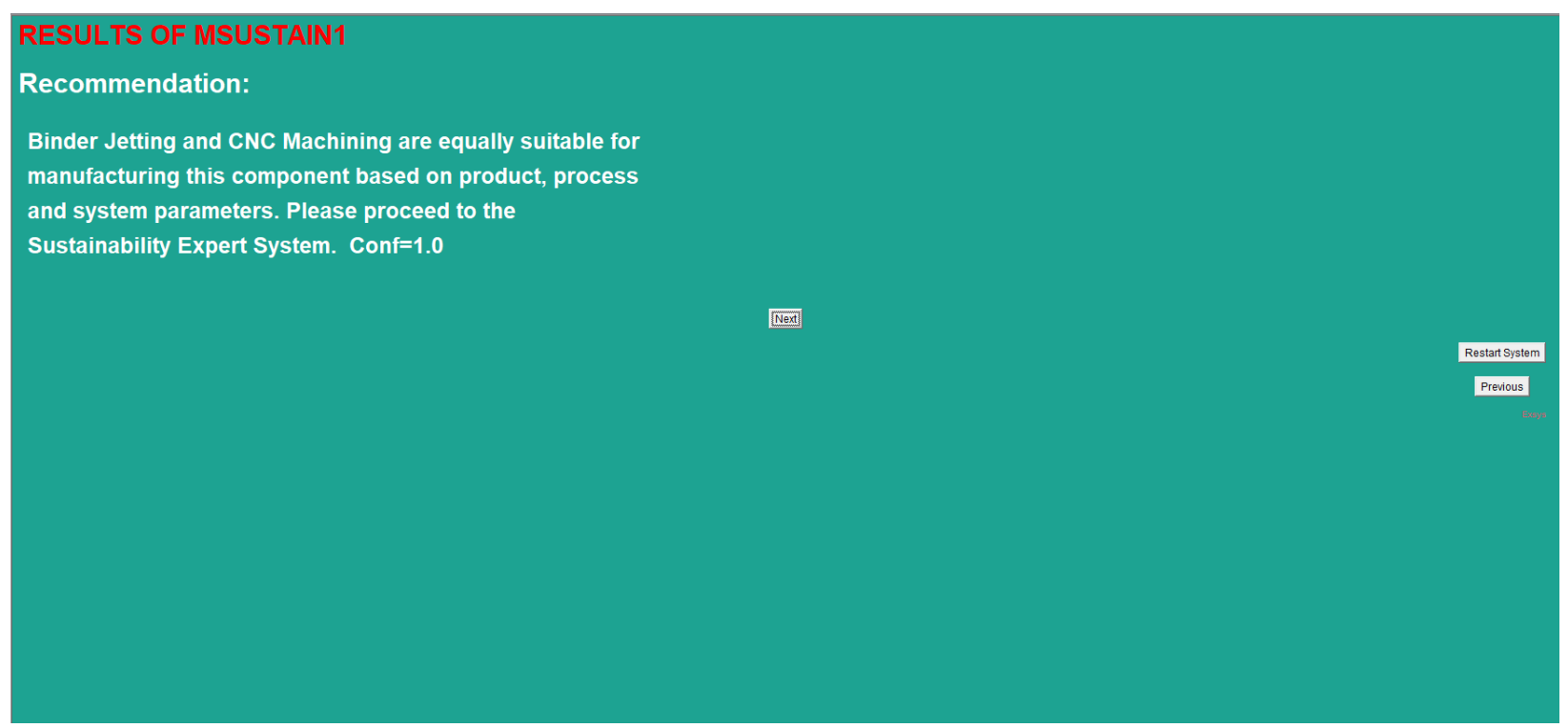

Figure 5.11: Results Screen of MSUSTAIN1 for Case Study Component

It is clear that the product parameters listed in table 5.8 are within the equal viability criteria for $\mathrm{BJP}$ and $\mathrm{CNC}$ as per section 4.1.1. Upon evaluating the logical rules associated with the product parameters, MSUSTAIN1 then proceeds to calculate the attainable cycle times for BJP and CNC based on process parameters. The cycle time for each process is crosschecked against the cycle time required by the manufacturing system. The cycle times for BJP, and CNC based on the process parameters listed in tables 5.10 and 5.11 are 5.06 hours and 3.65 hours, respectively. The cycle time required by the customer in this hypothetical scenario is 6.72 hours (table 5.9) Therefore, the results shown in figure 5.11 are justified. 


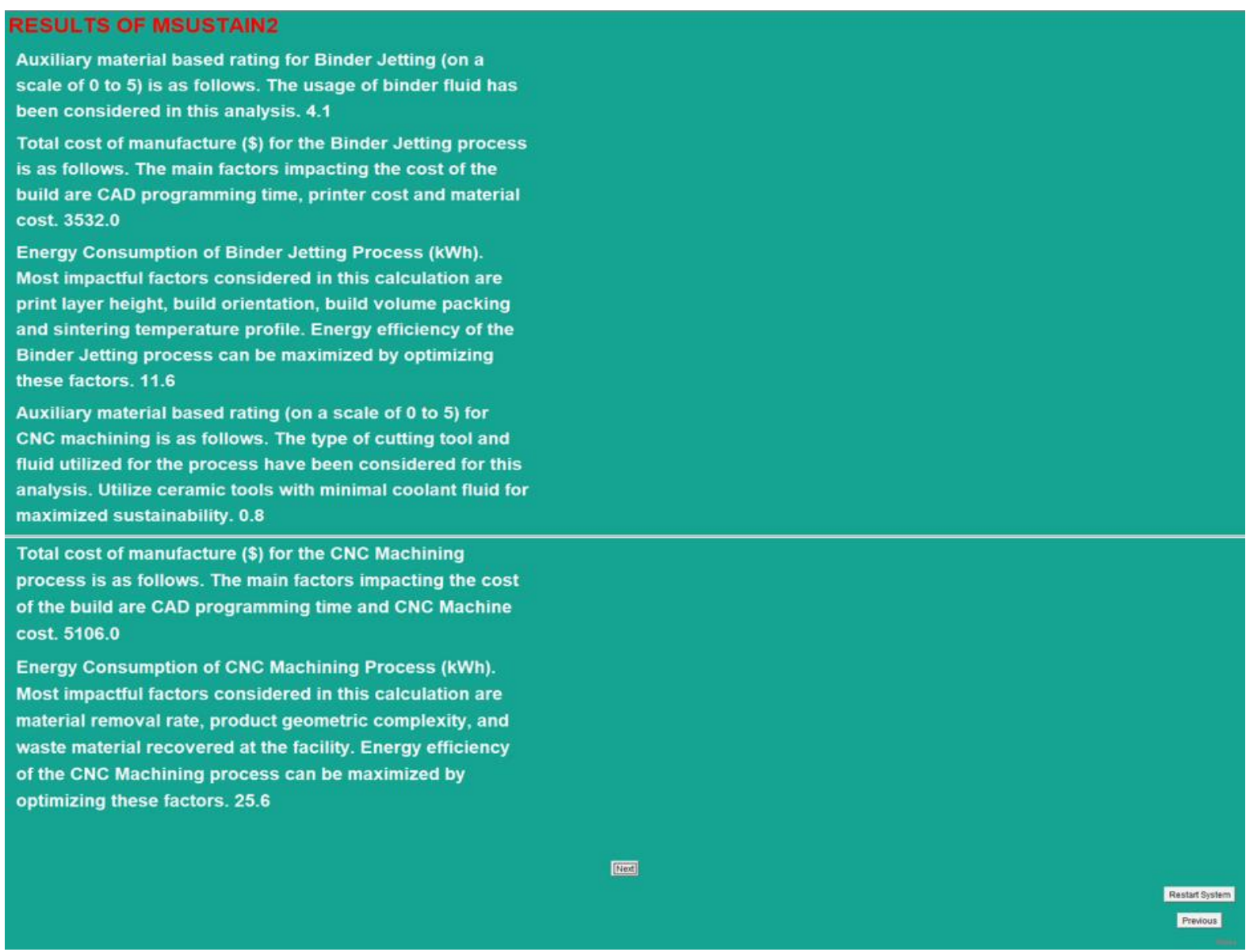

Figure 5.12: Results Screen of MSUSTAIN2 for Case Study Component

In order to assign the values depicted in figure 5.12, MSUSTAIN2 system carries out the calculation procedures described in 4.1.2, 4.1.3, 4.1.4 and 4.2. The energy consumption values for BJP and CNC machining have been determined to be $11.6 \mathrm{kWh}$ and $25.59 \mathrm{kWh}$, resulting in $55 \%$ energy savings from the utilization of BJP for the manufacturing process. The higher energy efficiency of BJP can be justified due its use of build volume optimization during the printing process. Since the average current draws of the printer, curing/sintering ovens remain fairly consistent during processing of any number of builds, higher utilizations of the build platforms result in significantly lower energy consumption values. The model results also suggest that the total energy requirement for material, workpiece, and waste metal chip processing tend to be higher than that of the atomization process required for BJP metal powder. The costs involved in fabricating the component have been evaluated to be $\$ 3,532$ for $\mathrm{BJP}$ and $\$ 5,106$ for CNC machining, resulting in $31 \%$ cost savings due to the use of BJP for the process. Although material and equipment costs for $\mathrm{CNC}$ machining are much lower than BJP, the cost effectiveness of using BJP for this specific process can be explained due to its minimal labor involvement and reduced 
energy consumption. The labor involvement due to machining process plan development on CAD software can be challenging/time consuming and needs to be accounted for in the cost calculation. Water based binding liquid has been used for the BJP process. In terms of auxiliary systems for the $\mathrm{CNC}$ machining process, water miscible coolant fluid and carbide tools were used. The tools were not reground upon breakages/end of life. Since only the binder fluid required for the build is utilized in the BJP process, there are no requirements for disposal and recycling. Therefore, the only sustainability impact of the BJP auxiliary systems would be during the production of binder fluid material. Since a water-based fluid has been used for the purpose of this build, the sustainability of BJP in the domain of auxiliary material can be considered to be significantly higher than that of CNC machining. Considering these facts, the expert system has utilized appropriate values from the AHP scale of relative importance (4.2) in order to rate each technology on based on auxiliary material consumption. The final performance values depict that Binder Jetting is characterized with significantly higher sustainability for fabrication of the stainless-steel control arm relative to $\mathrm{CNC}$ machining based on all indicators.

The AHP-based calculations/algorithms undertaken by the system during the allocation of auxiliart material weights for the manufacturing processes (BJP and CNC Machining) of the stainless steel 316L control arm are detailed below.

The first step of the algorithm is to allocate weights to each criterion based on the subjective knowledge presented in in 4.2 .

Table 5.15: Judgement Matrix for Cost, Energy, Auxiliary Material

\begin{tabular}{ccccc}
\hline Criteria & Cost & Energy & Auxiliary Material & Priority Vector \\
\hline Cost & 1 & 5 & 7 & 0.6758 \\
Energy & $1 / 5$ & 1 & 7 & 0.2595 \\
Auxiliary Material & $1 / 7$ & $1 / 7$ & 1 & 0.0647 \\
\hline Sum & 1.34 & 6.14 & 15 & 1.00 \\
\hline
\end{tabular}

Upon determination auxiliary material usage (utilizing the logical rules) based on the process parameters of BJP and CNC Machining, suitable priority vectors are calculated. The priority vectors are obtained from normalized Eigenvectors of each matrix. As per the details of the case 
study, the following priority vectors (table 5.16) have been allocated to appropriate variables in MSUSTAIN2.

Table 5.16: Priority Weights Allocated to BJP, CNC Machining Based on Auxiliary Material

\begin{tabular}{cccc}
\hline Auxiliary Material & Binder Jetting & CNC Machining & Priority Vector \\
\hline BJP & 1 & 5 & 0.83 \\
CNC Machining & $1 / 5$ & 1 & 0.17 \\
\hline Sum & 1.2 & 6 & 1.00 \\
\hline
\end{tabular}

According to the requirements of the research study, ratings have been transformed to a scale ranging from 1 to 5 . Therefore, the priority weights need to be multiplied by 5 .

Table 5.17: Ratings Allocated to BJP, CNC Machining Based on Auxiliary Material

\begin{tabular}{|c|c|}
\hline Manufacturing Technology & Auxiliary Material-Based Rating \\
\hline BJP & 4.1 \\
\hline CNC Machining & 0.8 \\
\hline
\end{tabular}

Additionally, the calculation procedure of energy consumption for CNC and BJP utilized in the expert system logic blocks has been tested alongside real energy consumption values (based on logged current data) to analyze the accuracy of the models. The results are shown below.

Table 5.18: Model Accuracy Determination of Energy Consumption

\begin{tabular}{|c|c|c|c|}
\hline $\begin{array}{c}\text { Manufacturing } \\
\text { Process }\end{array}$ & $\begin{array}{c}\text { Energy Consumption (kWh) } \\
\text { Model }\end{array}$ & $\begin{array}{c}\text { Energy Consumption (kWh) - } \\
\text { Actual }\end{array}$ & $\begin{array}{c}\text { Accuracy } \\
(\%)\end{array}$ \\
\hline$*$ Binder Jetting & 8.8 & 9.1 & $96.7 \%$ \\
\hline$* *$ CNC Machining & 4.3 & 3.9 & $90.7 \%$ \\
\hline
\end{tabular}

* Does not include material processing energy consumption

** Does not include material processing and primary processing (rolling) energy consumption 
Furthermore, sensitivity analysis has been conducted for the parameters deemed most crucial to the sustainability performance of each manufacturing technology. It is important to note that the sensitivity analysis is limited to the primary and secondary stages of the manufacturing processes.

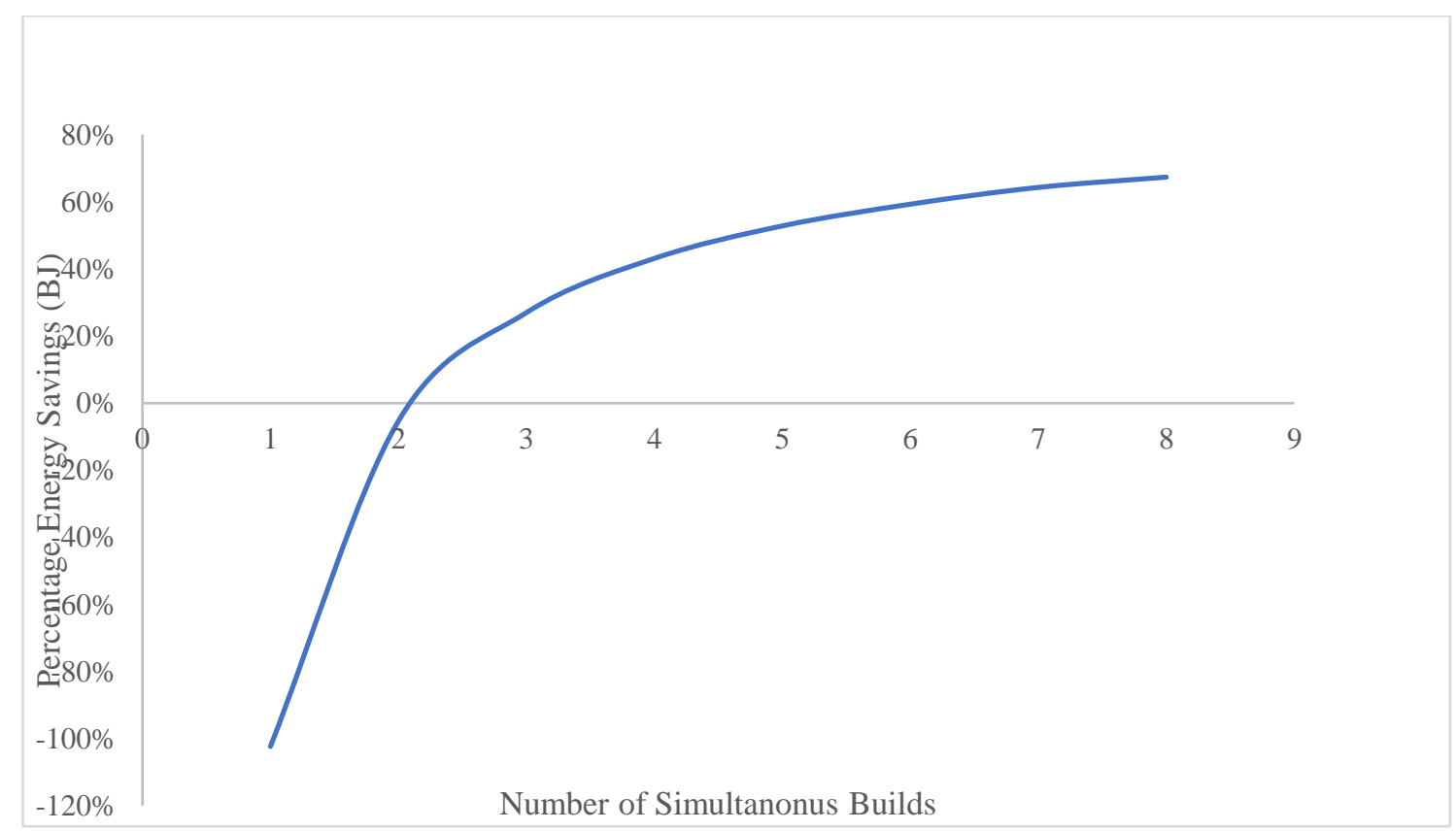

Figure 5.13: Variation in BJP Energy Savings (vs CNC) due to Build Volume Utilization

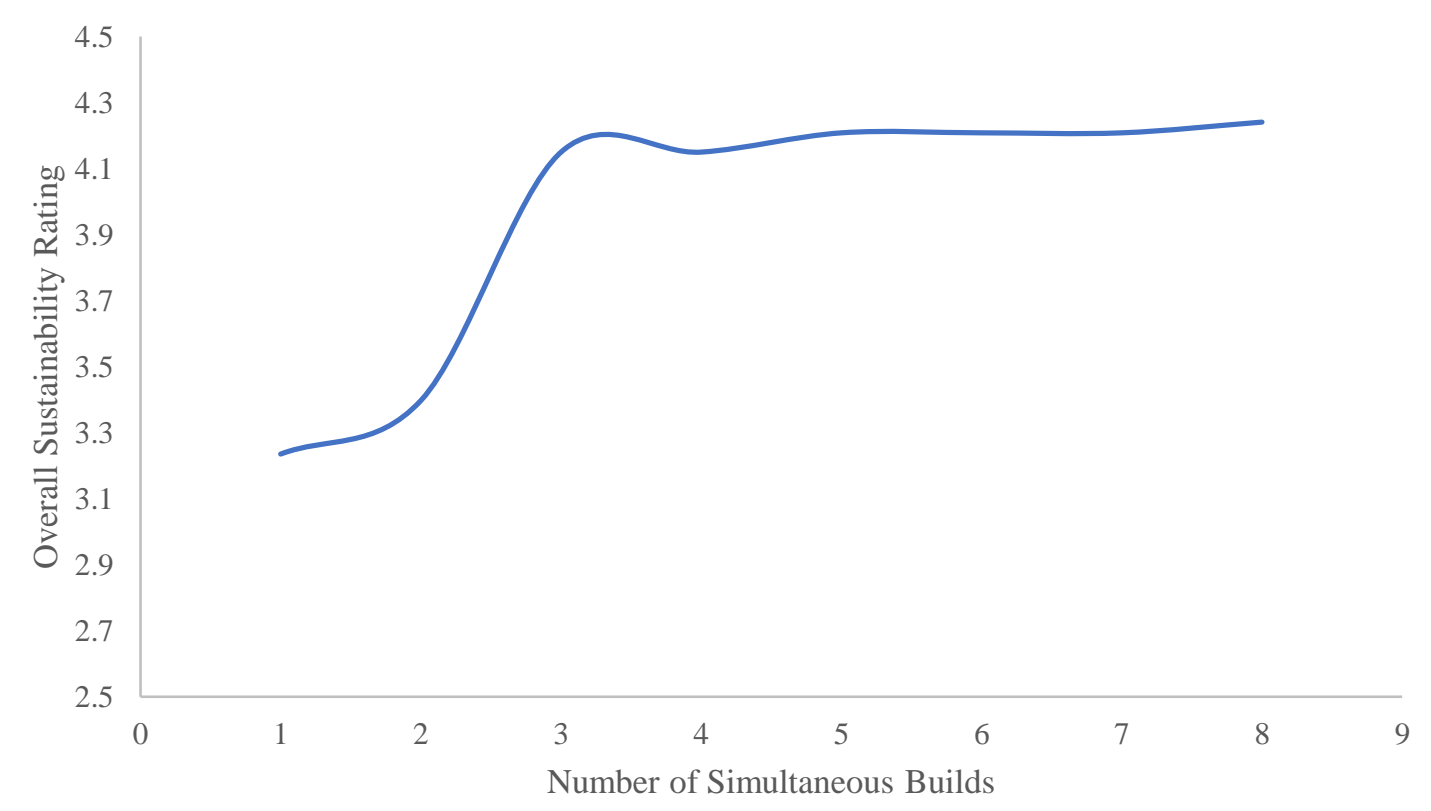

Figure 5.14: Variation in Overall Sustainability Rating for BJP due to Build Volume Utilization 
Build volume optimization is vital for the energy performance of Binder Jetting. Increased efficiency of the process is due to the reduced energy intensity per part resulting from the curing and sintering processes. As it can be seen from figure 5.13, the energy consumption of the CNC process is lower than BJP if the build plate consists of one or two components. Manufacturing scenarios as such, have the capability of reversing the yielded sustainability ratings. Therefore, it is important to consider optimal build plate utilization factors and print angles for the components prior to the BJP process.

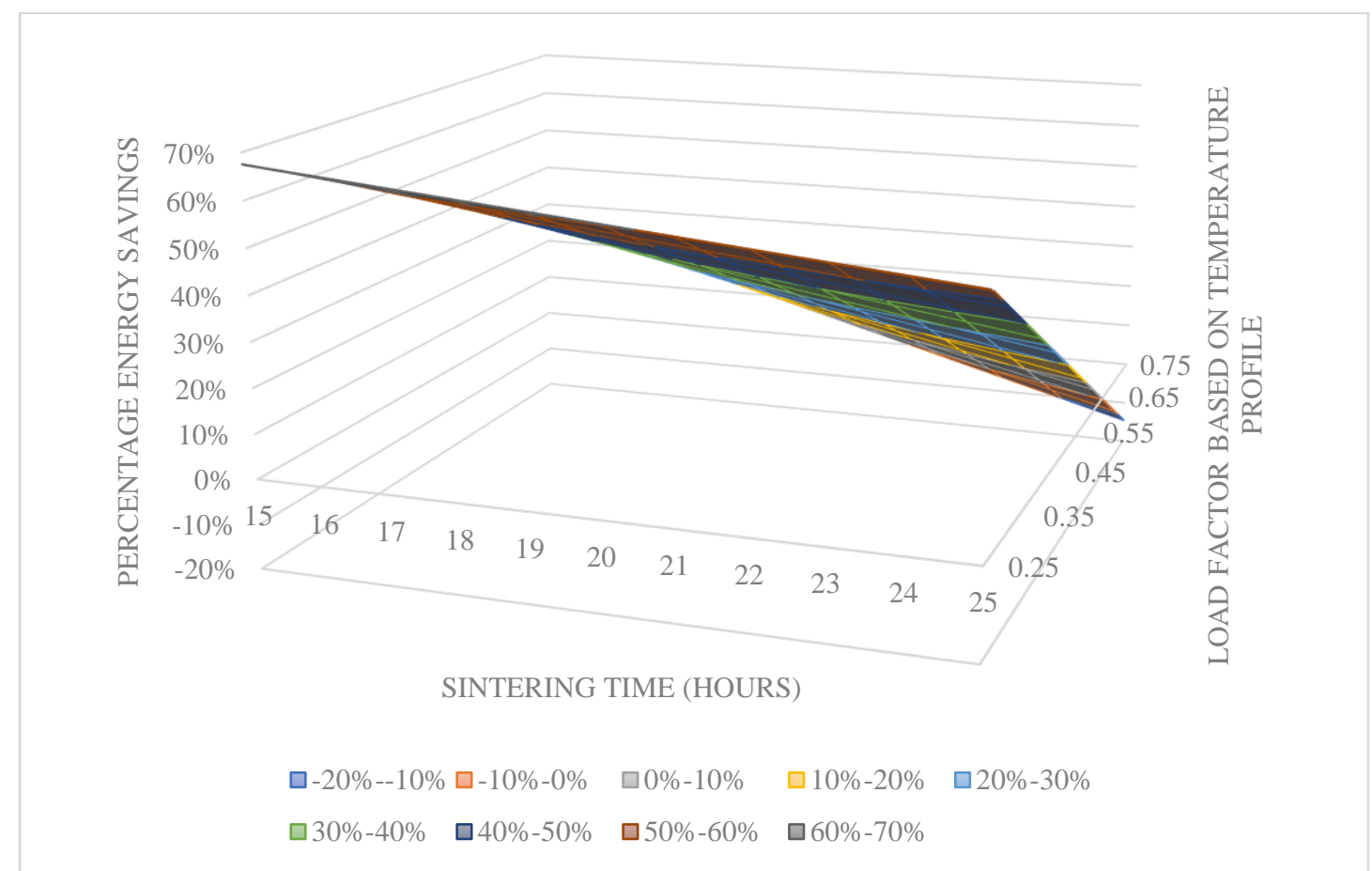

Figure 5.15: Variation in BJP Energy Performance due to the Sintering Profile Utilized

Sintering is the most energy intensive aspect of the BJP process. As the temperature profile used for sintering is predominantly dependent on the required mechanical properties of the component, optimal conditions for the process are still being heavily researched. The temperature profile utilized in fabricating the control arm was based on manufacturer specifications. As depicted in figure 5.15, energy consumption of the BJP process has a linear relationship with the temperatures and times used in sintering. Therefore, energy performance of the BJP process for fabricating the control arm can be increased by using a slightly lower temperature setting for each allocated time range of sintering. 


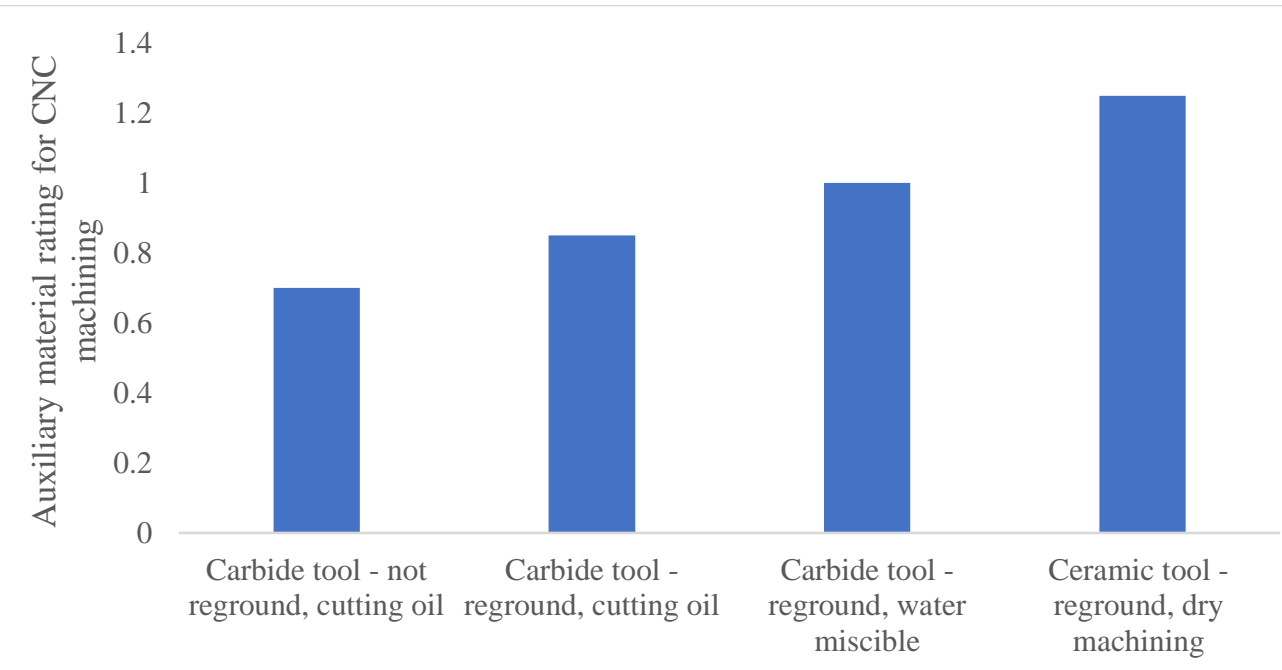

Type of cutting tool and fluid used

Figure 5.16: Variation in Auxiliary Material Rating for CNC due to Types Utilized

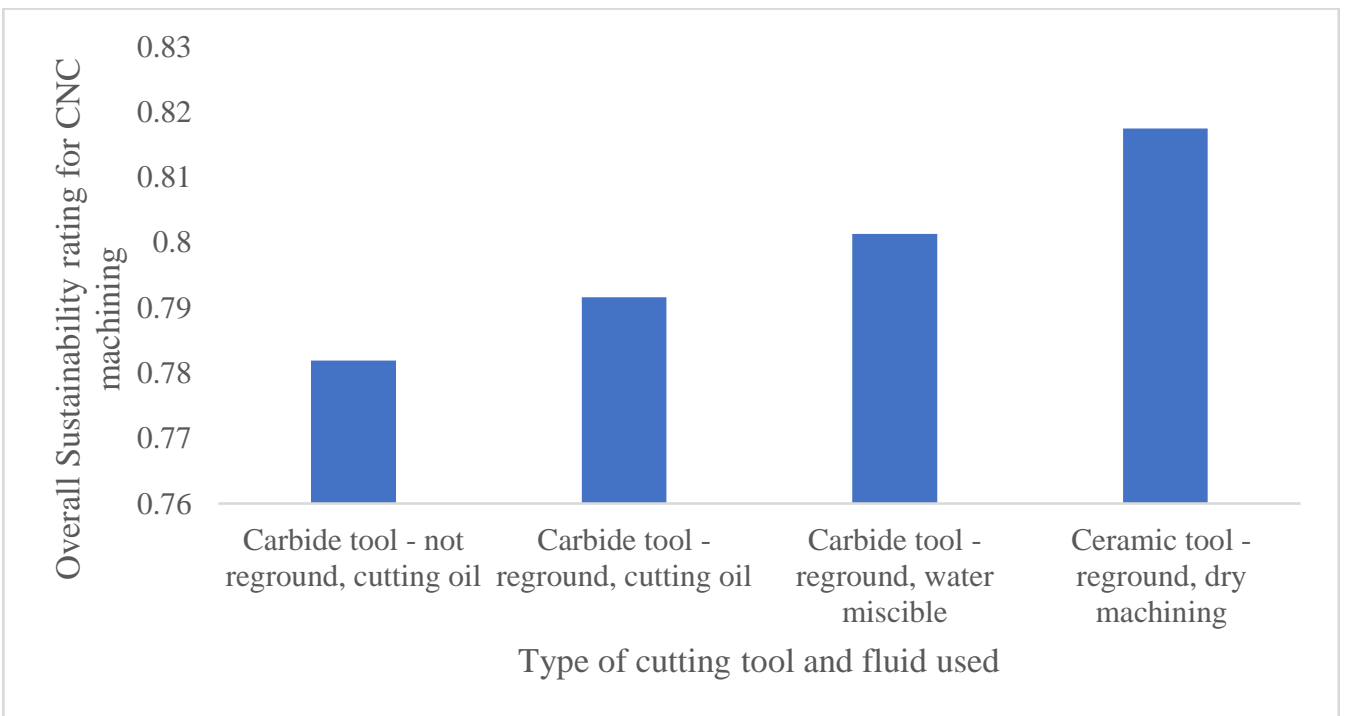

Figure 5.17: Variation in Overall Sustainability Rating for CNC due to Auxiliary Material Types Utilized

During fabrication of the control arm using CNC machining, carbide tools and water miscible fluid were used. Additionally, tools were not reground and reused upon breakages. As depicted in figures 5.16 and 5.17, auxiliary material and overall sustainability ratings for CNC machining can be significantly improved due to the use of resource efficient auxiliary systems. It is clear that sustainability performance of BJP in the domain of auxiliary material is superior to that of CNC machining. However, by using ceramic tooling in the minimal coolant/dry condition and adopting 
best practices such as tool regrinding, sustainability rating for CNC machining of the control arm can be improved.

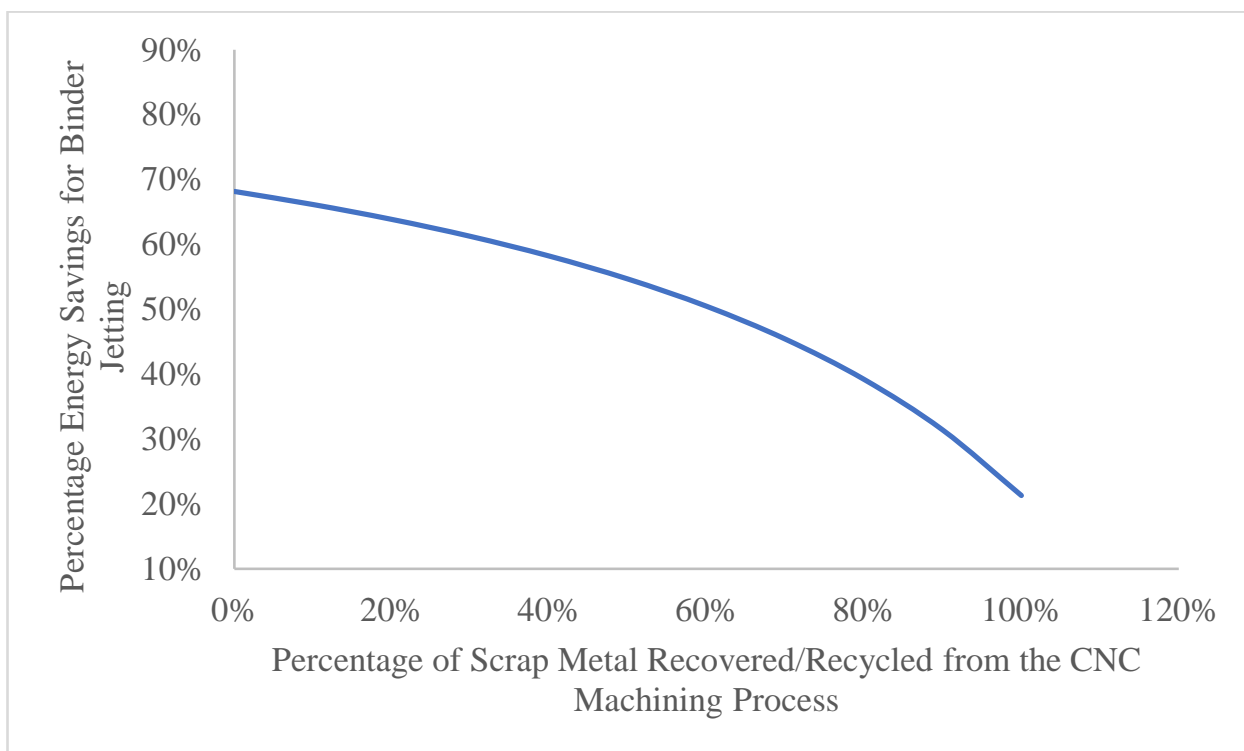

Figure 5.18: Variation in Overall Energy Performance due to CNC Waste Material Recovered

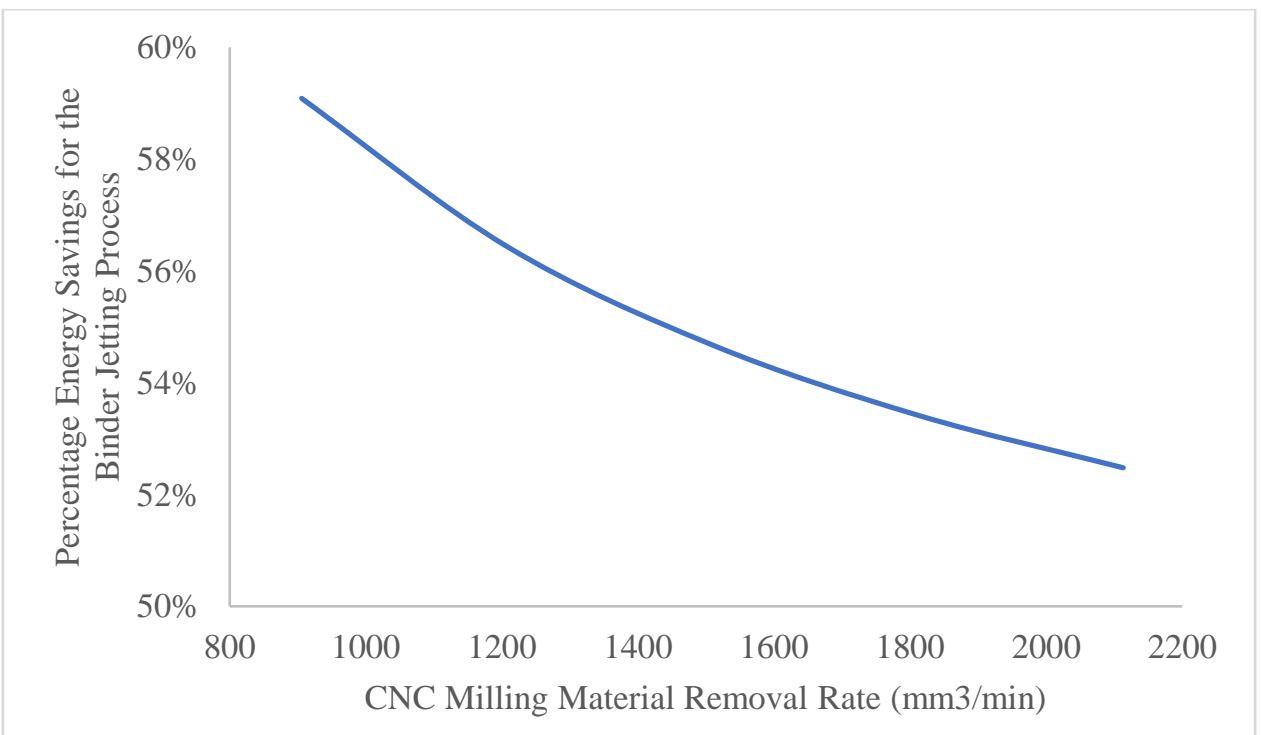

Figure 5.19: Variation in Energy Performance due to the Milling Removal Rate Utilized

As depicted in figured 5.18, recovery/recycling of waste material chips resulting from CNC machining can significantly improve the energy efficiency of the process. Since stainless steel is nearly $100 \%$ recyclable, manufacturing facilities should attempt to maximize the recovery of metal chips. Higher waste recovery percentages would decrease material processing energy for CNC 
machining due to the lessened burden on virgin material production. It has been assumed that $50 \%$ of the waste metal chips will be recovered/recycled from the manufacturing workshop. However, overall energy consumption for the CNC process can be reduced by increasing the recovered percentage of metal.

During the milling operations, a material removal rate of $1,510 \mathrm{~mm}^{3} / \mathrm{min}$ was used. According to figure 5.19, higher material removal rates result in lower energy consumption. Since load factor for $\mathrm{CNC}$ machines remain fairly constant through a range of cutting speeds/feeds, the decrease in energy consumption is predominantly due to the lesser time taken for the machining process. However, it is important to note that cutting speeds and feeds should be selected based on optimality for the cutting tool/workpiece material types. Unsuitably high material removal rates may cause damage to the cutting tools and component, resulting in a negative impact on sustainability. Material removal rate selection for the machining process of the control arm was based on judgement and previous experience. For economic purposes, the cutting speed and feed were selected conservatively. The energy consumption of the CNC machining process can be reduced by increasing the cutting speed and feed to a more optimal level.

\subsubsection{Conclusion}

Verification of the developed expert systems is imperative prior to implementation in manufacturing facilities. Robustness of the design of MSUSTAIN1/MSUSTAIN2 have been tested by evaluating the feasibility and sustainability of BJP and CNC Machining during the manufacture of a stainless steel 316L component. Furthermore, a sensitivity analysis has been conducted to determine the impact of various process parameters on sustainability of BJP and CNC Machining. According to the results of the case study, energy consumption algorithms of MSUSTAIN2 yielded accuracy levels of $96.7 \%$ and $90.7 \%$ for BJP and CNC Machining, respectively. BJP was characterized with more favorable sustainability indicators for manufacturing a metal component feasible for each technology. 


\section{Conclusion and Future Work}

In this research, the sustainability aspects revolving Binder Jetting, Direct Metal Laser Sintering and $\mathrm{CNC}$ machining in metal fabricating industries have been examined and ascertained. In order to aid manufacturers in conducting a sustainability comparison of additive manufacturing and CNC machining, two expert systems were developed. The knowledge base for the expert systems comprises of quantitative/qualitative subjective knowledge pertaining to viable product, process and system parameters, energy consumption, economics, and auxiliary material usage of the aforementioned manufacturing methodologies. The research study has also presented a ratingbased approach to evaluating auxiliary material consumption of AM and CNC machining. Analytical Hierarchy Process has been used as the basis for the rating system. The first expert system aids users in ascertaining the equally feasible product, process, and system parameters viable for impartial comparison of $\mathrm{CNC}$ machining and additive manufacturing. The second expert system provides sustainability performance values for the compared technologies based on characteristics inherent to the manufacturing systems. Exsys Corvid® ${ }^{\circledR}$ was used to develop the programs and transform the knowledge base into logical rules such that user input can be evaluated using backward chaining.

The developed expert systems have been verified by analyzing the fabrication process of a stainless-steel 316L component. For this purpose, the outputs of the expert systems were compared against information found in existing literature, and data collected during the fabrication of an automotive control arm using Binder Jetting and CNC machining. Results of the model are deemed to be reflective of realistic manufacturing situations. Key findings of the research study based on the conducted analysis can be listed as follows.

1. Build volume optimization of Binder Jetting printers is vital to the reduction of process energy consumption and cycle time.

2. The most energy intensive aspect of Binder Jetting is the sintering process. Utilization of an optimal temperature profile will result in significant manufacturing energy savings.

3. Current draw of Binder Jetting machines does not vary significantly with the number of print layers in the build plate.

4. Sustainability revolving $\mathrm{CNC}$ machining can be enhanced by the use of optimal material removal rates, and auxiliary material systems such as ceramic tooling and water miscible 
coolant fluids. Additionally, load factor for CNC machines tend to remain fairly constant through a range of cutting speeds and feeds.

5. Higher metal chip recovery rates at manufacturing facilities can result in significantly lower overall energy consumption for CNC machining processes.

6. The energy expenditure for material processing of $\mathrm{CNC}$ machining coupled with the energy consumption of waste metal chip processing, tend to be higher than the energy intensity of atomization required for metal powder production.

7. Cost of manufacture, energy consumption (of manufacturing and material production) and auxiliary material usage tend to be more favorable for Binder Jetting in the fabrication of components equally feasible (in terms of product, process, and system parameters) for CNC machining and Binder Jetting.

8. Impartial sustainability comparison of manufacturing technologies requires the evaluation of equally viable product, process, and system parameters. Aspects such as material type and associated mechanical properties, geometric complexity, dimensional accuracy, cycle time of processes, as well as production quantities which can be justified on a cost basis, are important considerations for determining the equal feasibility criteria of additive manufacturing and $\mathrm{CNC}$ machining.

9. Market transformation and global impact of utilizing AM in manufacturing processes is significant. According to existing research, in 2025 it is estimated that the market will consist of 235,000 CNC machines and 112,000 AM machines (CNC market will reach USD 100 Billion [61], and 3D printing market is expected to rise to USD 50 billion [62].) The energy intensity values obtained from the conducted research were $191 \mathrm{kWh} / \mathrm{lb}$ (this refers to pounds of material processed) and $86 \mathrm{kWh} / \mathrm{lb}$ for CNC machining and BJP respectively. However, it is important to note that these process embodied values are only applicable for products within the viability regions of both technologies. As per the results of this research study, estimating energy use reduction by $5 \%$ due to the user-initiated alterations of process parameters, the total energy savings are estimated to be 2,240,000 $\mathrm{kWh} / \mathrm{lb}$ and 481,000 kWh/lb in the CNC machining and AM markets respectively. This would result in potential carbon emissions savings of 2,720,000 lbs $\mathrm{CO} 2 / \mathrm{lb}$.

10. This research will considerably facilitate efforts in implementing ISO 50001/SEP and ISO 14001 standards within manufacturing facilities. 
Although the knowledge bases contained in the expert systems are robust enough for the purposes of this research, further improvements can be made. Considerations for future work are stated below.

1. Incorporate the impact of additive manufacturing and CNC machining on supply chains, product use phase/end of life energy consumption, worker safety and health.

2. Expand the analysis criteria to other metal additive manufacturing techniques.

3. Include additional $\mathrm{CNC}$ machining operations.

4. Implement an algorithm which considers intricate details of geometric features for the estimation of product geometric complexity.

5. Thermodynamically model heat treatment equipment. 


\section{References}

[1] B. Purvis, Y. Mao and D. Robinson, "Three Pillars of Sustainability: In Search of Conceptual Origins," Sustainability Science, no. 14, pp. 681-695, 2019.

[2] "Report: Energy Flow Charts: Energy, Water and Carbon Informatics.," Lawrence Livermore National Laboratory, 2019.

[3] "U.S Manufacturing Energy Use and Greenhouse Gas Emissions Analysis.," United States Department of Energy, 2012.

[4] S. Kalpakjian and S. Schmid, Manufacturing Engineering Technology, 6 ed., Pearson, 2010.

[5] Varotsis. A, "Report: What is 3D Printing? The Definitive Guide.," 3D Hubs, 2019.

[6] E. Mancanares, E. Zancul, J. Silva and M. P, "Additive Manufacturing Process Selection Based on Parts Selection Criteria.," International Journal of Advanced Manufacturing Technology, vol. 80, no. 5-8, pp. 1007-1014, 2015.

[7] S. Hashimi and I. Choudhary, Encyclopedia of Renewable and Sustainable Materials, Elsevier, 2020.

[8] Varotsis, A, "Report: CNC Machining: The Complete Engineering Guide," 3D Hubs, 2019.

[9] K. Abdulrahman, E. Akinlabi and R. Mahamood, "Laser Metal Deposition Technique: Sustainability and Environmental Impact.," Procedia Manufacturing, vol. 21, pp. 109-116, 2018.

[10] Z. Liu, C. Li , X. Fang and Y. Guo, "Energy Consumption in Additive Manufacturing of Metal Parts," Procedia Manufacturing, vol. 26, pp. 834-845, 2018.

[11] M. L. Calvanese, P. Albertelli, A. Martha and M. Taisch, "Analysis of Energy Consumption in CNC Machining Centers and Determination of Optimal Cutting Conditions," in 20th CIRP International Conference on Life Cycle Engineering, Singapore, 2013.

[12] J. Dahmus and T. Gutowski, "An Environmental Analysis of Machining.," in International Mechanical Engineering Congress RD\&D Expo, Anaheim, 2004.

[13] S. Pavanaskar, "Improving Energy Efficiency in CNC Machining," UC Berkeley, 2014.

[14] C. Li, Y. Tang, L. Chi and Q. Yi , "Quantitative Analysis of Carbon Emissions of CNC-Based Machining Systems," in 10th IEEE International Conference on Networking, Sensing and Control, Evry, France, 2013.

[15] J. Giarratano and G. Riley, Expert Systems: Principles and Programming, 2nd ed., 1993.

[16] T. Mpofu, C. Maware and M. Mukosera, "The Impact and Application of 3D Printing Technology.," International Journal of Science and Research, 2014.

[17] M. Pour, M. Zanardini, A. Bacchetti and S. Zanoni, "Additive Manufacturing Impacts on Production and Logistics Systems," IFAC-PapersOnLine, vol. 49, no. 12, pp. 1679-1684, 2016.

[18] B. Kianian, S. Tavassoli, T. Larsson and O. Diegel, "The Adoption of Additive Manufacturing Technology in Sweden.," Procedia CIRP, vol. 40, pp. 7-12, 2016. 
[19] M. Fouseva, D. Vojtech, J. Kubasek, D. Dvorsky and M. Machova, "3D Printing as an Alternative to Casting, Forging and Machining Technologies.," Manufacturing Technology, no. 15(5), pp. 809-814, 2015.

[20] A. Vevers, A. Kromanis, E. Gerins and J. Ozolins, "Additive Manufacturing and Casting Technology Comparison: Mechanical Properties, Productivity and Cost Benchmark," Latvian Journal of Physics and Technical Sciences, vol. 55, pp. 56-63, 2018.

[21] J. Faludi, C. Bayley, S. Bhogal and M. Iribarne, "Comparing Environmental Impacts of Additive Manufacturing vs. Traditional Machining Via Life Cycle Assessment.," Rapid Prototyping Journal, 2015.

[22] P. Dudek and K. Zagorski, "Cost, Resources and Energy Efficiency of Additive Manufacturing," ES3 Web of Conferences, vol. 14, 2016.

[23] M. Wedlund and J. Bergman, "Decision Support Model for Selecting Additive or Subtractive Manufacturing," University of Gavle, Gavle, Sweden, 2018.

[24] J. Watson and K. Taminger, "A Decision Support Model for Selecting Additive Versus Subtractive Manufacturing Based on Energy Consumption," Journal of Cleaner Production, vol. 176, pp. 1316-1322, 2018.

[25] K. Kellens, R. Mertens, D. Paraskevas, W. Dewulf and J. Duflou, "Environmental Impact of Additive Manufacturing Processes: Does AM Contribute to a More Sustainable Way of Part Manufacturing?," Procedia CIRP, vol. 61, pp. 582-587, 2017.

[26] S. Ford and M. Despeisse, "Additive Manufacturing and Sustainability: An Exploratory Study of the Advantages and Challenges.," Journal of Cleaner Production, vol. 137, pp. 1573-1587, 2016.

[27] F. Bourhis, O. Kerbrat, L. Dembinski, J. Hascoet and P. Mognol, "Predictive Model for Environmental Assessment in Additive Manufacturing Processes.," Procedia CIRP, vol. 15, pp. 26-31, 2014.

[28] J. Faludi, M. Baumers, I. Maskery and R. Hague, "Environmental Impacts of Selective Laser Melting: Do Printer, Powder or Power Dominate?," Journal of Industrial Ecology, 2016.

[29] K. Kellens, E. Yasa, W. Dewulf and J. Duflou, "Environmental Assessment of Selective Laser Melting and Selective Laser Sintering," in Going Green - Care Innovation: From Legal Compliance to Energy Efficient Products and Services, Vienna, 2010.

[30] T. Peng, "Analysis of Energy Utilization in 3D Printing Processes," Procedia CIRP, vol. 40, pp. 62-67, 2016.

[31] M. Baumers, C. Tuck, I. Bourell, R. Sreenivasan and Hague R, "Sustainability of Additive Manufacturing: Measuring the Energy Consumption of Laser Sintering Processes.," Proceedings of the Institution of Mechanical Engineers, Part B: Journal of Engineering Manufacture, vol. 225, pp. 2228-2239, 2011.

[32] M. Baumers, C. Tuck, R. Wildman, I. Ashcroft, E. Rosamund and R. Hague, "Combined Build Time, Energy Consumption and Cost Estimation for Direct Metal Laser Sintering," 23rd Annual International Solid Freeform Fabrication Symposium - An Additive Manufacturing Conference, pp. 932-944, 2012. 
[33] M. Baumers, C. Tuck, R. Hague, I. Ashcroft and Wildman R, "A Comparative Study of Metallic Additive Manufacturing Power Consumption," 21st Annual International Solid Freeform Fabrication Symposium - An Additive Manufacturing Conference, pp. 278-288, 2010.

[34] M. Baumers, C. Tuck, R. Wildman, I. Ashcroft and R. Hague, "Shape Complexity and Process Energy Consumption in Electron Beam Melting: A Case of Something for Nothing in Additive Manufacturing?," Journal of Industrial Ecology, 2016.

[35] S. Meteyer, X. Xu, N. Perry and Y. Zhao, "Energy and Material Flow Analysis of Binder Jetting Additive Manufacturing Processes.," Procedia CIRP, vol. 15, pp. 19-25, 2014.

[36] F. Fang, K. Cheng, H. Ding and S. Chen, "Sustainable Design and Anlaysis of CNC Machine Tools: Sustainable Design Index Based Approach and its Application Perspectives," in ASME 2016 11th International Manufacturing Science and Engineering Conference, Blacksburg, VA, 2016.

[37] M. Alvarez, M. Barcena and F. Gonzalez, "A Review of Sustainable Machining Engineering: Optimization Process Through Triple Bottom Line," Journal of Manufacturing Science and Engineering, vol. 138, no. 10, 2016.

[38] C. Zhang and P. Jiang, "Sustainability Evaluation of Process Planning for Single CNC Machine Tool Under the Consideration of Energy Efficient Control Strategies Using Random Forests," Sustainability, vol. 11, 2019.

[39] "Report: Impact of Layer Height - 3D Printing," 3D Hubs, 2019.

[40] "Report: What is Binder Jetting?," The ExOne Company, 2019.

[41] "Report: Stainless Steel 17-4 DMLS Material Specifications," Stratasys, 2019.

[42] "Report: Stainless Steel 316L DMLS Material Specifications," Stratasys, 2019.

[43] T. Saaty, "Decision Making with the Analytic Hierarchy Process," International Journal Services Sciences, vol. 1, no. 1, 2008.

[44] B. Valentan, "Basic Solutions on Shape Complexity Evaluation of STL Data," Journal of Achievements in Materials and Manufacturing Engineering, vol. 26, 2008.

[45] S. Merkt, "Geometric Complexity Analysis in an Integrative Technology Evaluation Model for Selective Laser Melting," South African Journal of Industrial Engineering, vol. 23, pp. 97-105, 2012.

[46] Varotsis, A, "Report: 3D Printing vs CNC Machining - Knowledge Base," 3D Hubs, 2019.

[47] J. Tomkins, J. White, Y. Bozer and J. Tanchoco, Facilities Planning, Fourth ed., Wiley, 2010, pp. 60-63.

[48] S. Nimbalkar and D. Cox, "AM Energy Impacts Assessment Tool," Oak Ridge National Laboratory, 2014. [Online]. Available: https://energyefficiency.ornl.gov/wpcontent/uploads/2018/09/AM-Energy-Impacts-Assessment-Tool-BETA-V1-ENGLISH09182014.xlsm. [Accessed 29 August 2019].

[49] H. Miyanaji, "Binder Jetting Additive Manufacturing Process Fundamentals and the Resultant Influences on Part Quality," The University of Louisville, 2018.

[50] "Report: Stainless Steel CNC Machining," 3DHubs, 2019. 
[51] FE Reference Handbook 10.0.1, Clemson, NC: NCEES.

[52] O. Silva, J. Souza, M. Nono, G. Martins, M. Ribeiro and J. Machado, "Development of Ceramic Cutting Tools for Future Application on Dry Machining," Minerals Science Forum, Vols. 660-661, pp. 724-729, 2010.

[53] Richter, Alan , "Report: Cutting Benefits of Ceramic and Cermet Tools," CTEMAG, 2019.

[54] Cutting Tool Engineering, "Report: Recycling on the Rise," 2020.

[55] S. Skerlos, "Cutting Fluids and Their Environmental Impact," in Encyclopedia of Tribology, 2013.

[56] Z. Silveira, "Selecting Low Cost 3D Printers Using the AHP Method: A Case Study," SN Applied Sciences, no. 335, 2019.

[57] "Report: Stainless Steel 316L Material Information," Speedy Metals, 2019.

[58] "Stainless Steel Machining," SSINA, 2020.

[59] "Report: Milling Knowledge," Sandvik Coromant, 2018.

[60] "Report: CO2 Produced," Energy Information Adminstration, 2019.

[61] "Report: Secondary Finishing Processes in Metal Additive Manufacturing," Metal-AM, 2019.

[62] "Report: Sustainable Manufacturing," United States Environmental Protection Agency, 2019.

[63] P. Mognol, D. Lepicart and N. Perry, "Rapid Prototyping: Energy and Environment in the Spotlight.," Rapid prototyping Journal, vol. 12, pp. 26-34, 2006.

[64] R. Sreenivasan, A. Goel and D. Bourell, "Sustainability Issues in Laser-Based Additive Manufacturing," Physics Procedia, Vols. 5,A, pp. 81-90, 2010. 
APPENDICES 


\section{APPENDIX A: Samples of MSUSTAIN1 Expert System}

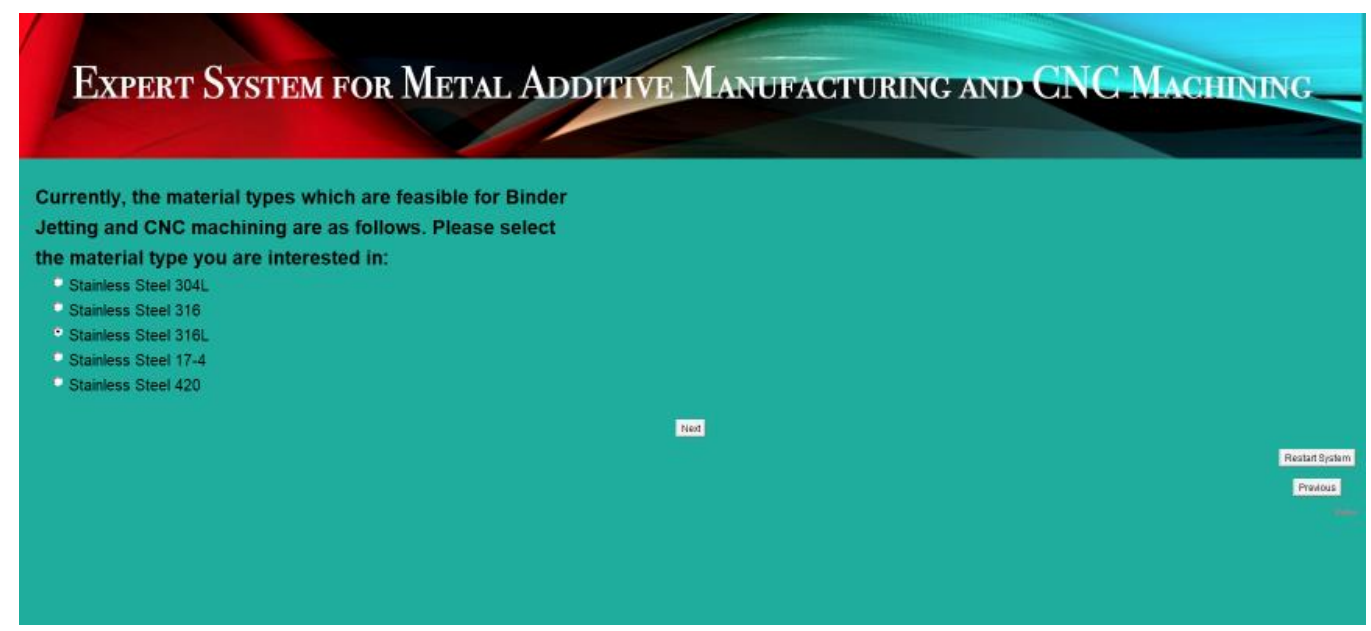

Figure A-1: Selection of Product Material Type

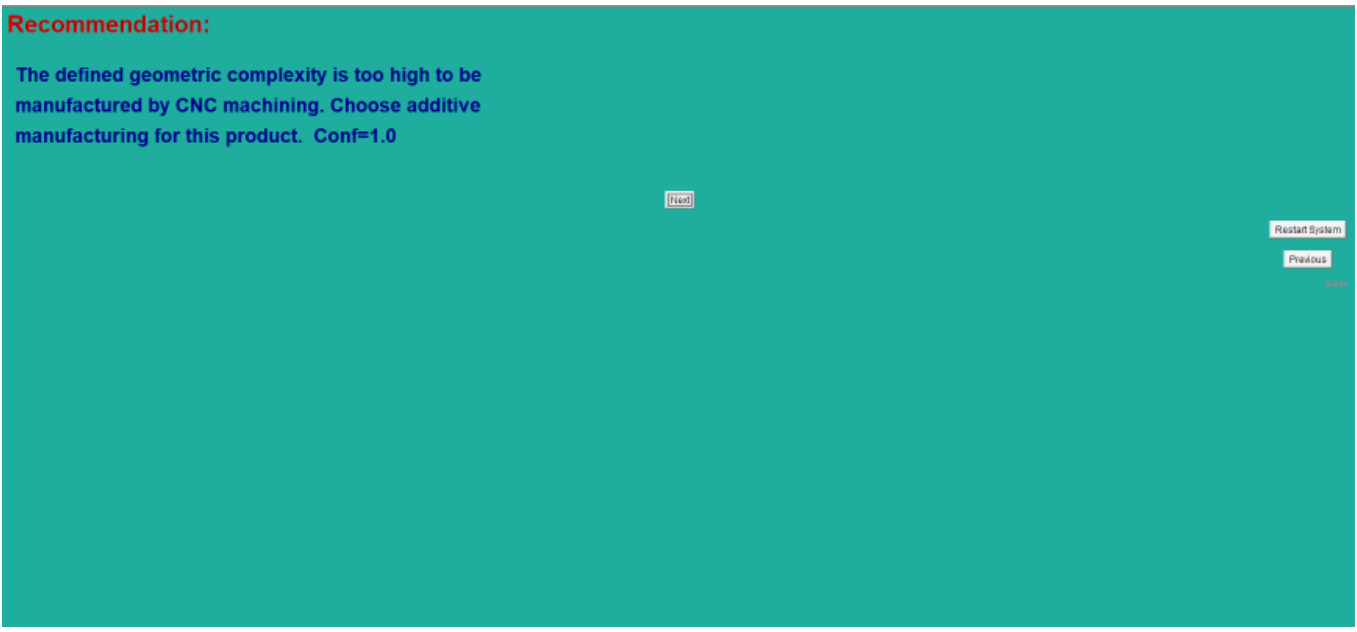

Figure A-2: Recommendation for Invalid Geometric Complexity

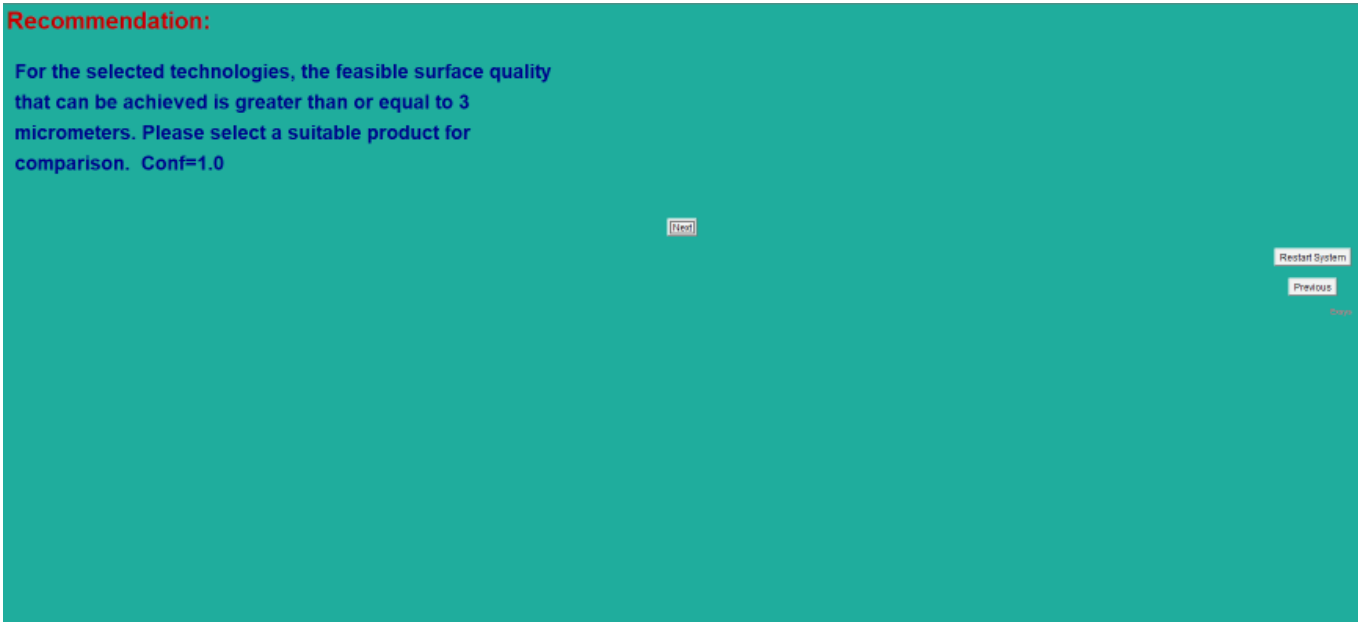

Figure A-3: Recommendation for Invalid Surface Quality 


\section{APPENDIX B: Samples of MSUSTAIN2 Expert System}

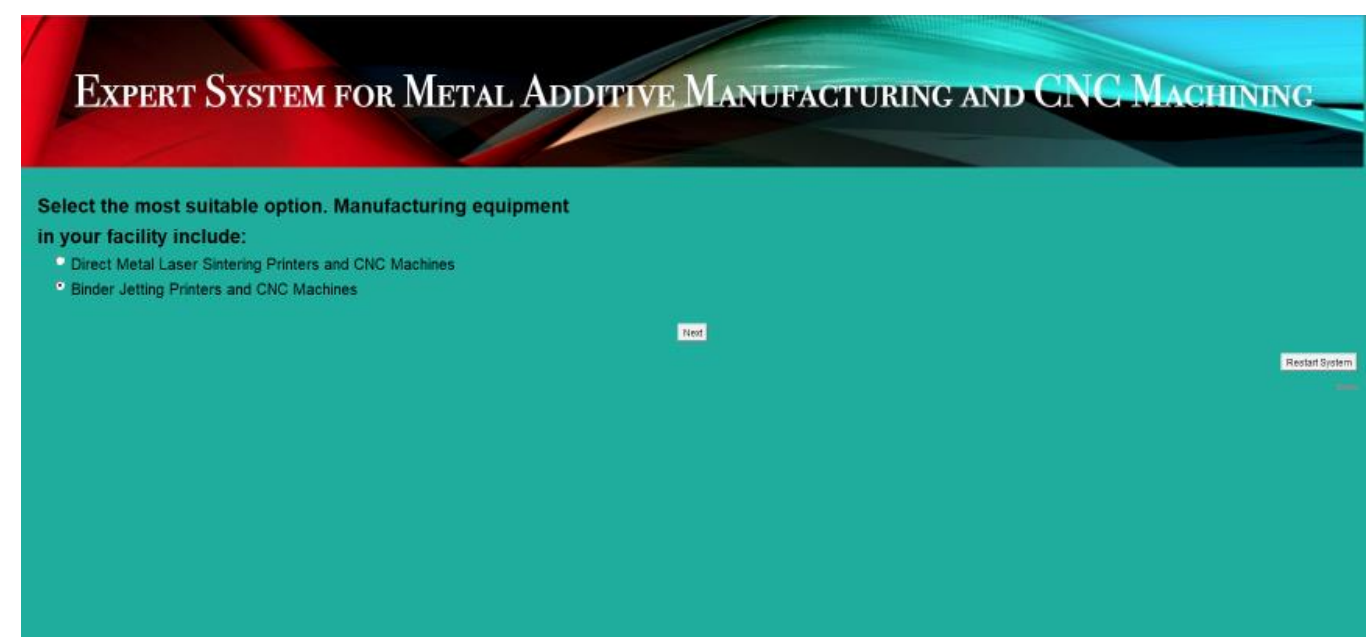

Figure B-1: Selection of Technologies for Comparison

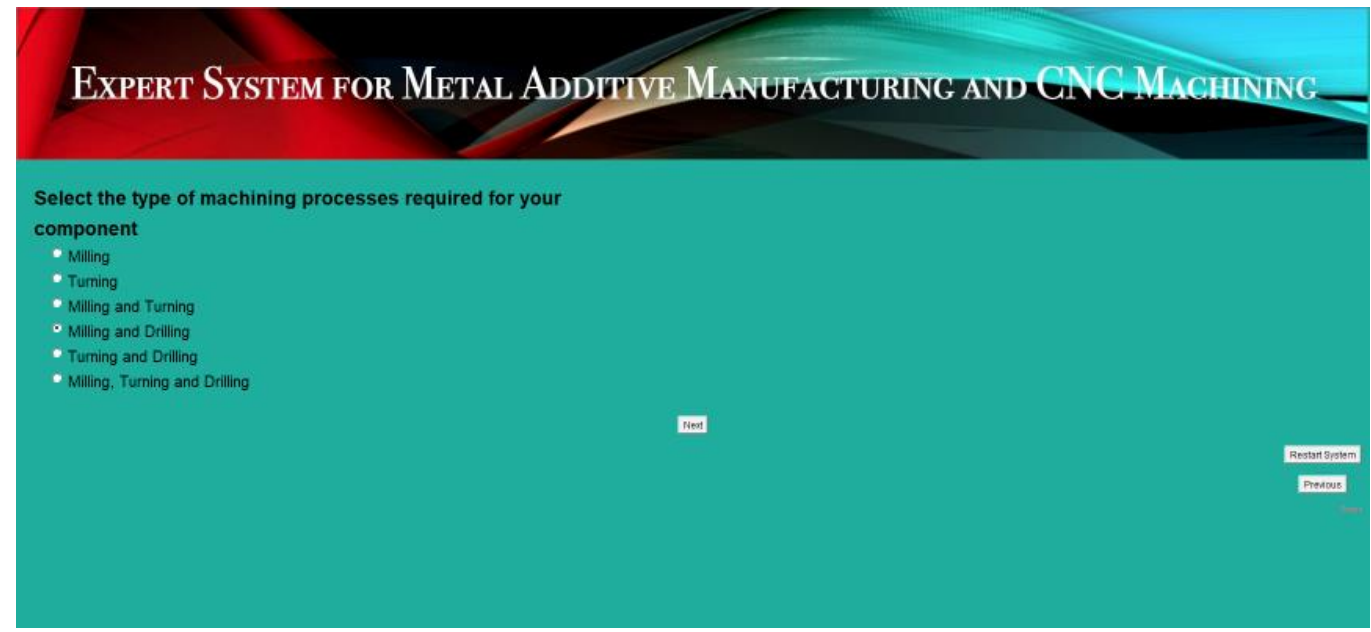

Figure B-2: Selection of Required CNC Machining Operations

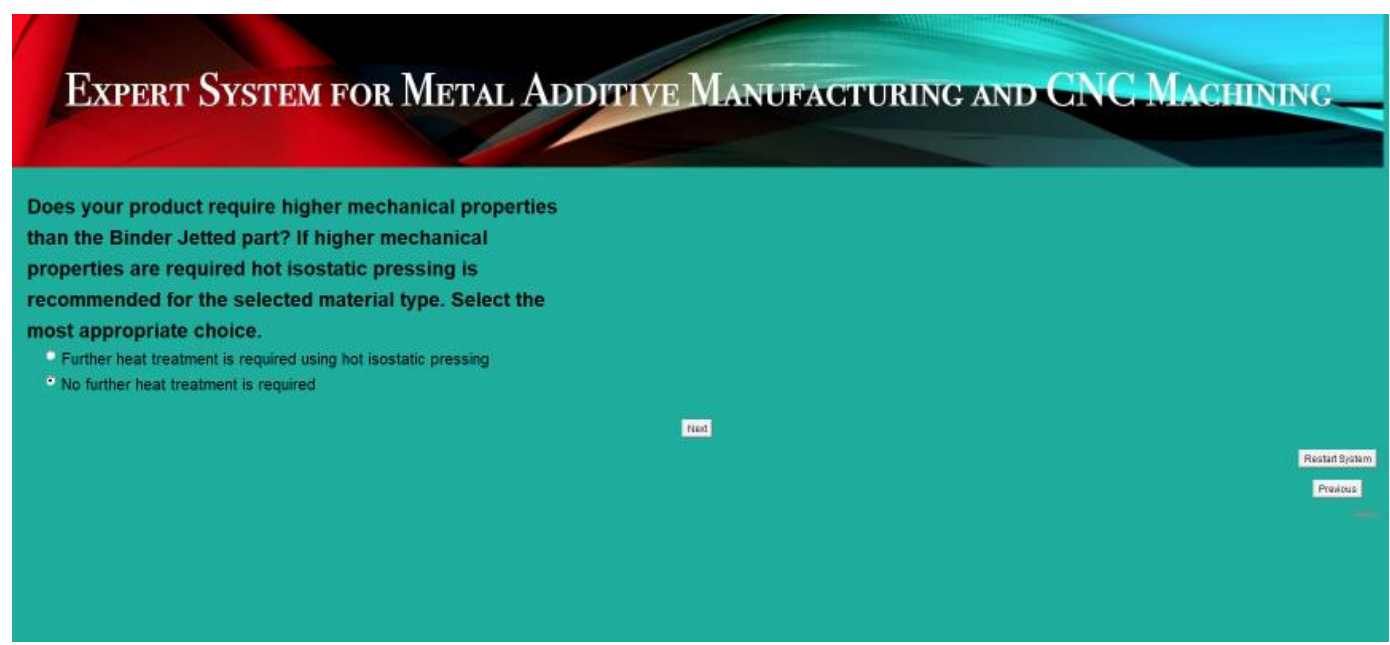

Figure B-3: Selection of Technologies for Comparison 


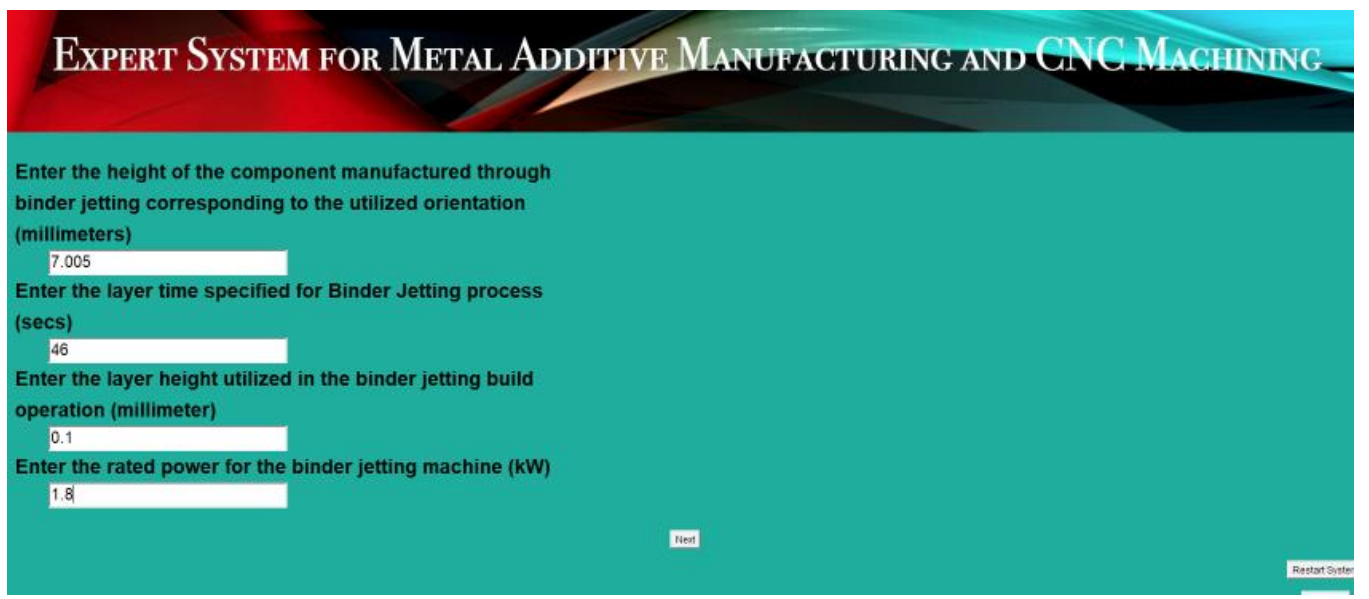

Figure B-4: Input Screen for CNC Component Mass and Waste Recovery Fraction

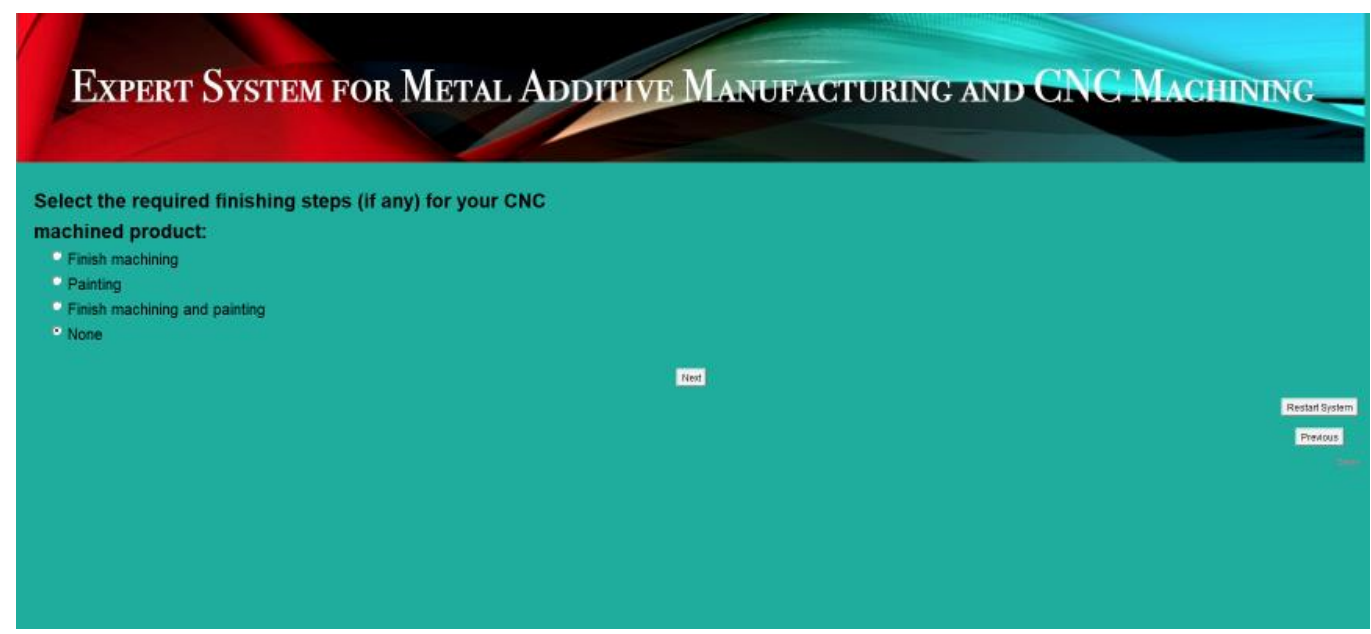

Figure B-5: Selection of Finishing Steps for CNC Machining

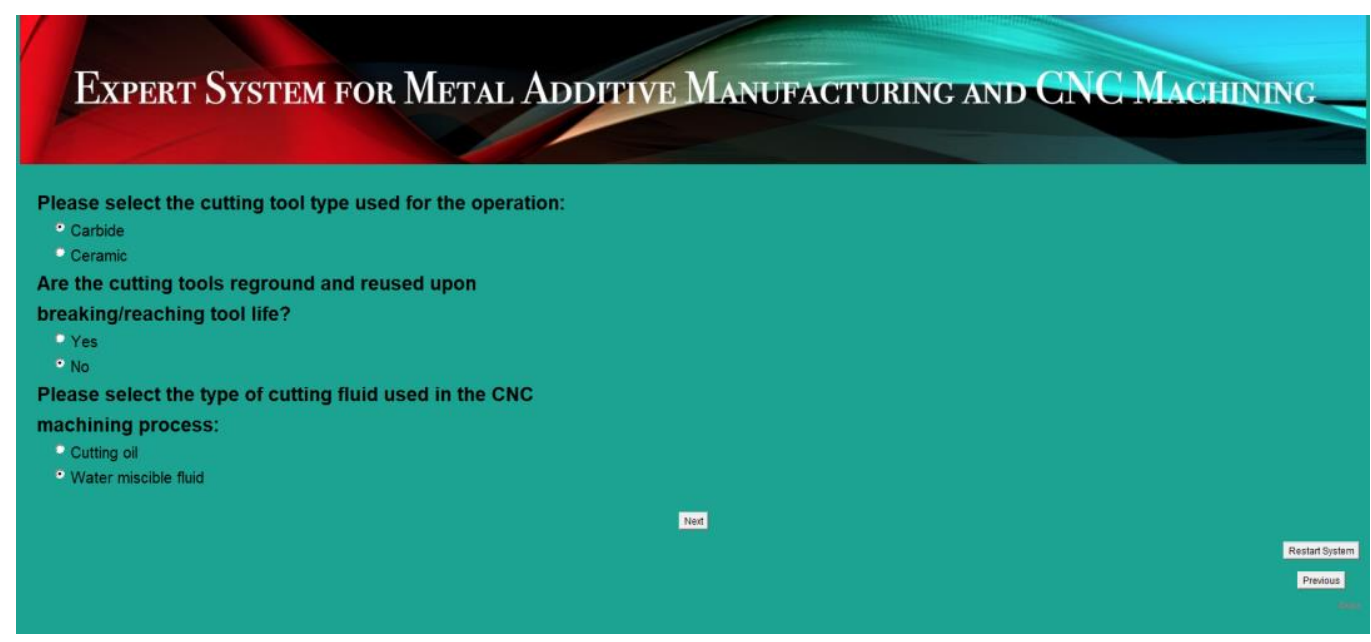

Figure B-6: Auxiliar Material Selection for CNC Machining 


\section{APPENDIX C: Sample Exsys Corvid ${ }^{\circledR}$ Codes}

IF:

THEN:

$([$ Volume $] /[$ Facets $])>=3$

Complexity factor $=2.5$

IF:

$(([$ Volume $] /[$ Facets $])>=1.5) \&(([$ Volume $] /[$ Facets $])<3)$

THEN:

Complexity factor $=5$

IF:

$(([$ Volume $] /[$ Facets $])>=0.5) \&(([$ Volume $] /[$ Facets $])<1.5)$

THEN:

Complexity factor $=7.5$

IF:

$([$ Volume $] /[$ Facets] $)<0.5$

THEN:

Complexity factor $=10$

IF: Manufacturing Equipment $=$ Direct Metal Laser Sintering and CNC Machining

AND: $\quad$ Material Type $=$ Stainless Steel 17-4

AND: $\quad 1.5<=$ Complexity Factor $<3$

AND: $\quad$ Surface Quality $>=6$

AND: $\quad$ Hardness $<=100$

AND: $\quad$ Strength $<=106$

AND: $\quad$ Tolerance $>=0.127$

AND: Production Quantity $<=100$

AND: $\quad$ Cycle Time $>$ (Required process time)/[Production Quantity)

THEN:

The process parameters entered for Direct Metal Laser Sintering are not capable of achieving the desired process time and production quantity for this particular product.: Confidence $=1.0$ 